Distribution Category:

LMFBR Structural Materials and Design Engineering ( $\mathrm{UC}-79 \mathrm{~h}$ )

LMFBR Safety (UC-79p)

ANL- 78-38

ARGONNE NATIONAL LABORATORY

9700 South Cass Avenue

Argonne, Illinois 60439

EXPERIMENTAL VALIDATION OF PTA-1 COMPUTER CODE FOR PRESSURE-TRANSIENT ANALYSIS INCLUDING

THE EFFECT OF PIPE PLASTICITY

by

C. K. Youngdahl, C. A. Kot, and $R$. A. Valentin

Components Technology Division

July 1978

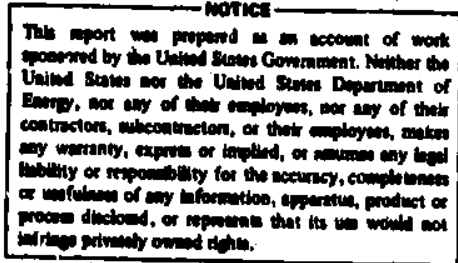



TABLE OF CONTENTS

Page

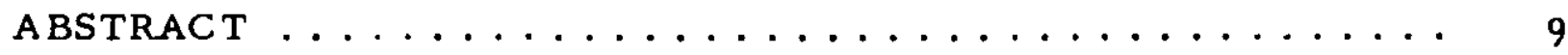

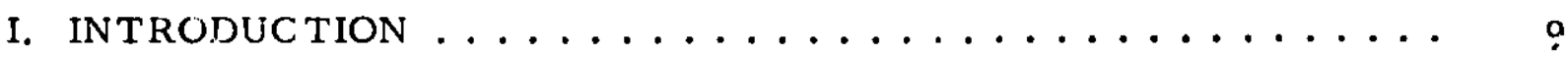

II. STANFORD RESEARCH INSTITUTE EXPERIMENTS . . . . . . . 12

III. PTA-I MODELING OF EXPERIMENTS . . . . . . . . . . . 16

A. Stress-Strain Curve for Nickel-200 Piping ......... 16

B. Material Properties of Steel Piping and Elbows . . . . . . . 17

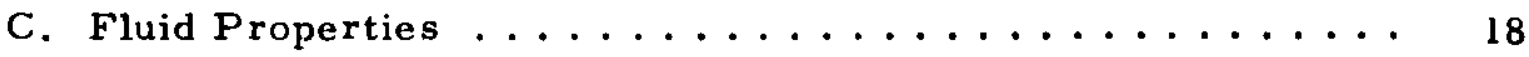

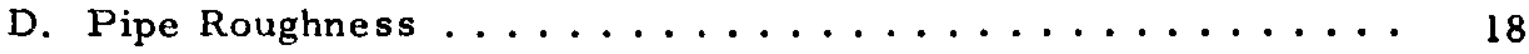

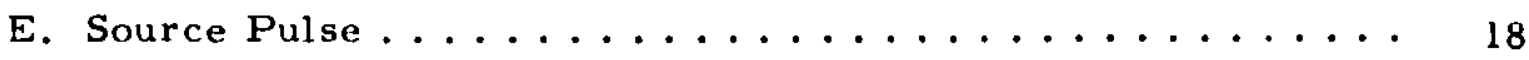

F. Modeling of Flanges ..................... 18

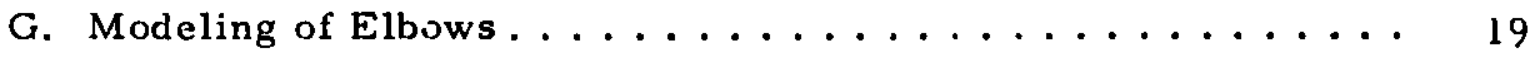

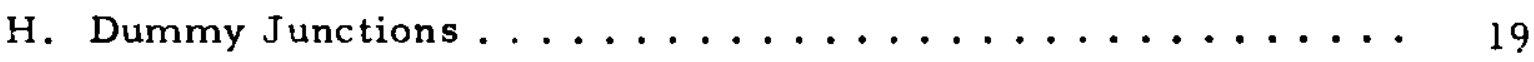

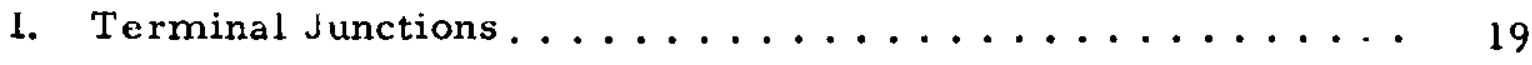

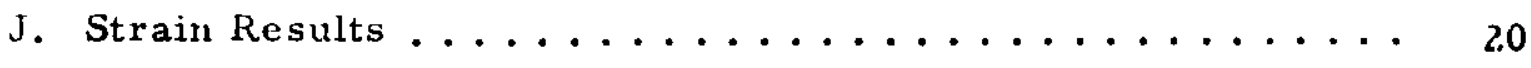

K. Time Step and Running Time ................ 20

IV. COMPARISONS BETWEEN PTA-1 COMPUTATIONS AND

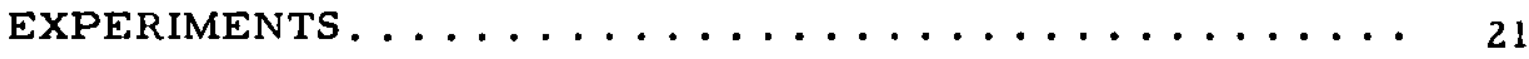

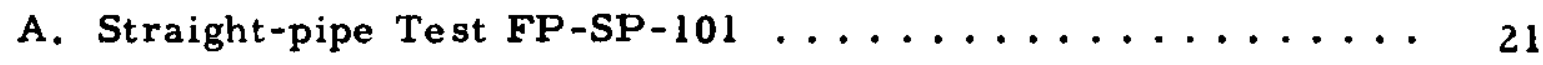

B. Straight-pipe Test FP-SP-102 .................... 29

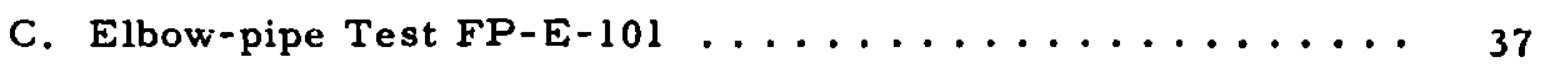

D. Elbow-pipe Test FP-E-103 ..................... 45

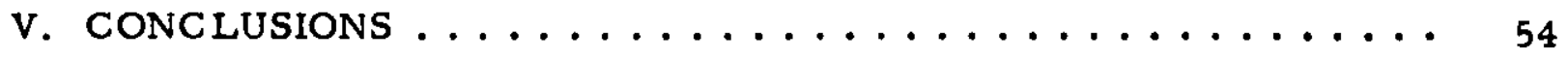

A. Effect of Pipe Plasticity on Pressure-transient Analysis . . 54

B. Effect of Elbows on Pulse Propagation . . . . . . . . . . . 54

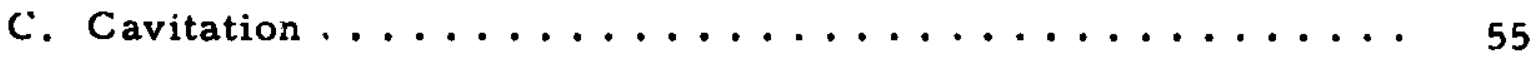

D. Strain-measurement Accuracy ................ 55

E. Miscellaneous Effects ....................... 56

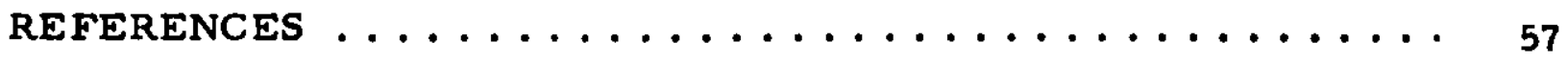




\section{LIST OF FIGURES}

No.

Title

Page

1. Experimental Stress-Strain Relation for Nickel 200 . . . . . .

2. Piping and Instrumentation Layout for Straight-pipe Experiments FP-SP-101 and -102

3. Piping and Instrumentation Layout for Elbow-pipe Experiment FP-E-101 ....................

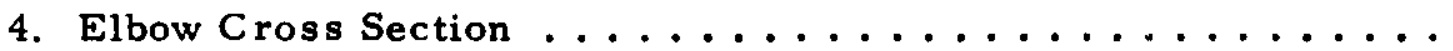

5. Piping and Instrumentation Layout for Elbow-pipe Experiment FP-E-103 ............................ 14

6. Fitted Stress-Strain Relation for Nickel 200 . . . . . . . . 17

7. Pressure-Strain Relation for Nickel 200 F'iping Used in

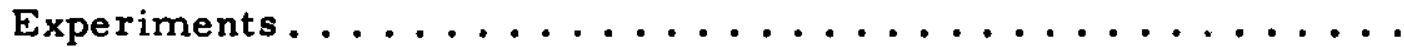

8. Test FP-SP-101: Experimental Pressure Pulse $P_{1}$ Used as Source Pulse for PTA-1 Computation ...............

9. Test FP-SP-101: Experimental and Computed Pressure

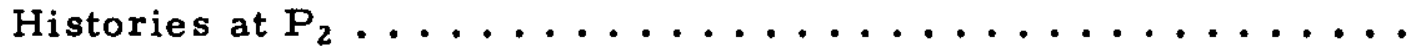

10. Test FP-SP-101: Experimental and Computed Pressure Histories at $\mathrm{P}_{3} \ldots \ldots \ldots \ldots \ldots \ldots \ldots \ldots$

11. Test FP-SP-101: Experimental and Computed Pressure Histories at $\mathrm{P}_{4} \ldots \ldots \ldots \ldots \ldots \ldots \ldots \ldots \ldots$

12. Test FP-SP-101: Experimental and Computed Pressure Histories at $P_{5} \ldots \ldots \ldots \ldots \ldots \ldots \ldots$

13. Test FP-SP-101: Experimental and Computed Pressure

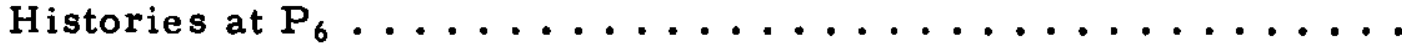

14. Test FP-SF-101: Experimental and Computed Pressure

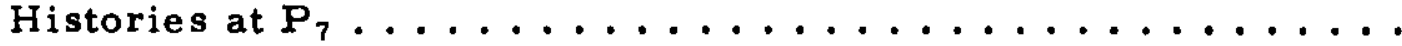

15. Test FP-SP-101: Experimental and Computed Pressure

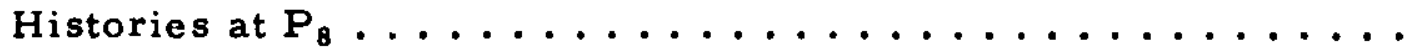

16. Test FP-SP-101: Experimental and Computed Pressure

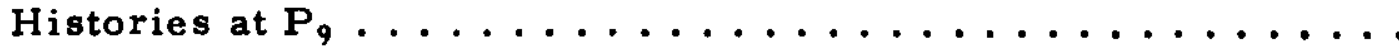

17. Test FP-SP-101: Experirnental and Computed Pressure

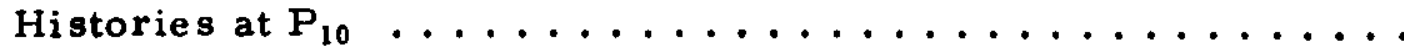

18. Test FP-SP-101: Experimental and Computed Pressure

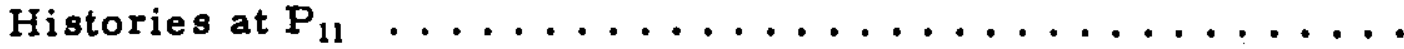




\section{LIST OF FIGURES}

No.

Title

Page

19. Test FP-SP-101: Experimental and Computed Strain Histories at First Snt of Gauges, $\mathbf{S G}_{1}-\mathrm{SG}_{5} \ldots \ldots \ldots$

20. Test FP-SP-101: Experimental and Computed Strain Histories at Second Set of Gauges, $\mathrm{SG}_{6}-\mathrm{SG}_{10} \ldots \ldots . \ldots . \ldots$

21. Test FP-SP-101: Experimental and Computed Strain

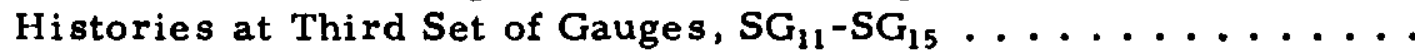

22. Test FP-SP-101: Experimental and Computed Strain Histories at Fourth Set of Gauges, $\mathrm{SG}_{16}-\mathrm{SG}_{20} \ldots \ldots . . \ldots 27$

23. Test FP-SP-101: Profiles of Experimental and Computed Maximum Dynamic Strain along Nickel Pipe ............ 28

24. Test FP-SP-101: Profiles of Experimental and Computed Permanent Plastic Strain along Nickel Pipe ...........

25. Test FP-SP-102: Experimental Pressure Pulse $P_{1}$ Used as Source Pulse for PTA-1 Computation .............

26. Test FP-SP-102: Experimental and Computed Pressure

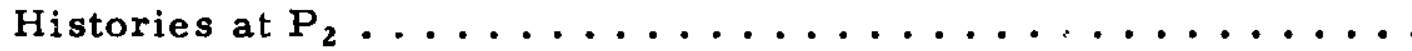

27. Test FP-SP-102: Experimental and Computed Pressure

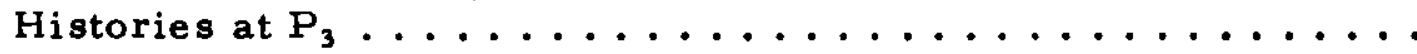

28. Test FP-SP-102: Experimental and Computed Pressure

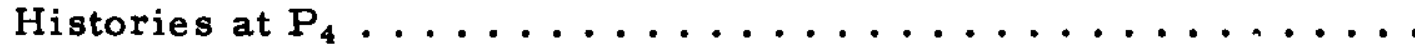

29. Test F'P-SP-102: Experimental and Computed Pressure

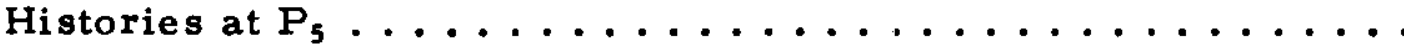

30. Test FP-SP-102: Experimental and Computed Pressure

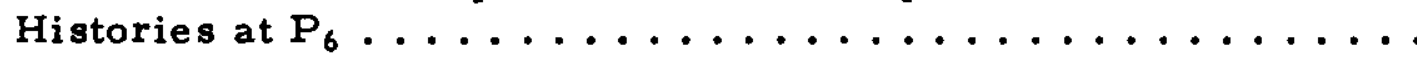

31. Test FP-SP-102: Experimental and Computed Pressure

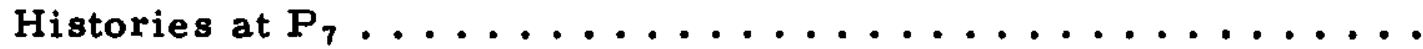

32. Test FP-SP-102: Experimental and Computed Pressure

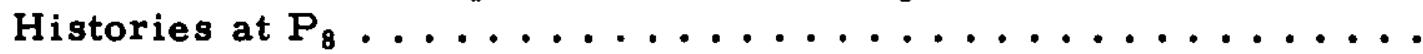

33. Test FP-SP-102: Experimental and Computed Pressure

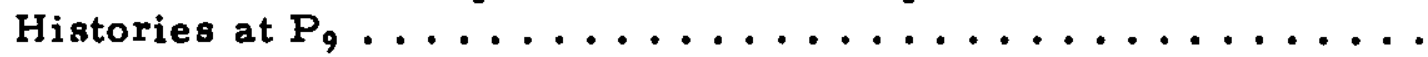

34. Test FP-SP-102: Experimental and Computed Pressure

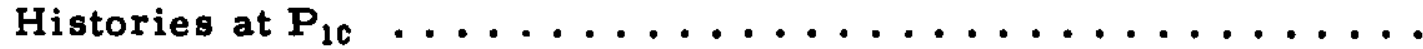

35. Test FP-SP-102: Experimental and Computed Pressure Histories at $P_{11}$ 


\section{LIST OF FIGURES}

No. Title

36. Test FP-SP-102: Experimental and Computed Strain Histories at First Set of Gauges, $\mathrm{SG}_{1}-\mathrm{SG}_{5} \ldots \ldots \ldots \ldots$

37. Test FP-SP-102: Experimental and Computed Strain Histories at Second Set of Gauges, $\mathrm{SG}_{6}-\mathrm{SG}_{10} \ldots \ldots \ldots \ldots \ldots$

38. Test FP-SP-102: Experimental and Computed Strain Histories at Third Set of Gauges, $\mathrm{SG}_{11}-\mathrm{SG}_{15} \ldots \ldots \ldots \ldots$

39. Test FP-SP-102: Experimental and Computed Strain Histories at Fourth Set of Gauges, $\mathrm{SG}_{16}-\mathrm{SG}_{20} \ldots \ldots \ldots \ldots$

40. Test FP-SP-102: Profiles of Experimental and Computed Maximum Dynamic Strain along Nickel Pipe. . . . . . . . .

41. Test FP-SP-102: Profiles of Experimental and Computed Permanent Plastic Strain along Nickel Pipe . . . . . . . . .

12. Test FP-E-101: Experimental Pressure Pulse $P_{1}$ Used as Source Pulse for PTA-1 Computation ...........

43. Test FP-E-101: Experimental and Computed Pressure

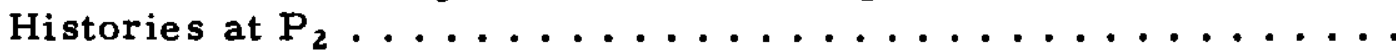

44. Test FP-E-101: Experimental and Computed Pressure

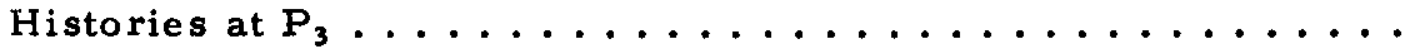

45. Test FP-E-101: Experimental and Computed Pressure

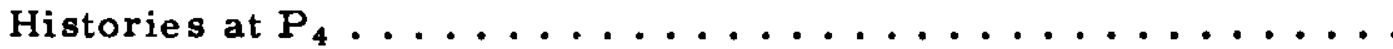

46. Test FP-E-101: Experimental and Computed Pressure

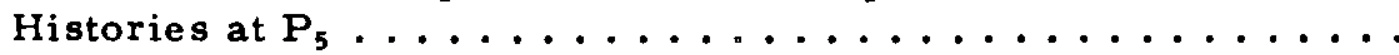

47. Test FP-E-101: Experimental and Computed Pressure

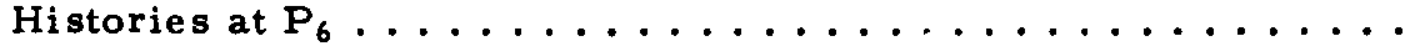

48. Test FP-E-101: Experimental and Computed Pressure

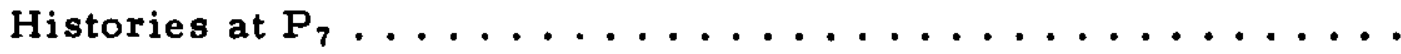

49. Test FP-E-101: Experimental and Computed Pressure

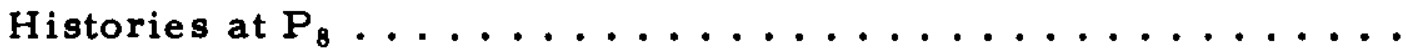

50. Test FP-E-101: Experimental and Computed Pressure

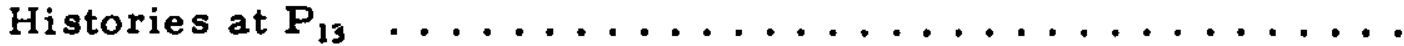

51. Test FP-E-101: Experimental and Computed Pressure

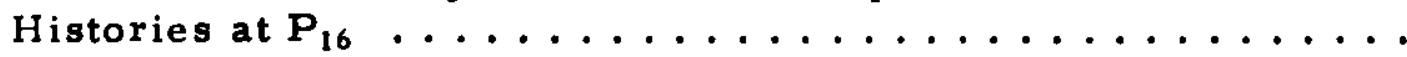

52. Test FP-E-101: Experimental and Computed Pressure

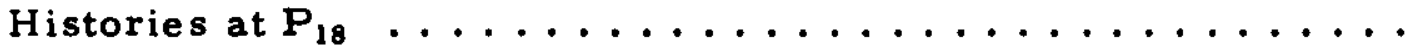




\section{LIST OF FIGURES}

No.

53. Test FP-E-101: Experimental and Computed Strain Histories at First Set of Gauges, $\mathrm{SG}_{1}-\mathrm{SG}_{5} \ldots \ldots \ldots \ldots \ldots$

54. Test FP-E-101: Experimental and Computed Strain Histories at Second Set of Gauges, $\mathbf{S G}_{6}-\mathrm{SG}_{10} \ldots \ldots \ldots \ldots$

55. Test FP-E-101: Experimental and Computed Strain Histories at Third Set of Gauges, $\mathrm{SG}_{11}-\mathrm{SG}_{15} \ldots \ldots \ldots \ldots$

56. Test FP-E-101: Experimental and Computed Strain Histories at Fourth Set of Gauges, $\mathbf{S G}_{16}-\mathrm{SG}_{20} \ldots \ldots \ldots \ldots$

57. Test FP-E-101: Profile of Experimental and Computed Maximum Dynamic Strain along First Nickel Pipe . . . . . . .

58. Test FP-E-101: Profiles of Experimental and Computed Permanent Plastic Strain along First Nickel Pipe . . . . . . .

59. Test FP-E-103: Experimental Pressure Pulse $P_{1}$ Used as Source Pulse for First PTA-1 Computation . . . . . . . . .

60. Test FP-E-103: Experimental and Computed Pressure

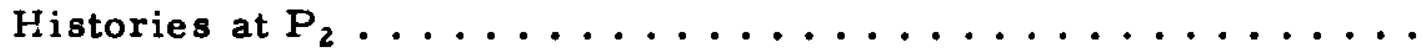

61. Test FP-E-103: Experimental and Computed Pressure

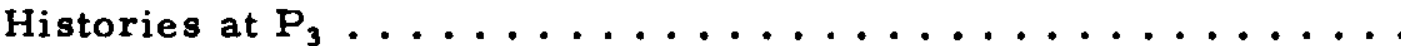

62. Test FP-E-103: Experimental and Computed Pressure

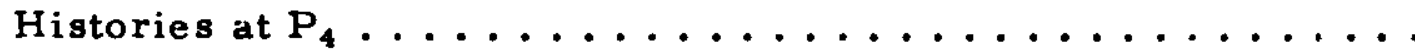

63. Test FP-E-103: Experimental and Computed Pressure

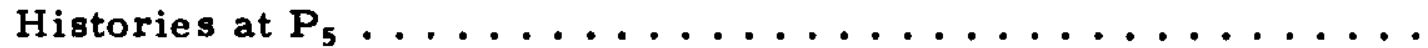

64. Test FP-E-103: Experimental and Computed Pressure

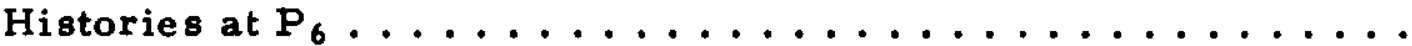

65. Test FP-E-103: Experimental and Computed Pressure

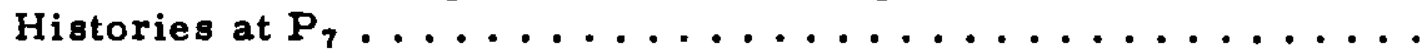

66. Test FP-E-103: Experimental and Computed Pressure

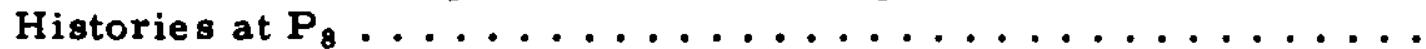

67. Test FP-E-103: Experimental and Computed Pressure

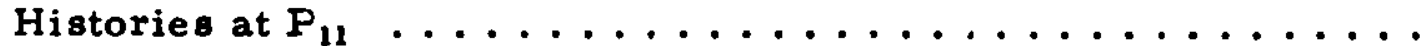

68. Test FP-E-103: Experimental and Computed Pressure

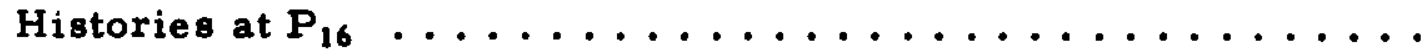

69. Test FP-E-103: Experimental and Computed Pressure

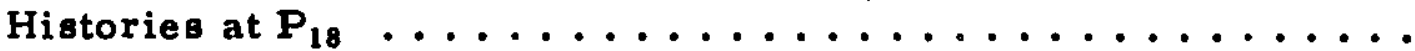




\section{LIST OF FIGURES}

No.

Title

Page

70. Test FP-E-103: Experimental and Computed Strain Histories at First Set of Gauges, $\mathrm{SG}_{1}-\mathrm{SG}_{5} \ldots \ldots \ldots$

71. Test FP-E-103: Experimental and Computed Strain Histories at Second Set of Gauges, $\mathbf{S G}_{6}-\mathrm{SG}_{10} \ldots \ldots \ldots$

72. Test FP-E-103: Experimental and Computed Strain Histories at Third Set of Gauges, $\mathrm{SG}_{11}-\mathrm{SG}_{15} \ldots \ldots \ldots$

73. Test FP-E-103: Experimental and Computed Strain Histories at Fourth Set of Gauges, $\mathrm{SG}_{16}-\mathrm{SG}_{20} \ldots \ldots \ldots$

74. Test FP-E-103: Profiles of Experimental and Computed Maximum Dynamic Strain along First Nickel Pipe.........

TABLE

No. Title

I. Comparison of Peak Strains and Stresses for

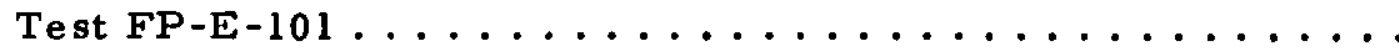




\title{
EXPERIMENTAL VALIDATION OF PTA-1 COMPUTER CODE FOR PRESSURE-TRANSIENT ANALYSIS INCLUDING THE EFFECT OF PIPE PLASTICITY
}

by

C. K. Youngdahl, C. A. Kot, and R. A. Valentin

\begin{abstract}
The PTA-1 code for computing pressure transients in piping networks includes a computational model to treat the significant effect of plastic deformation of the piping on pulse propagation. Stanford Research Institute has completed an experimental program on the response of piping systems to internal pressure pulses which plastically deform portions of the piping. This report makes extensive comparisons between PTA-l computations and these experimental results. The excellent agreement obtained for both pressure histories and strain histories for all the experiments indicates that the PTA-1 computational model for pipe plasticity effects is accurate. The computation-experiment comparisons also permit a number of observations and conclusions to be made on other aspects of computational modeling of pressure transients, particularly with respect to pulse propagation around elbows.
\end{abstract}

\section{INTRODUCTION}

The PTA-1 computer code analyzes pressure transients in complex piping systems, using the one-dimensional method of characteristics applied to a fluid-hammer formulation. It differs from other transient-analysis codes primarily in that the computaticn includes the effect of plastic deformation of the piping on pulse propagation. The code has been validated using data obtained in a series of experiments performed at Stanford Research Institute (SRI). The excellent agreement between the experimental results and PTA-1 computations for both pressure-pulse propagation in the fluid and dynamic plastic strains in the piping indicates that the modeling of plastic-deformation effects in PTA-1 is accurate. This report presents details of the code validation, along with some conclusions on pressure-transient analysis that may be drawn from the comparisons and experimental results. 
PTA-l is described in detail in Ref. 1. To facilitate its usage as a design and analysis tool, we have minimized input requirements, preliminary computations, and running times and carried out much of the computation in subroutines that ar easily replaced or altered. Pipe network connections, node spacings, fluid properties, pipe material properties, flow areas, friction factors, wave speeds, and junction losses are computed internally. Subroutines for a variety of junction types are included, such as tees, closed ends, surge tanks, sudden-area changes, dummy junctions, acoustic-impedance discontinuities, nonreflecting far-end boundaries, pressure sources, and simple models of pumps and rupture disks.

A number of computer codes familiar to the nuclear-reactor industry are based on classical fluid-hammer theory; ${ }^{2}$ these include TRANSWRAP, ${ }^{3}$ WHAM, ${ }^{4}$ NATRANSIENT, ${ }^{5}$ BREAK, ${ }^{6}$ and HYTRAN. ${ }^{7}$ PTA-1 differs from the se codes in that it computes the effect of plastic deformation of piping on the pressure transient. This effect is particularly significant in analyzing transients in the heat-transport systems of liquid-metal-cooled reactors. Thinwalled piping is used because operating pressures are low; hypothesized pressure pulses from a sodium/water reaction in a steam generator or from a core accident would be expected to deform portions of the piping system well into the plastic range. Plastic deformation tends to chop the pulse peak to the pipe yield pressure and to broaden the pulse; ${ }^{8}$ consequently, it has a significant effect on pressure-pulse propagation in a piping network and on the transient loading on system components.

A detailed treatment of structure-fluid interaction in a large piping network would require a computational effort that would be incompatible with the use of a pressure-transient code as a design and analysis tool. Consequently, a relatively simple computational model for the effect of pipe plasticity on pulse propagation was developed ${ }^{9}$ that is consistent with a one-dimensional treatment of a piping system. The intent was not to model in detail the dynamic structural response of the piping to transient loads, but to incorporate into the code those features of the response that have the strongest influence on pulse propagation in the fluid.

In modeling pipe plasticity effects, we assume the pipe to be sliced into a series of unconnected rings; bending moments, axial forces, pipe inertia, and waves in the pipe wall are all neglected. The pipe response is thus quasistatic, and deformations are not required to be continuous functions of axial position. The result of the se assumptions on pipe response is that the only influence of pipe deformation on transient propagation in the fluid is through its effect on local wave speed.

SRI has performed four one-eighth-scale experiments ${ }^{10,11}$ on the effects of pressure pulses on reactor piping. Since the pressure pulses plastically deformed the piping, and since extensive dynamic pressure and strain measurements were made, these experiments are an excellent source of data for 
validating the modeling of plastic-deformation effects incorporated in PTA-1. Detailed comparisons have been made between PTA-1 computations and the SRI experimental results, and brief summaries of some of these comparisons have been published. ${ }^{12,13}$ This report provides a reasonably complete presentation of the full set of validation studies.

Some conclusions that may be drawn from the results of the four SRI tests and the PTA-1 validation studies are:

1. Plastic deformation of piping typical of reactor heat-transport systems has a significant qualitative and quantitative effect on pressure-pulse propagation.

2. Classical fluid-hammer formulations that do not account for the effect of pipe plasticity give completely erroneous results for transient propagation if the pulse peak exceeds the yield pressure of the piping.

3. The simple, one-dimensional computational model incorporated in PTA-l for predicting plastic-deformation effects on pressure transients and pipe strains is accurate, as demonstrated by the excellent agreement between computation and experiment for both pressure- and strain-history results. The agreement for the dynamic-strain results is particularly noteworthy in that the fluid-structure interaction model in PTA-I was developed to predict pressure transients in the fluid and was not intended or expected to accurately compute piping deformation.

4. Wave interactions in plastically deforming piping can cause cavitation at unexpected times and locations in the system.

5. A one-dimensional computational model for the effect of an elbow on pulse propagation is appropriate, at least for the elbow geometry used in the SRI experiments.

6. The effect of elbow curvature on pulse propagation is negligible, except perhaps right at the elbow; however, the effect of plastic deformation on the pulse may be masking the effect of elbow curvature.

The SRI tests are described briefly in Sec. II, and Sec. III contains the computer modeling and PTA-l input appropriate to the tests. Computed and experimental results for the four tests are compared in Sec. IV. Finally, implications and conclusions pertaining to pressure-transient analysis that may be drawn from the tests and the code validation are discussed in Sec. V. 


\section{STANFORD RESEARCH INSTITUTE EXPERIMENTS}

Four tests were performed by $S \mathrm{SI}^{10,11}$ to provide data on the effect of pipe plasticity on pressure-pulse propagation in LMFBR piping systems. A geometric scaling factor of one-eighth was used in the tests; i.e., test-section piping with 76-mm (3-in.) outside diameter, 1.65-mm (0.065-in.) wall thickness, and $1.5-\mathrm{m}(5-\mathrm{ft})$ length was used to model reactor piping having $0.61-\mathrm{m}$ (24-in.) outside diameter, 13-mm (0.5-in.) wall thickness, and 12-m $(40-\mathrm{ft})$ length. Nickel-200 was used for the test-section piping because its stress-strain curve at room temperature is similar to that of Type 304 stainless steel at reactor temperature. Room-temperature water was used for the fluid because its acoustic impedance is similar to that of sodium and it is easier to handle. All flanges in the piping systems were rigidly fixed to eliminate gross pipe motion.

Pressure pulses were produced by an explosively driven pulse gun developed at SRI. The pulses had a peak pressure of about 10-15 MPa (1500$2200 \mathrm{psi}$ ), a rise time of about $0.2 \mathrm{~ms}$, and a duration of about $3 \mathrm{~ms}$. Since pressure does not scale, and time scales with the same one-eighth factor as the geometry, these test pulses correspond to reactor pulses having a peak pressure of 10-15 MPa, a rise time of $1.6 \mathrm{~ms}$, and a duration of $24 \mathrm{~ms}$. These pulse parameters were selecied as being representative of a hypothetical core-dis ruptive accident in an LMFBR; they are also a reasonable choice for representing hypothetical pressure pulses resulting from a sodium/water reaction in a steam generator.

Seven stress-strain tests at various strain rates (i) were performed on Nickel-200 specimens cut from scrap sections of the thin-walled piping

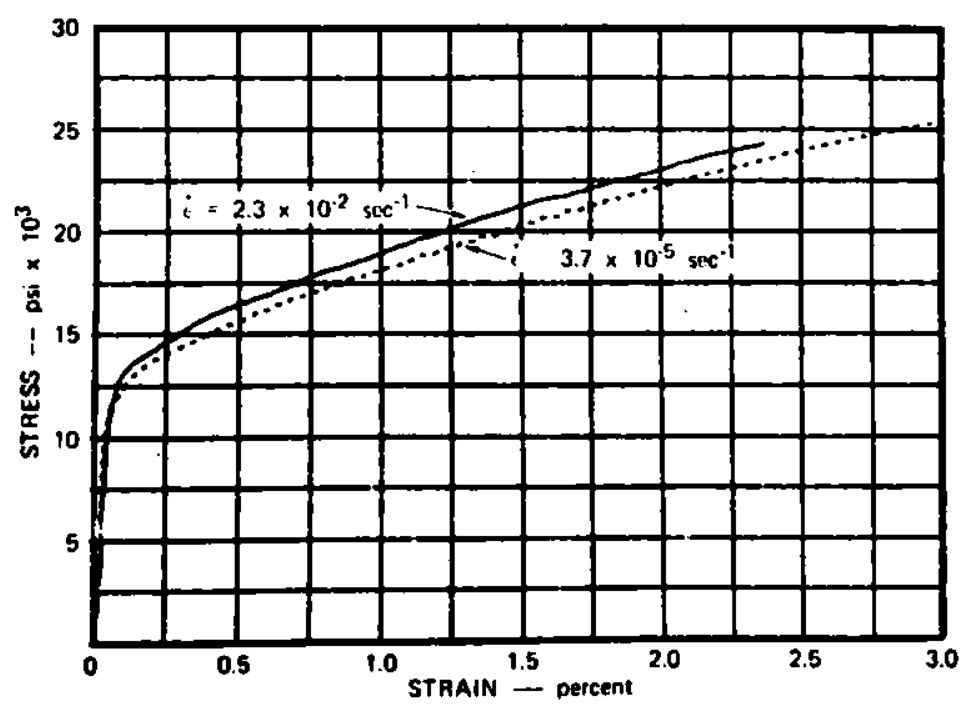

Fig. 1. Experimental Stress-Strain Relation for Nickel 200. Reproduced from Romander and Cagliostro. ${ }^{10}$ Conversion factor: $1 \mathrm{psi}=6.895 \mathrm{kPa}$. used in the experiments. Results of two of the tests are shown in Fig. I. The elastic modulus is $190 \mathrm{GPa}$ ( $28 \mathrm{x}$ $\left.10^{6} \mathrm{psi}\right)$; the departure from linearity occurs at a stress of about $76 \mathrm{MPa}(11,000 \mathrm{psi})$ and a strain of about $0.04 \%$. The corresponding yield pressure of the piping is then about 3.4 $\mathrm{MPa}$ (500 psi).

The four SRI tests consisted of two straight-pipe tests (FP-SP-101 and -102) and two tests (FP-E-101 and -103) that had an elbow as part of the piping system. The test configurations for both 
straight-pipe tests were identical and are shown in Fig. 2. A 3-m (10-ft) length of thick-walled steel pipe was located between the pulse gun at the left of the piping system and the Nickel-200 test section. This pipe sufficiently separated the test section and the pulse gun so that pulses reflected back and forth between them would not interfere with the original pulse. It also provided convenient locations for measuring the pulse before it reached the test section. The inside diameter of the steel pipe was the same as the nickel pipe, and its wall thickness was $5 \mathrm{~mm}$ (0.188 in.). This pipe is only deformed elastically by the pressure pulse. A thick blind flange closes the right end of the nickel pipe. Dynamic-pressure measurements were made at three locations in the steel pipe $\left(P_{1}-P_{3}\right)$ and at eight locations in the nickel pipe $\left(P_{4}-P_{11}\right)$. Dynamic-strain measurements were made at four axial locations along the nickel pipe; measurements were made at five circumferential positions at each of the se axial locations, so that 20 strain gauges $\left(S_{1}-S_{20}\right)$ were used in all. Pressure-time and strain-time data for all gauges were reported in both graphical and digital form.

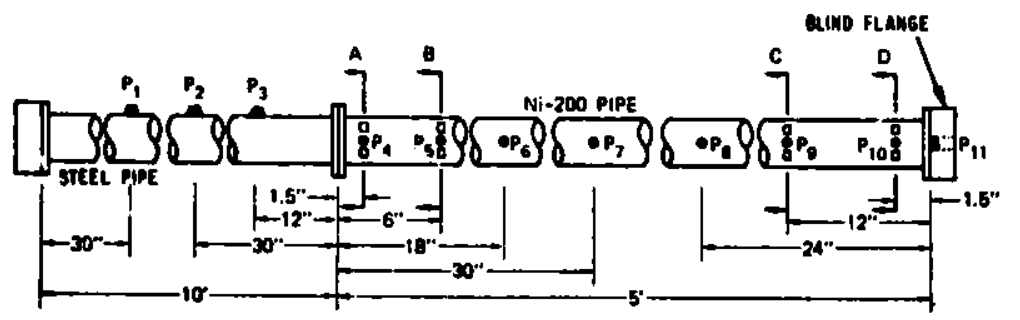

Fig. 2

Piping and Instrumentation Layout for Straight-pipe Experiments FP-SP-101 and -102 . Reproduced from Romander and Cagliostro. ${ }^{10}$ Conversion factor:

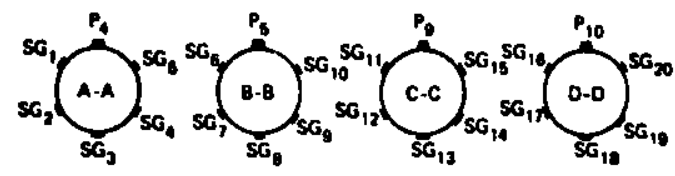
1 in. $=2.54 \mathrm{~cm}$.

The test configuration for elbow Test FP-E-101 is shown in Fig. 3. From left to right, the system consists of the pulse gun, a thick-walled steel pipe, a nickel-pipe test section, a thick-walled elbow, another nickel-pipe test section, and a heavy flange ending in a free surface. The steel and nickel pipes have the same dimensions as in the straight-pipe tests.

Fig. 3

Piping and Instrumentation Layout for Elbow-pipe Experiment FP-E-101. Reproduced from Romander and Cagliostro. ${ }^{10}$ Conversion factor: 1 in. $=2.54 \mathrm{~cm}$.

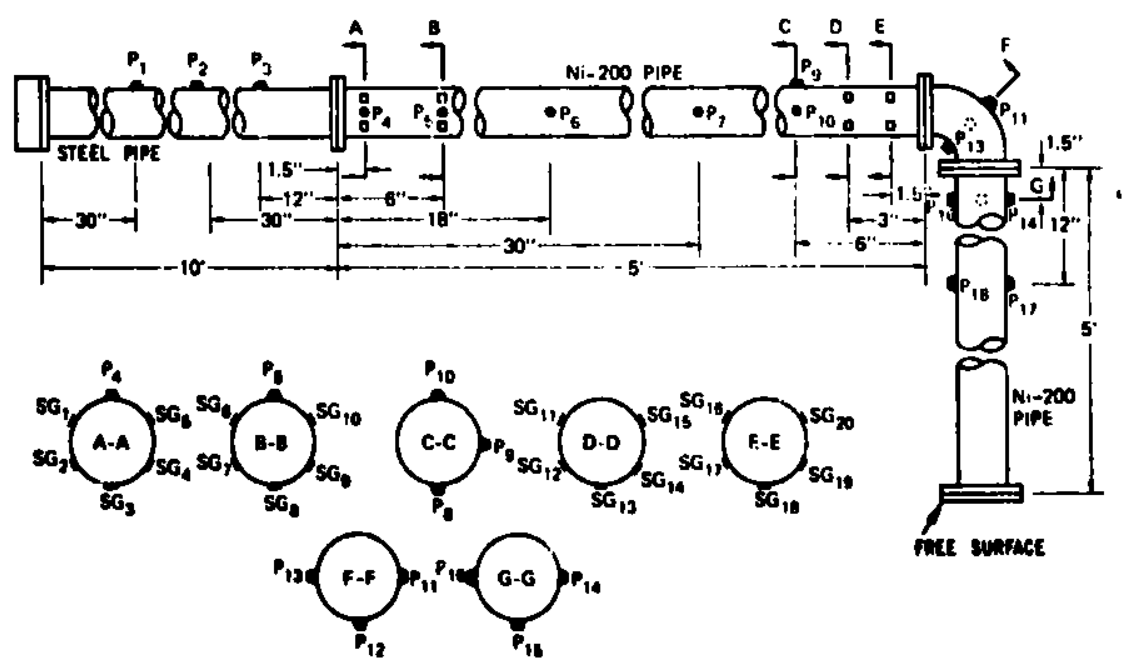




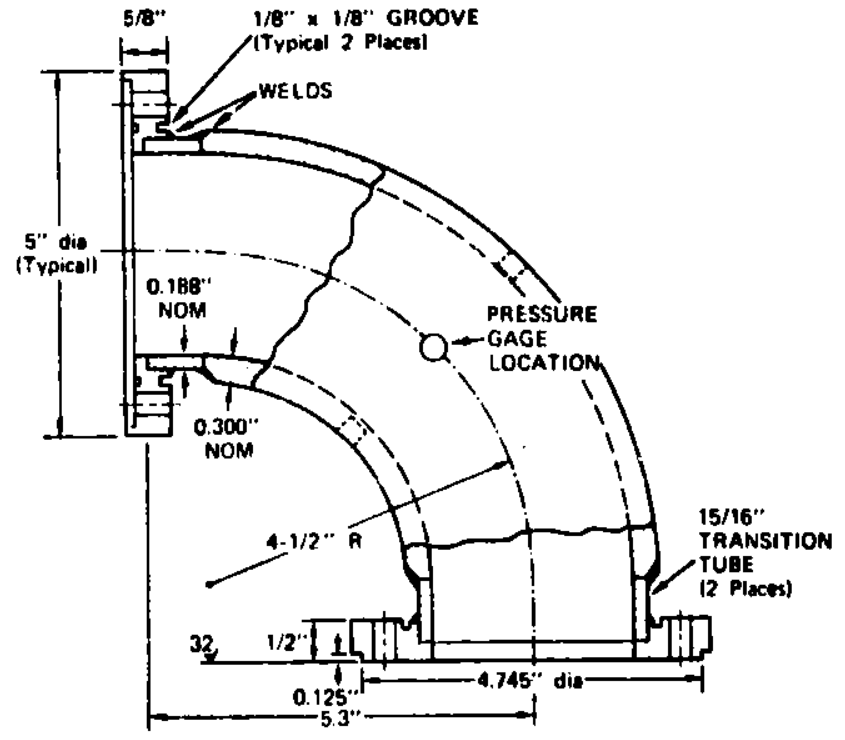

Fig. 4. Elbow Cross Section. Reproduced from Romander and Cagliostro. ${ }^{10}$ Conversion factor: $1 \mathrm{in.}=2.54 \mathrm{~cm}$.
The dimensions of the elbow are shown in Fig. 4. SRI measurements showed that the elbow cross section was slightly egg -shaped and varied from one end to the other. The inside diameter ranged between 69.37 and $70.87 \mathrm{~mm}(2.731$ and 2.790 in.) with an average value for 16 measurements of $70.26 \mathrm{~mm}$ (2.766 in.). The average inside diameter of the short transition pieces was $72.9 \mathrm{~mm}$ (2.85 in.). The wall thicknesses of the elbow and transition pieces were 7.62 and $4.78 \mathrm{~mm}$ ( 0.300 and 0.188 in.), respectively, and the elbow centerline radius was $114 \mathrm{~mm}$ (4.5 in.).

With reference to Fig. 3, three dynamic-pressure gauges $\left(P_{1}-P_{3}\right)$ were located along the steel pipe to measure the input pulse. The first nickel pipe had seven pressure gauges $\left(P_{4}-P_{10}\right)$, with $P_{8}-P_{10}$ distributed circumferentially at the same axial location. The elbow had pressure gauges $P_{11}-P_{13}$ arranged circumferentially around its center cross section. The second nickel pipe had five pressure gauges $\left(P_{14}-P_{18}\right)$, with $P_{14}$, $P_{15}$, and $P_{16}$ distributed around the circumference just beyond the elbow and $P_{17}$ and $P_{18}$ at an axial location farther downstream. The purpose of the multiple gauges at and near the elbow was to measure dynamic-pressure gradients across the diameter as the pulse interacted with the elbow and thereby to obtain information on the multidimensionality of the flow around the elbow.

Twenty dynamic-strain gauges $\left(\mathrm{SG}_{1}-\mathrm{SG}_{20}\right)$ again were arranged in groups of five at four axial locations in the first nickel pipe.

The test configuration of elbow Test FP-E-103 is shown in Fig. 5. It is identical to that of Test FP-E-101, except that a heavy blind flange terminates the layout.

Fig. 5

Piping and Instrumentation Layout for Elbowpipe Experiment FP-E-103. Reproduced from Romander and Cagliostro. ${ }^{10}$ Conversion factor: 1 in. $=2.54 \mathrm{~cm}$.

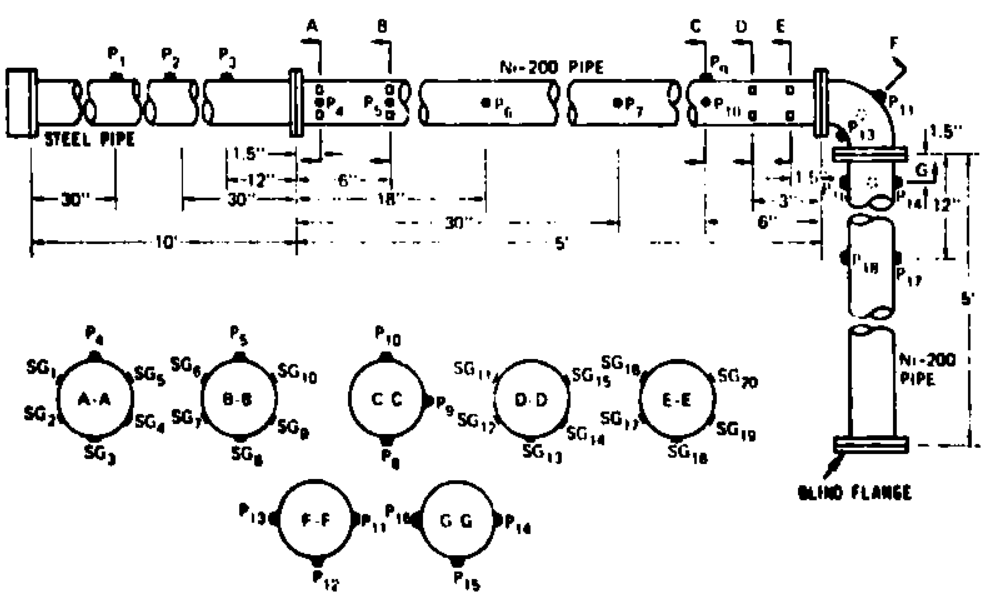


A fifth test, elbow Test FP-E-102, completed the series. A smaller pulse with a peak of $1.4 \mathrm{MPa}$ (200 pai) was used. Since the response of the nickel pipe to this pulse was completely elastic, this test did not provide useful information for validating the plasticity model in PTA-l and will not be discussed here.

Following are some SRI observations that a re pertinent to the inter pretation of the test results shown in subsequent sections of this report:

1. From measurements of the stress-strain curve of Nickel 200 at various strain rates (Fig. 1), SRI concluded that strain-rate effects would not be significant in the pulse-propagation tests.

2. The wall thickness of the Nickel-200 piping varied by about $\pm 0.08 \mathrm{~mm}(0.003 \mathrm{in}$.$) . SRI partially attributed the significant circumferential$ variations in dynamic strain at each axial location to this wall-thickness variation. (In general, the highest strains occurred at the gauge at the circumferential position having the smallest wall thickness, and vice versa.)

3. There is no significant pressure gradient across the diameter of the elbow as the pulse travels through the elbow. In addition, the flow downstream from the elbow is one-dimensional. The peak pressure on the outside turn of the elbow deviated from the peak pressure on the inside turn of the elbow by about $0.5 \%$. It was concluded that the transient flow through the elbow is one-dimensional.

4. A $15 \%$ decrease in peak pressure was measured as the pulse moved through the elbow for each elbow test. (PTA-1 computations indicate that this effect is accounted for by differences in wall thickness, diameter, and material of the elbow and nickel piping, leaving essentially no residual effect to be attributed to elbow curvature.) 


\section{PTA-1 MODELING OF EXPERIMENTS}

Details of the PTA-l code and its input requirements are given in the user's manual. ${ }^{1}$ The discussion here will be concentrated on those aspects of the computer modeling of the SRI experiments that require some additional elaboration or explanation.

\section{A. Stress-Strain Curve for Nickel-200 Piping}

A convenient procedure for obtaining a functional representation for strain-hardening materials is given in Appendix A of Ref. 9. With this technique, the measured stress-strain curve for Nickel-200 (Fig. 1) was modeled as a linear elastic region, followed by a parabolic plastic region and a linear plastic region; the parabola is tangent to the two straight lines. In conventional units, this representation is

$$
\left.\begin{array}{rl}
e= & \sigma / E, E=28 \times 10^{6} \mathrm{psi}, 0 \leq \sigma \leq 11,000 \mathrm{psi} ; \\
e= & 0.018229-3.2786 \times 10^{-6} \sigma+1.5065 \times 10^{-10} \sigma^{2}, \\
& 11,000 \mathrm{psi} \leq \sigma \leq 19,000 \mathrm{psi} ; \\
e= & 2.4464 \times 10^{-6} \sigma-3.6161 \times 10^{-2}, \sigma \geq 19,000 \mathrm{psi} ;
\end{array}\right\}
$$

where $\sigma, c$, and $\mathrm{E}$ are stress, strain, and elastic modulus, respectively. In SI units, these relations become

$$
\left.\begin{array}{rl}
\epsilon= & \sigma / E, E=193 \mathrm{GPa}, 0 \leq \sigma \leq 75.86 \mathrm{MPa} ; \\
\epsilon= & 0.018229-4.7540 \times 10^{-10} \sigma+3.1674 \times 10^{-18} \sigma^{2}, \\
& 75.86 \mathrm{MPa} \leq \sigma \leq 131.0 \mathrm{MPa} ; \\
\epsilon= & 3.5478 \times 10^{-10} \sigma-3.6161 \times 10^{-2}, \sigma 2131.0 \mathrm{MPa},
\end{array}\right\}
$$

where $\sigma$ is in pascals.

Elastic unloading after plastic deformation was assumed to be linear and to have the same slope as the initial elastic-loading region. Yielding in compression was as sumed never to occur in these experiments. 'The fit given by Eqs. 1 or 2 to the experimental stress-strain curve of Fig. 1 is indicated in Fig. 6. The slope do/de of the stress-strain curve, which is needed for the determination of wave speed in the fluid, is easily determined from Eqs. 1 or 2 as a function of $\sigma$. 


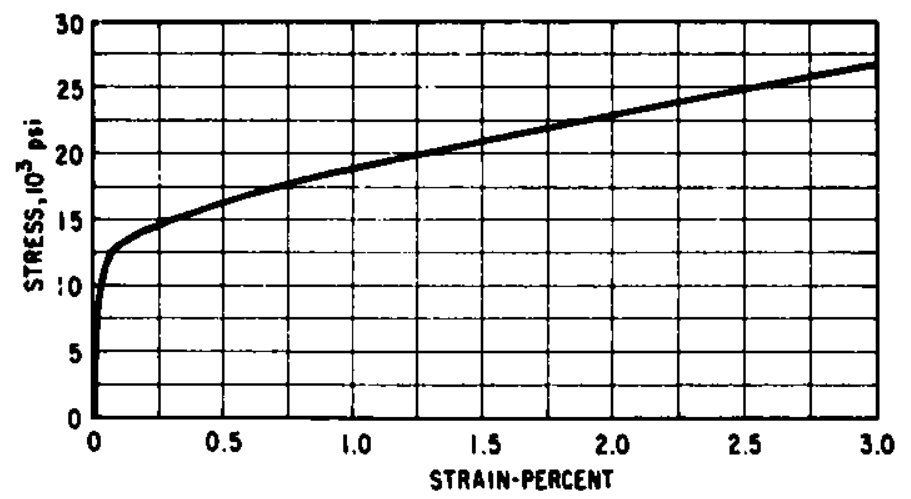

Fig. 6

Fitted Stress-Strain Relation for Nickel 200. Conversion factor: $1 \mathrm{psi}=6.895 \mathrm{kPa}$.

The as sumptions made in the fluid-structure interaction model* used in PTA-l imply that fluid pressure $p$ and circumferential pipe stress $\sigma$ are related by

$$
\mathbf{p}=2 \sigma \mathrm{H} / \mathrm{D} \text {, }
$$

where $H$ is the wall thickness and $D$ is the inside diameter. Figure 7 shows the relation between pressure and circumferential strain that follows from Eqs. 1-3.

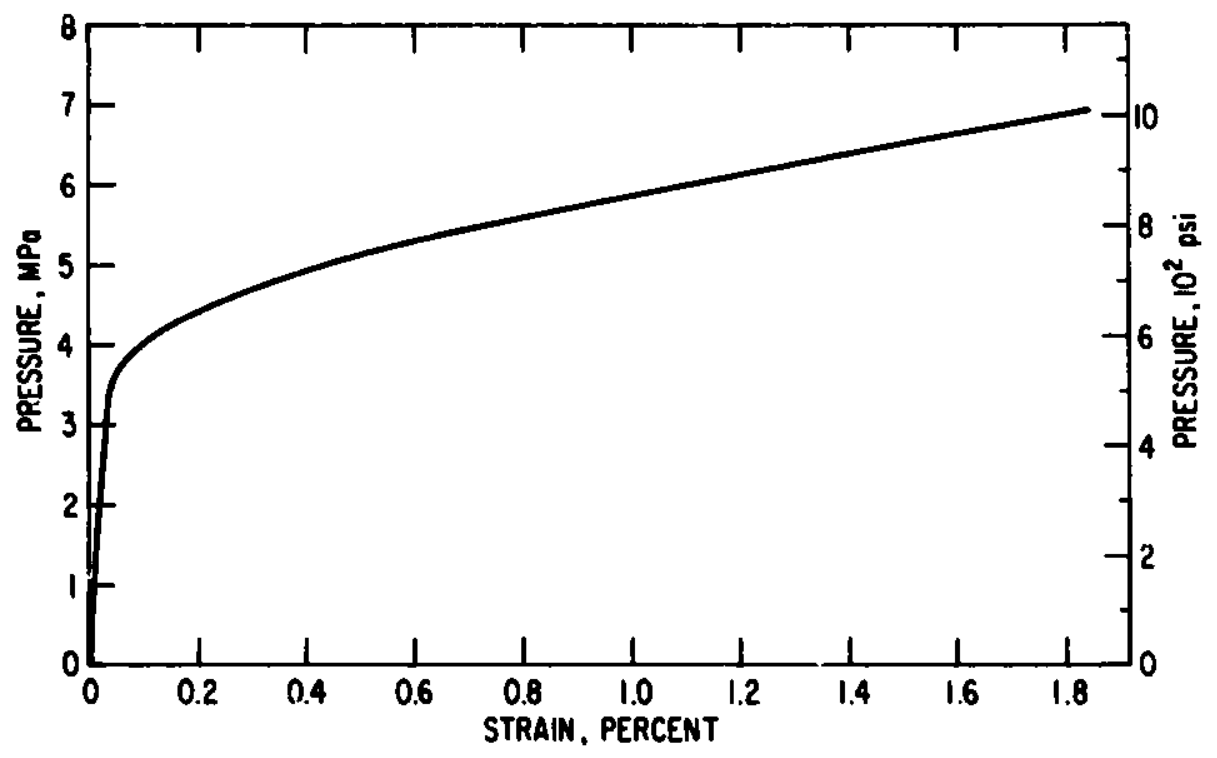

Fig. 7. Pressure-Strain Relation for Nickel 200 Piping Used in Experiments

\section{B. Material Properties of Steel Piping and Elbows}

Since the stainless steel piping and elbows are not deformed plastically by the pressure transients, the only material property needed is the elastic modulus. This was taken to be $193 \mathrm{GPa}\left(28 \times 10^{6} \mathrm{psi}\right)$ at room temperature. ${ }^{14}$

In particular, pipe inertia, bending moments, shear forces, and axial forces are neglected. 
C. Fluid Properties

The required fluid properties are specific weight $\gamma$ and sound speed $c_{0}$. For room-temperature water, these were taken to be

and

$$
\left.\begin{array}{l}
\gamma=9.81 \mathrm{kN} / \mathrm{m}^{3}\left(62.4 \mathrm{lb} / \mathrm{ft}^{3}\right) \\
c_{0}=1.5 \mathrm{~km} / \mathrm{s}(4910 \mathrm{ft} / \mathrm{s})
\end{array}\right\} \text {. }
$$

D. Pipe Roughness

Since the pipe roughnesses were not known and frictional losses were expected to be small for the short durations of the experimental transients, the pipe friction factors were set equal to zero and frictional losses were neglected in the computations.

E. Source Pulse

Except where otherwise noted in the description of the computationexperiment comparisons, the pulse measured at the first pressure gauge $\left(P_{1}\right)$ was used as the input pulse for the PTA-1 computation. Consequently, all piping to the left of this gauge was neglected (see Figs. 2, 3, and 5). The digitized data for pressure as a function of time at gauge $P_{1}$ presented in the SRI report ${ }^{10}$ was used directly as input to PTA-l with no modifications.

F. Modeling of Flanges

Sample calculations were made for some of the tests using two treatments of the heavy flanges: (1) The flanges were ignored, and (2) the flanges were modeled as short lengths of very thick-walled piping. There was no significant difference in the computed pressure transients, and all effects of the flanges on the pressure transients have been ignored in the computational results presented here.

Since all bending moments and shear forces in the pipe wall are neglected in the fluid-structure interaction model in PTA-1, modeling the flanges as short lengths of heavy pipe would not provide any constraint on radial deformation of the adjacent piping. Consequently, the two treatments gave similar results since the flange lengths are small compared to the pipe lengths. Moreover, the good agreement between computed and experimental strains, even at gauges that are close to flanges, indicates that neglecting pipe bending moments and shear forces is a reasonable assumption. 
G. Modeling of Elbows

One purpose of the Pressure Transient Analysis Techniques Project at Argonne National Laboratory is to determine reasonable computational models for the dynamic effects of pipe fittings on transient propagation. Since it is not clear how an elbow affects* a pressure pulse or whether it even has any significant effect, ${ }^{17}$ the elbow was modeled as an equivalent length of straight pipe having the same wall thickness, diameter, and material properties as the elbow.

The equivalent straight-pipe length was set equal to the length of the centerline of the elbow. Any unaccounted-for difference between computed and experimental results in the vicinity of the elbow could then be attributed to the effect of elbow curvature on the transient, and the comparisons would be useful in formulating an improved computational model for an elbow. As will be shown in Sec. IV, the comparisons indicate no significant effect of elbow curvature on transient propagation for the elbow geometry and contraint used in the tests. However, plastic deformation in the vicinity of the elbow may be masking other effects.

H. Dummy Junctions

Dummy junctions were placed at each axial position where pressure or strain gauges were located. This assures that a computational node occurs at each point of interest and simplifies the output, because only results at junctions need be printed. Although the number of pipes and junctions in the computational model is then considerably more than occurs in the experiment, the computational effort is not affected because a dummy junction is treated as an interior node.

\section{Terminal Junctions}

The blind flanges in Tests FP-SP-101, -102, and FP-E-103 were modeled as closed ends in PTA-1, i.e., as zero-velocity boundaries. The free surface at the end of Test FP-E-101 was modeled as a constant-pressure junction; the boundary pressure was maintained at atmospheric conditions (zero gauge pressure).

*For example. Swaffield ${ }^{15}$ concludes that elbow geometry has a significant effect on the transmission and reflection of incident pulses, but that the amount of applied restraint has no effect. Conversely. Fox ${ }^{16}$ (p. 146) states that a fixed elbow has no effect on a pulse and that pulse reflections result from elbow motions. 
J. Strain Results

Strains were not printed in the original version of PTA- $1,{ }^{1}$ because the program was intended to focus on the pressure transient in the fluid and was not expected to accurately model strains in the piping. Since SRI provided extensive pipe-strain results, instructions were added to PTA-1 to print out strain as a function of time as well as maximum dynamic strain and permanent plastic strain as functions of position. This was a simple modification to make to the code, since the pertinent point on the stress-strain curve had to be located anyway to compute the pipe-deformation effect on wave speed. The excellent agreement between computed and experimental strains indicates that the computation of pipe strain in PTA-1 is much more accurate than originally thought.

K. Time Step and Running Time

A time step of $0.01 \mathrm{~ms}$ was used to obtain the results presented in this report. The running time to simulate each experiment was then about one CPU minute on the IBM 370/195.

Some trial runs were made with a larger time step of $0.05 \mathrm{~ms}$; the running time per problem was then about eight CPU seconds. The results were similar to those for the shorter time step, but the initial narrow spike in the pulse was not as well resolved. Although the results for the 0.05-ms time step probably would be adequate for engineering purposes, the smaller time step of $0.01 \mathrm{~ms}$ was used, because the corresponding runuing time was short enough not to be a factor and because it was desirable to obtain accurate results to compare with the extensive SRI data. 


\section{COMPARISONS BETWEEN PTA-1 COMPUTATIONS AND EXPERIMENTS}

A. Straight-pipe Test FP-SP-101

The locations of the pressure and strain gauges for Test FP-SP-101 are shown in Fig. 2. The pulse measured at $P_{1}$ (see Fig. 8) was used as the source pulse for the PTA-1 computation. To demonstrate the significant qualitative and quantitative effect of pipe plasticity on the pressure transient in the fluid, a completely elastic computation was also performed; i.e., the nickel pipe was as sumed to be replaced by one made of a fictitious material that has the same elastic modulus as Nickel-200 but does not deform plastically at the computed pressures. In the comparisons of pressure histories that follow, the curves are experimental rasults from Ref. 10 , the circles are points computed by PTA-1 for the actual stress-strain curve of Nickel-200 (Eqs. 1 and Figs. 1 and 6 ), and the squares are computed points for idealized elastic response.

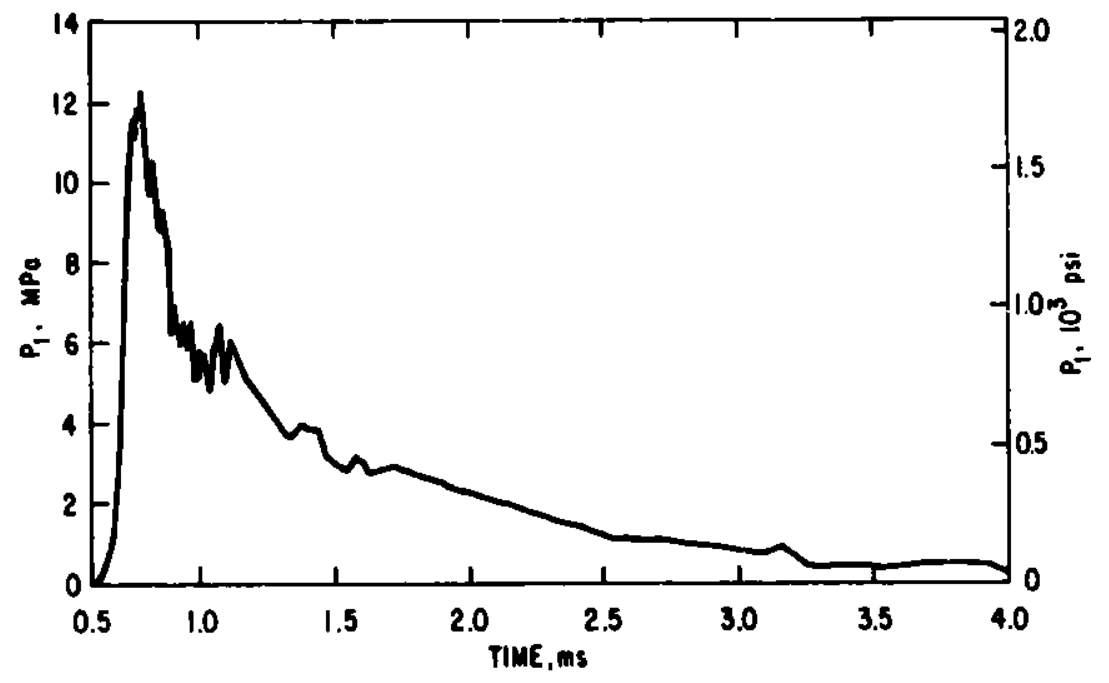

Fig. 8. Test FP-SP-101: Experimental Pressure Pulse $P_{1}$

Used as Source Pulse for PTA-1 Computation

Figures 9 and 10 show pressure histories at gauges $P_{2}$ and $P_{3}$ in the steel pipe. The computed cases are identical until a rarefaction wave reflects back from the junction with the nickel pipe. In the elastic-plastic case, this rarefaction wave causes cavitation at gauge $P_{2}$ at about $3 \mathrm{~ms}$, as indicated by the negative pressure computed there. This agrees well with the experimental results, which indicate cavitation at this location by gauge $\mathbf{P}_{2}$ "bottoming out." No cavitation occurs for the elastic computation, which is thus qualitatively inaccurate. Consequently, one result of including the effect of plastic deformation of the piping on pulse propagation is the unexpected, but experimentally verified, prediction of cavitation in a simple closed piping system. Moreover, the cavitation does not occur at the closed end, as might be expected to be associated with reflections from a free surface in the system. As a result of reflections from the softer plastically deforming pipe, the cavitation occurs at an interior point of a pipe that is not itself deforming plastically. 


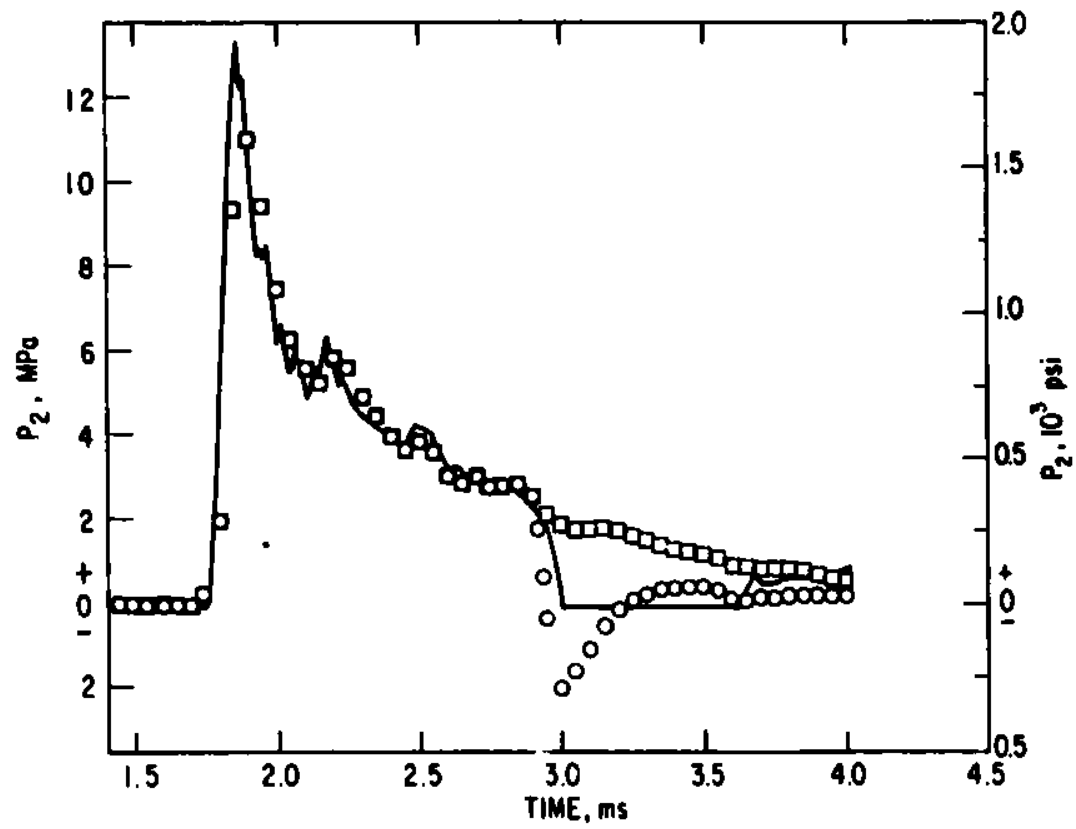

Fig. 9. Test FP-SP-101: Experimental and Computed Pressure Histories at $\mathrm{P}_{2}$

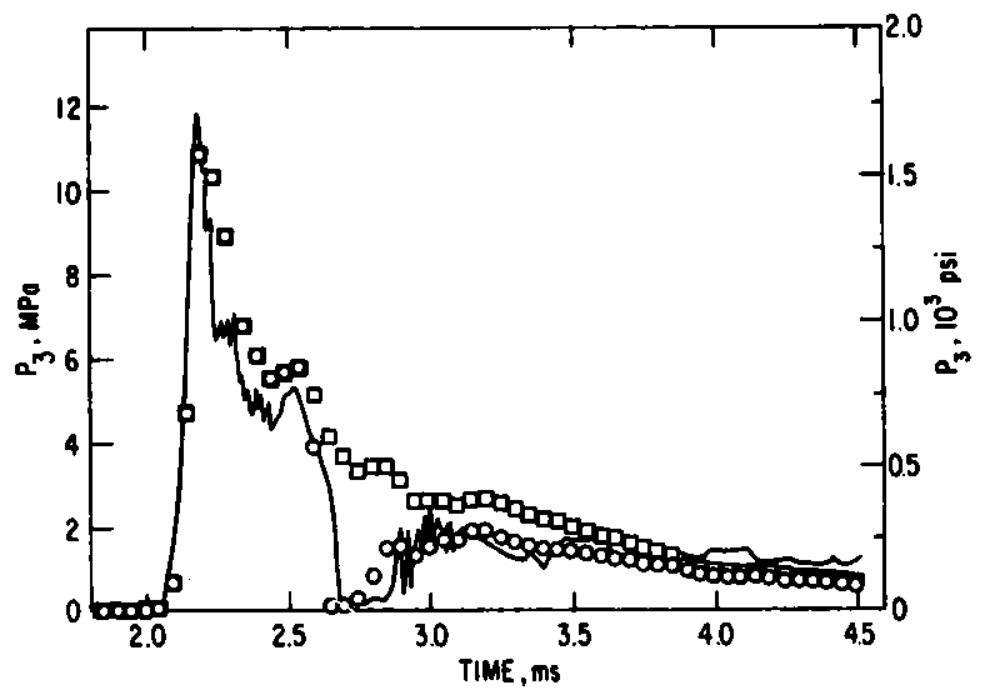

Fig. 10

Test FP-SP-101: Experimental and Computed Pressure Histories at $\mathbf{P}_{\mathbf{3}}$

Figures 11-18 show results at pressure-gauge locations in the plastically deforming nickel pipe. Again, the elastic-plastic PTA-1 computations and the experimental results agree well, both qualitatively and quantitatively. The initial pressure peak of the pulse is rapidly chopped off to the yield pressure of $3.4 \mathrm{MPa}(500 \mathrm{psi})$ as the pulse travels down the pipe. The pulse is reflected at the closed end of the system, but rather than doubling in amplitude, as would be predicted by an elastic computation, its peak value is only about 4.8 $\mathrm{MPa}$ (700 psi) because of plastic deformation near the pipe end.

The results of the all-elastic computation are significantly different. The initial pressure peak travels essentially undiminished down the pipe, doubles in amplitude to about $20.7 \mathrm{MPa}(3000 \mathrm{psi})$ at the closed end (Fig. 18), 
and returns up the pipe (the second peak in Figs. 12-16). [The reflected and ir_ident pulses almost coincide at gauge $P_{10}$ (see Fig. 17); therefore the peak there is almost double that of the initial pulse. At the other gauges (see Figs. 12-16), the reflected pulse is superimposed on the tail of the initial pulse and therefore has a higher peak than the initial pulse does.] This second peak is completely dispersed in both the experimental results and the elasticplastic computation.

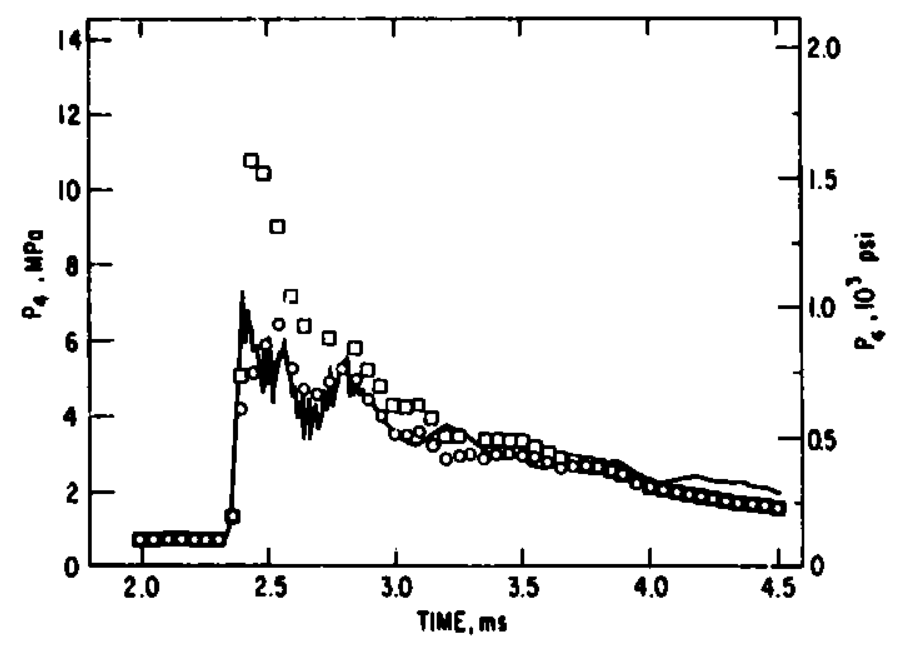

Fig. 11

Test FP-SP-101: Experimental and Computed Pressure Histories at $\mathrm{P}_{\mathbf{4}}$

Fig. 12

Test FP-SP-101: Experimental and Computed Pressure Histories at $P_{5}$
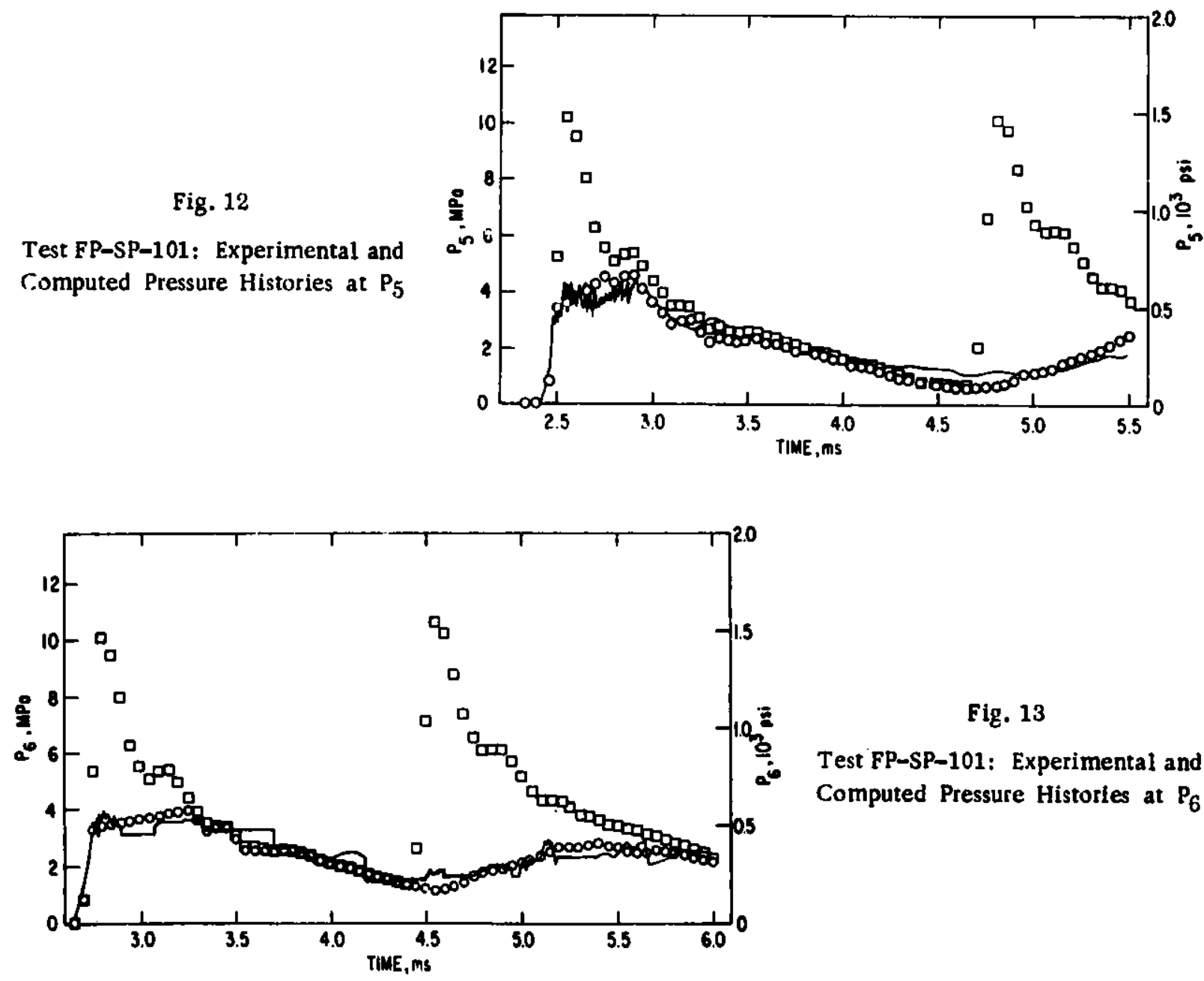

Fig. 13

Test FP-SP-101: Experimental and Computed Pressure Historles at $P_{6}$ 


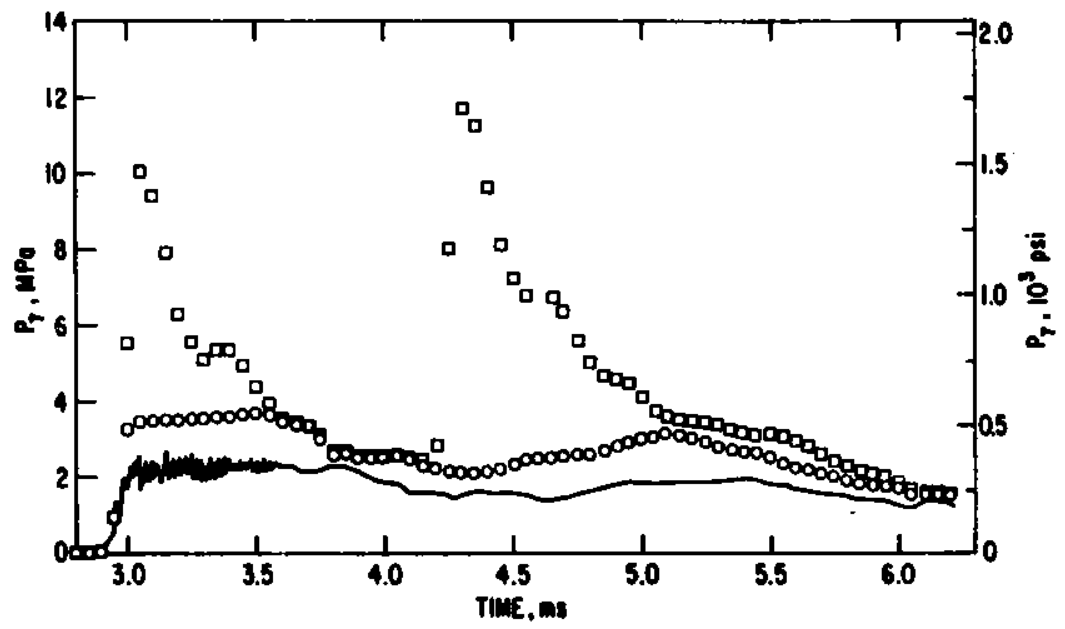

Fig. 14. Test FP-SP-101: Experimental and Computed Pressure Histories at $P_{7}$

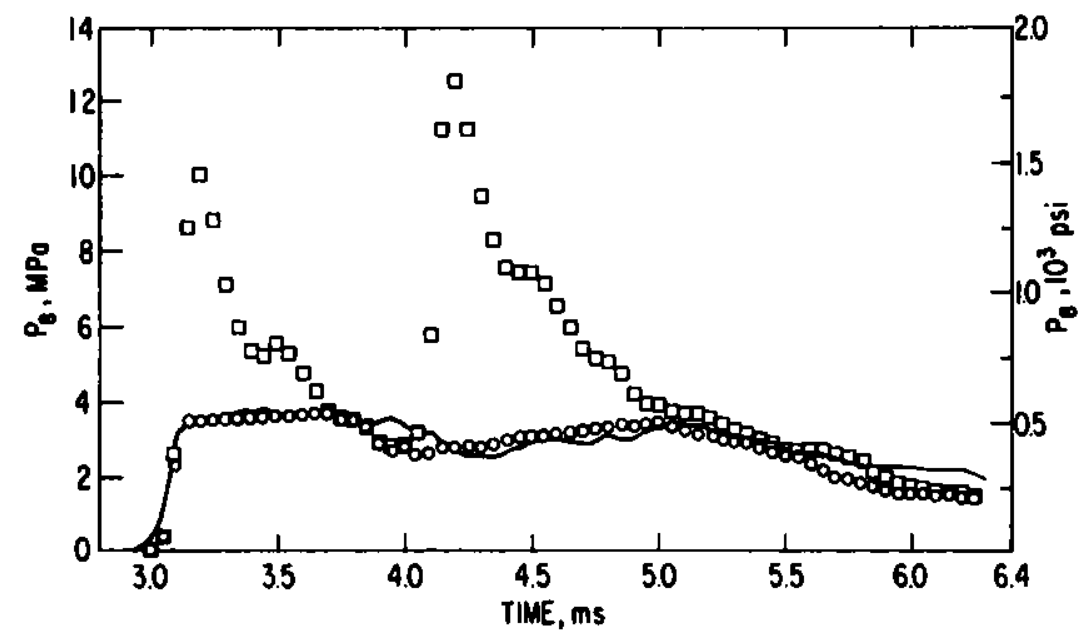

Fig. 15. Test FP-SP-101: Experimental and Computed Pressure Histories at $\mathbf{P}_{\mathbf{8}}$

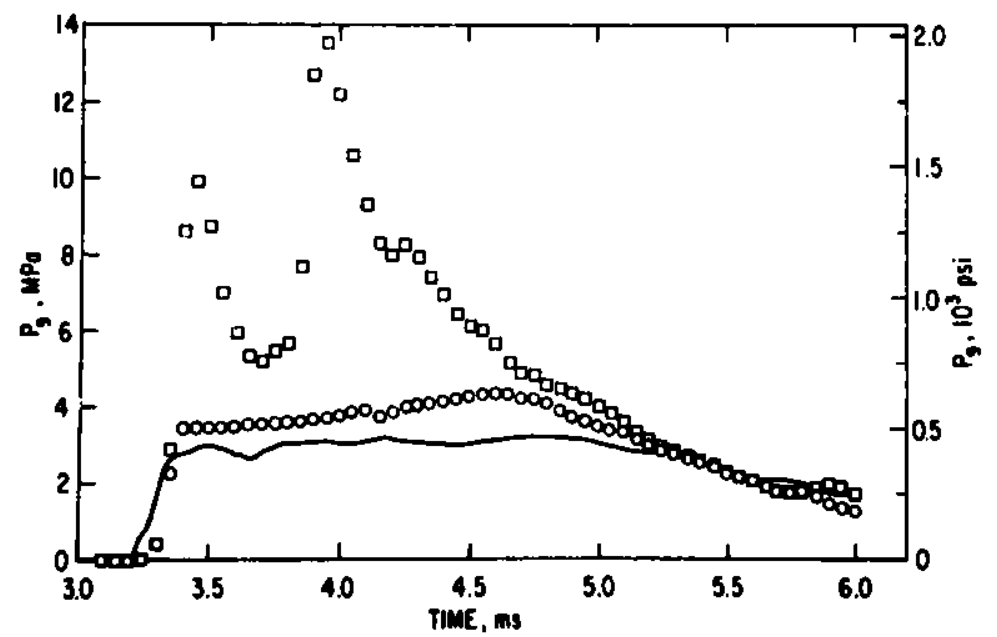

Fig. 16

Test FP-SP-101: Experimental and Computed Pressure Histories at P9 


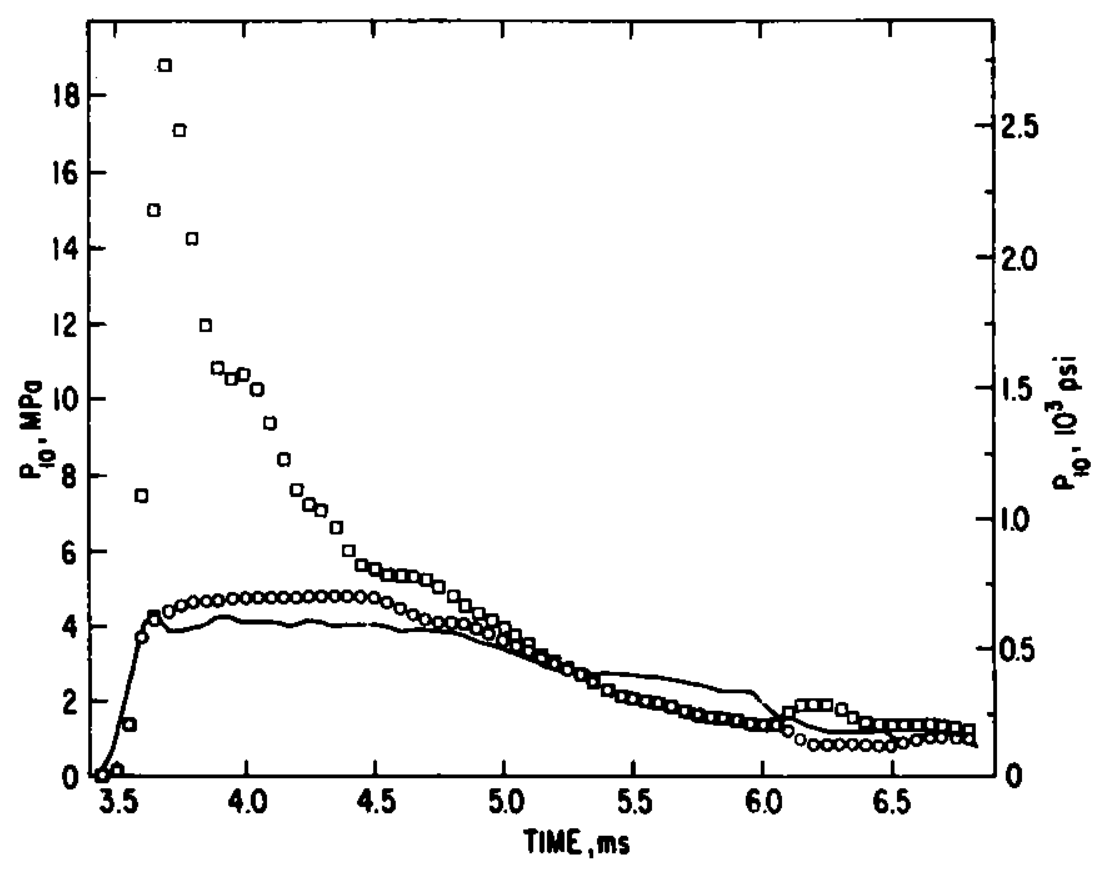

Fig. 17. Test FP-SP-101: Experimental and Computed Pressure Histories at $\mathrm{P}_{10}$

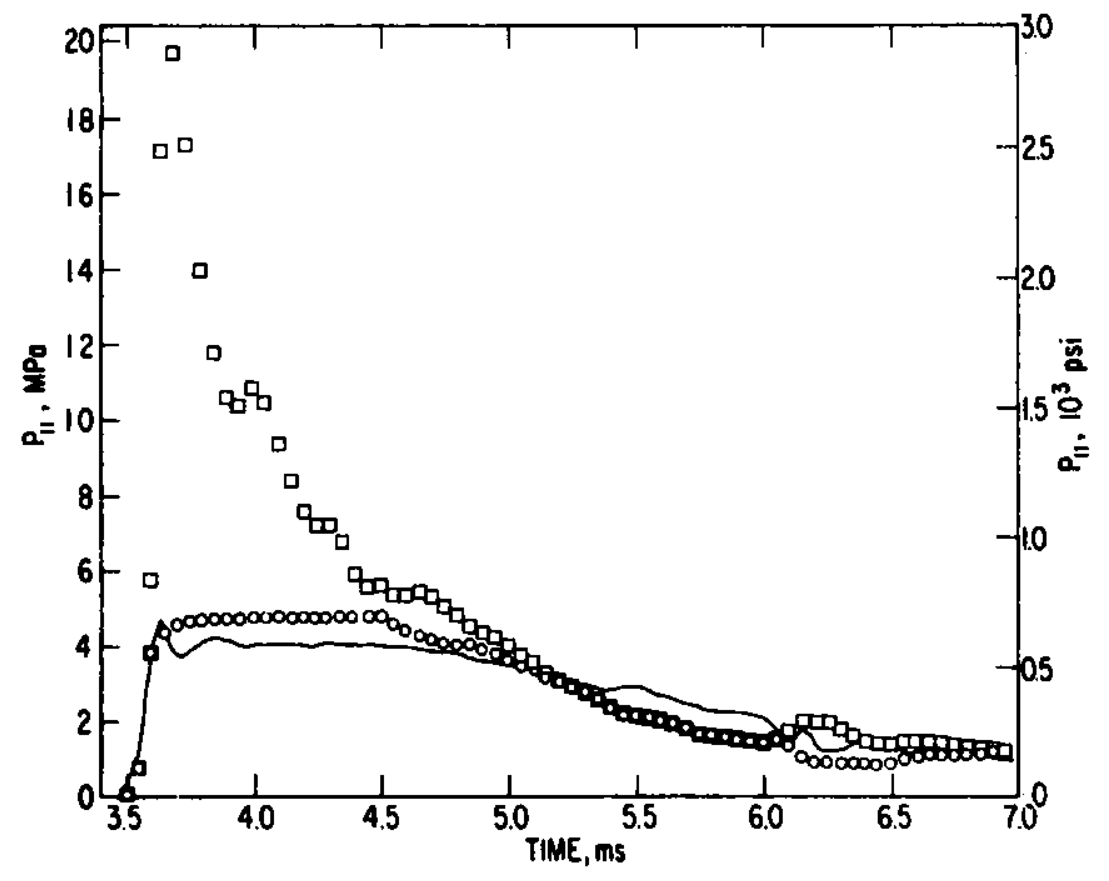

Fig. 18. Test FP-SP-101: Experimental and Computed Pressure Histories at $P_{11}$

The initial narrow spike at $2.4 \mathrm{~ms}$ in the experimental results at gauge $\mathrm{P}_{4}$ (see Fig. 11) does not show up in the PTA-1 elastic-plastic computation. This difference will be discussed later in connection with the straintime comparisons at this location. The rapid noise-type oscillations superimposed on the pulses measured at gauges $P_{2}-P_{7}$ (see Figs. 9-14) also do not show up in the PTA-1 computations. However, these may be caused by waves in the pipe wall or by instrumentation behavior, rather than indicating pressure 
fluctuations in the fluid; the oscillations tend to damp out with both axial coordinate and time. The longer-period damped oscillation at gauges $P_{10}$ and $P_{11}$ (see Figs. 17 and 18) may be caused by elastic deformation of the blind flange; this oscillation also occurs in Test FP-SP-102, where it is more pronounced. The initial plateau in the experimental results at gauge $P_{7}$ (see Fig. 14) is well below the yield pressure. This may indicate a calibration error at this gauge, because the experimental results at the gauges on either side, $P_{6}$ and $P_{8}$, have plateaus at the proper level (see Figs. 13 and 15).

The strain histories at the four sets of gauges are qualitatively and quantitatively different because of the complex fluid-structure interaction. At all gauge locations, the computed strain histories match the experimental results well with respect to general shape, location and duration of initial rises, location of peaks, and decay amplitudes. The agreement is particularly noteworthy in that PTA- 1 was developed originally to predict pressure transients in the fluid and was not intended to accurately compute piping deformation.

Figures 19-22 compare computed and experimental strain histories for Test FP-SP-101. The curves are experimental results from Ref. 10, and the circles are results computed with PTA-l for the actual stress-strain curve of Nickel-200. Results for the idealized all-elastic computation are not shown here, because elastic strains are quite small compared to the plastic strains that actually occur.

Results for the first set of strain gauges $\mathrm{SG}_{1}-\mathrm{SG}_{5}$ (see Fig. 2) are shown in Fig. 19; the pressure history at the same axial location is shown in Fig. 11. Since the total elastic strain for the nickel pipe is about $0.04 \%$, Fig. 19 indicates that the pipe has been deformed well into the plastic range. The initial pressure peak in the experimental results at $2.4 \mathrm{~ms}$ (see Fig. 11) did not produce any noticeable peak in the strain; but the pressure peak at $2.5 \mathrm{~ms}$ produced a large dynamic strain for both the experimental and computed

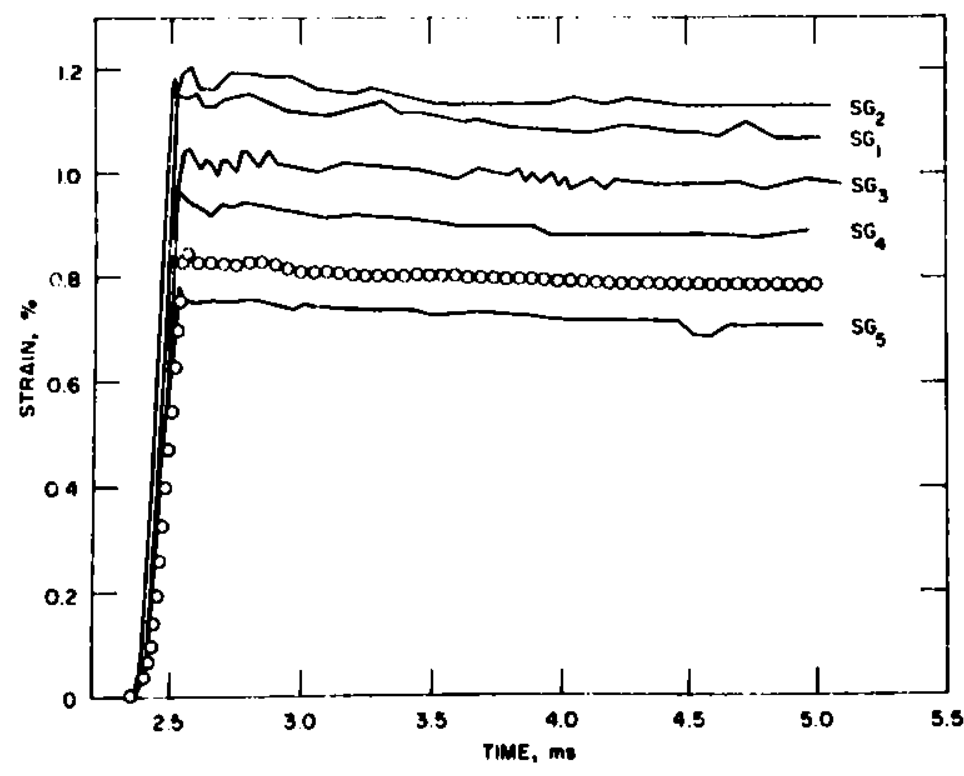

Fig. 19

T'est FP-SP-101: Experimental and Computed Strain Histories at First Set of Gauges, $\mathrm{SG}_{1}-\mathrm{SG}_{5}$ 


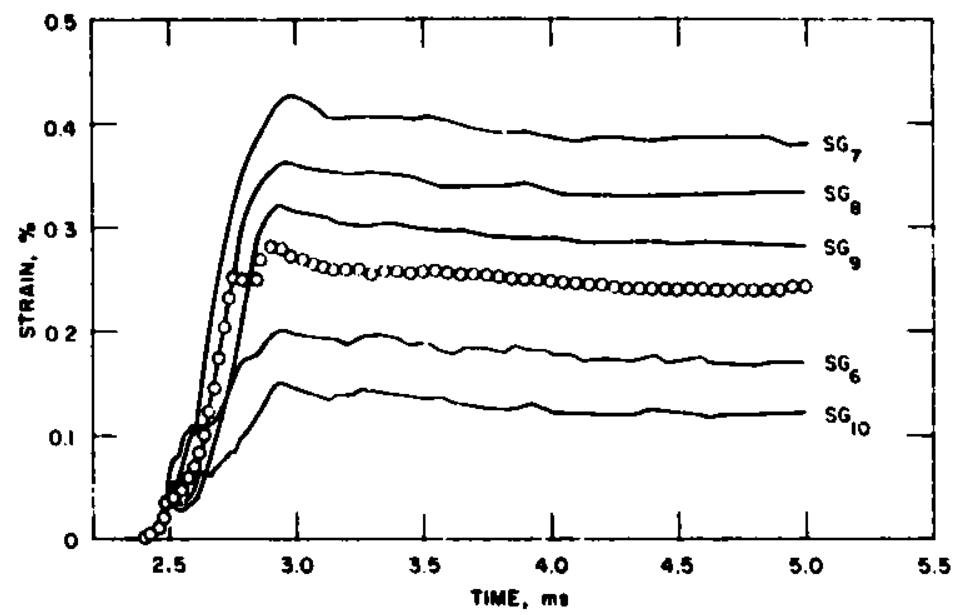

Fig. 20

Test FP-SP-101: Experimental and Computed Strain Histories at Second Set of Gauges, $\mathrm{SG}_{6}-\mathrm{SG}_{10}$

Fig. 21

Test FP-SP-101: Experimental and Computed Strain Histories at Third Set of Gauges, $\mathrm{SG}_{11}-\mathrm{SC}_{15}$
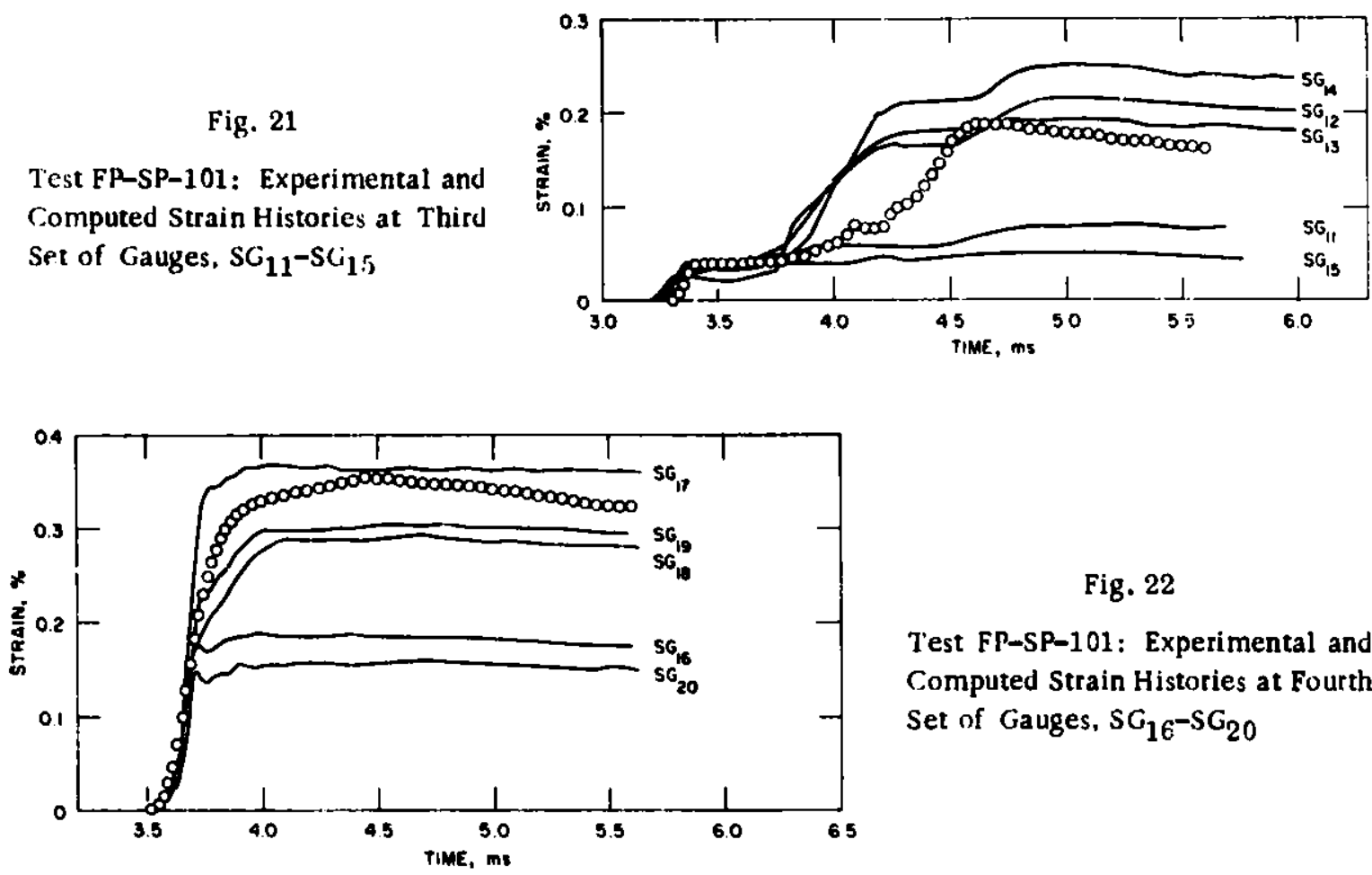

Fig. 22

Test FP-SP-101: Experimental and Computed Strain Histories at Fourth Set of Gauges, $\mathrm{SG}_{16}-\mathrm{SG}_{20}$

results. Similar behavior can be observed in the other three tests. Consequently, it may be that either the sharp pressure spike at $2.4 \mathrm{~ms}$ is fictitious and corresponds to an instrumentation overshoot, or a temporary increase in the yield stress occurred because of strain-rate hardening. The first explanation seems more likely, since the PTA-1 computations predict no pressure peak at $2.4 \mathrm{~ms}$. Subsequent pressure peaks are lower than that occurring at $2.5 \mathrm{~ms}$. Consequently, the later pressure fluctuations correspond to stressstrain states on the elastic unloading curve and produce only small elastic oscillations in the strain.

The peak strains at the other gauge locations are considerably lower than that at the first set, because the overall effect of plastic deformation on pressure-pulse propagation is to chop the pulse peaks to pressures close to 
the yield pressure. The rapid pressure rise to the yield pressure at $2.5 \mathrm{~ms}$ shown in Fig. 12 produces a short elastic "step" in the strain response measured by gauge: $S_{6}-S_{10}$ (see Fig. 20). Because of plastic yielding, the more gradual pressure increase occurring from 2.5 to $2.9 \mathrm{~ms}$ produces a much larger strain increase. The subsequent pressure decay results again in elastic spring-back of the piping strain.

The long step at the elastic limit shown in the strain-history results (see Fig. 21) at the third set of gauges, $S_{11}-S G_{15}$, corresponds to the initial flat plateau at the yield pressure that occurs in the pressure history shown in Fig. 16. The almost unperceptible reflected pulse then produces a large increase in strain, because its peak pressure is higher than the yield pressure.

At the last set of strain gauges $\left(\mathrm{SG}_{15}-\mathrm{SG}_{20}\right)$, the incident and reflected pressure pulses (see Fig. 17) arrive so close together that a smooth growth to the maximum dynamic strain results, as shown in Fig. 22.

The maximum dynamic strain and permanent plastic strain in the nickel pipe are shown as a function of axial location in Figs. 23 and 24, respectively. The curves are the computed results, the bars give the measured circumferential variation in strain, and the circles are averages of the five gauges at each location. The computed results are well within the circumferential variation in the experimental measurements and are close to the circumferentially averaged experimental values, even though the gauge locations are regions of steep axial gradients in the strain distribution. In addition, posttest measurements of diameter change as a function of axial location give a permanent deformation profile that agrees with the permanent strain dis tribution shown in Fig. 24.

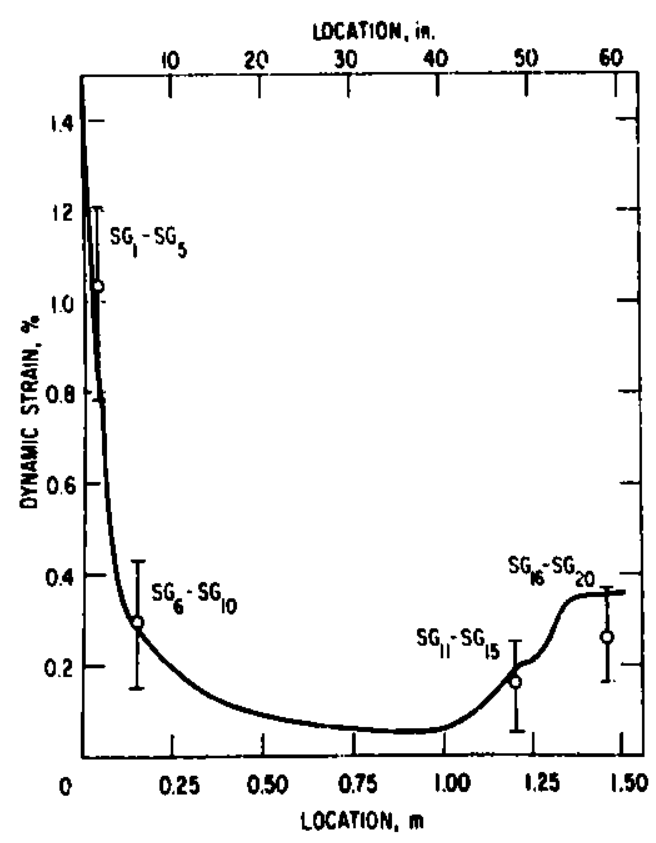

Fig. 23. Test FP-SP-101: Profiles of Experimental and Computed Maximum Dynamic Strain a long Nickel Pipe

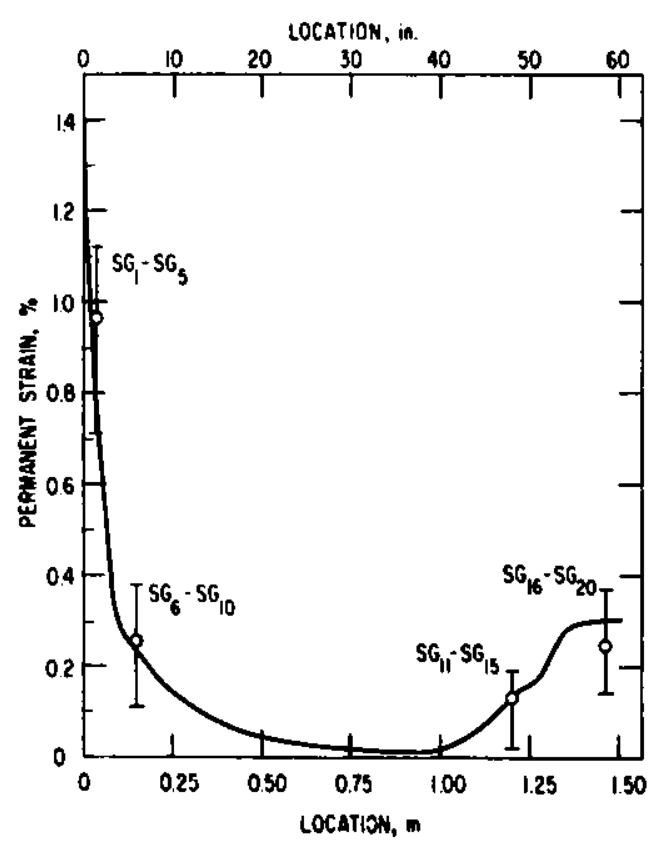

Fig. 24. Test FP-SP-101: Profiles of Experimental and Computed Permanent Plastic Strain along Nickel Pipe 


\section{B. Straight-pipe Test FP-SP-102}

The test configuration for this experiment is the same as that for FPSP-101 and is shown in Fig. 2. The pulse measured at $P_{1}$, shown in Fig. 25, was used as the source pulse for the PTA-l computation. The results for the two straight-pipe tests are similar, except that the higher initial peak of pulse $P_{1}$ for Test FP-SP-102 [14 MPa (2000 psi)], as compared to that for Test FPSP-101 [12 MPa (1750 psi)], enhances the effect of pipe plasticity on pulse propagation and results in larger plastic deformation.

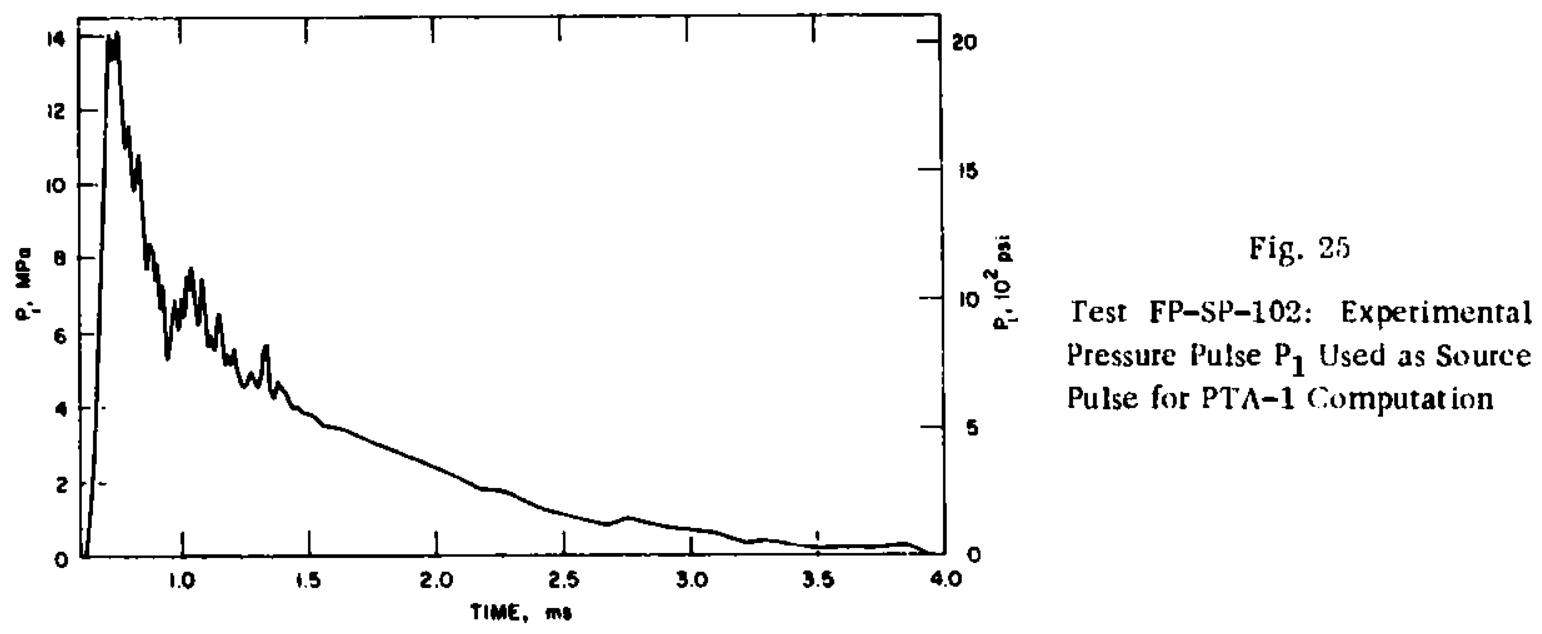

In the comparisons of computed and experimental pressure histories and strain histories for this test, the curves represent experimental results and the circles show results computed with PTA-1.

Figures 26 and 27 show pressure histories at gauges $P_{2}$ and $P_{3}$ in the steel pipe. The initial part of the pulse, in plastically deforming the nickel pipe, produces a rarefaction wave traveling from right to left; this causes cavitation to occur in the steel pipe, as is evident in the experimental and computed results at gauge $P_{2}$.

Fig. 26

Test FP-SP-102: Experimental and Computed Pressure Histories at $\mathbf{P}_{\mathbf{2}}$

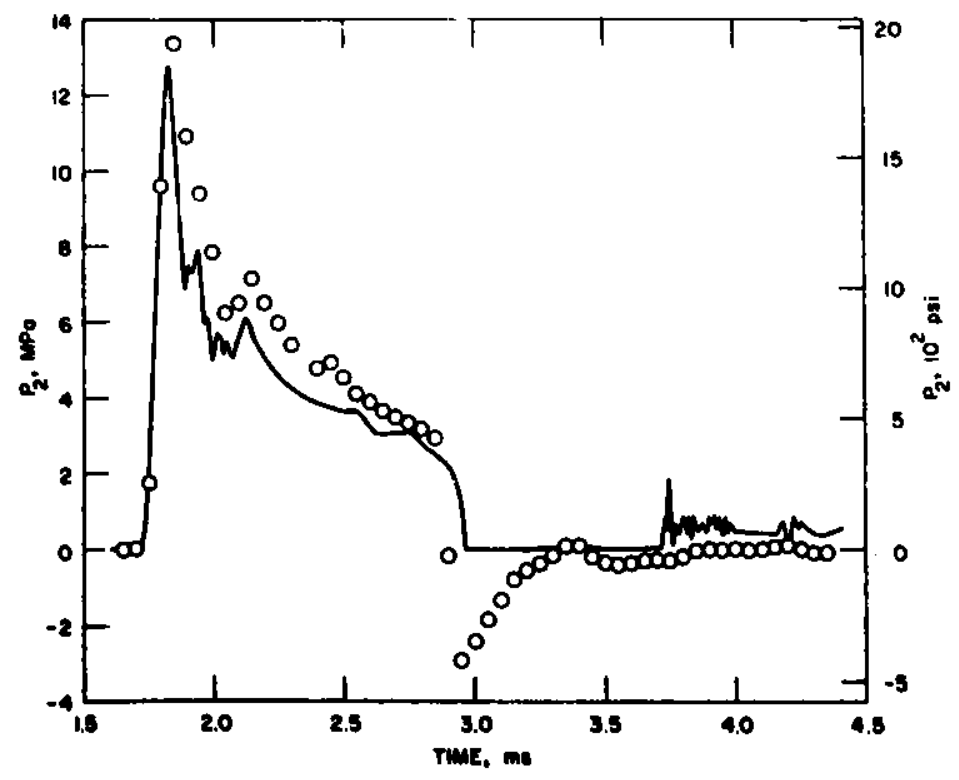




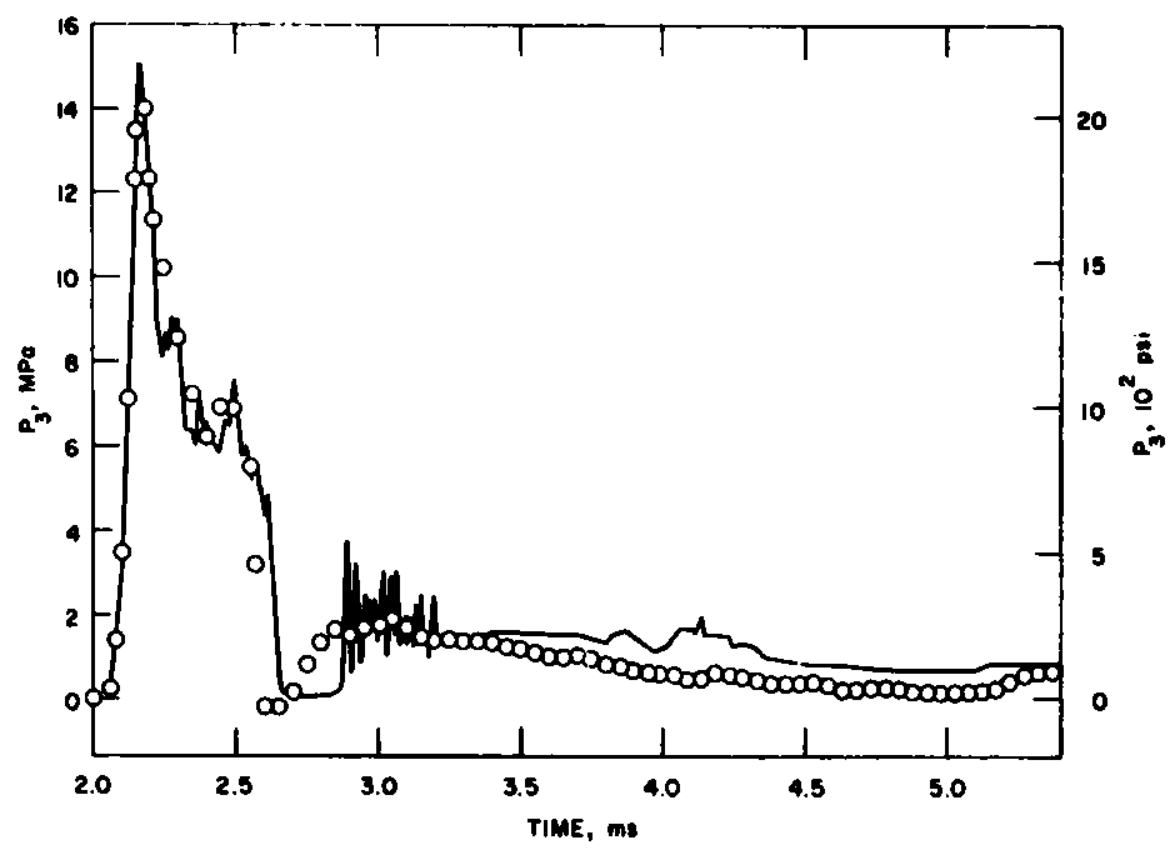

Fig. 27. Test FP-SP-102: Experimental and Computed Pressure Histories at $P_{3}$

The pressure histories at gauges $P_{4}-P_{11}$ (Figs. 28-35) in the nickel pipe show that the pressure peak is dispersed and chopped off to the yield pressure of the piping. If plastic deformation of the nickel piping had not occurred, the peak pressures of the initial wave and the wave reflected from the blind flange would remain essentially undiminished at $14 \mathrm{MPa}(2000 \mathrm{psi})$, and there would have been no cavitation in the system. The underprediction of the tails of the experimental curves by the computed result is caused by the neglect of cavitation effects in PTA-1. Preliminary calculations with the new code PTA-2, which includes cavitation as well as plasticity effects, give considerably better agreement with the tails of the experimental pulses. ${ }^{18}$

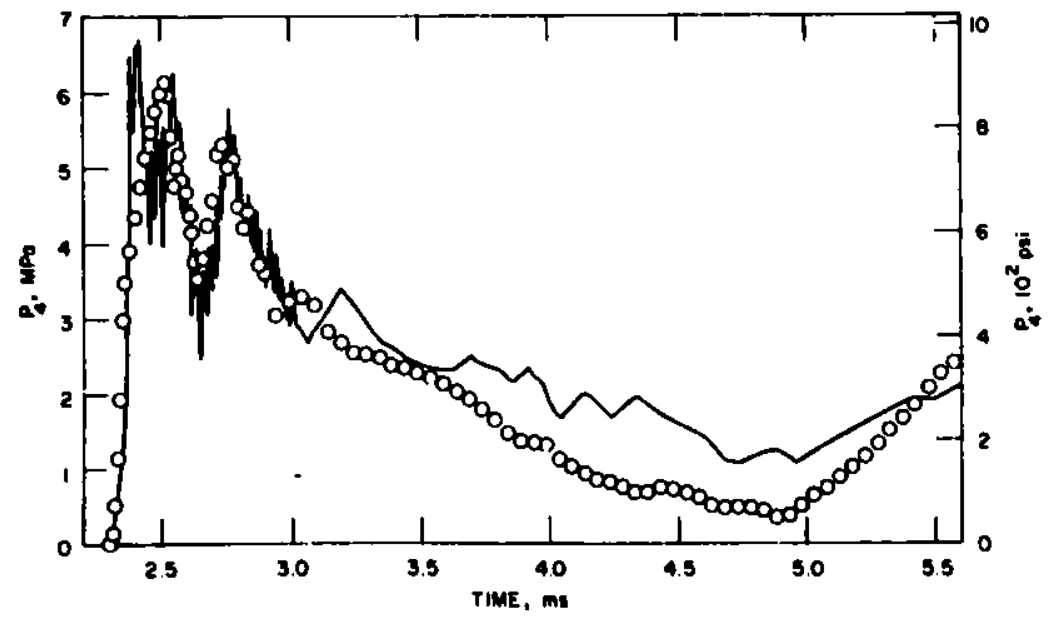

Fig. 28. Test FP-SP-102: Experimental and Computed Pressure Histories at $\mathbf{P}_{\mathbf{4}}$ 


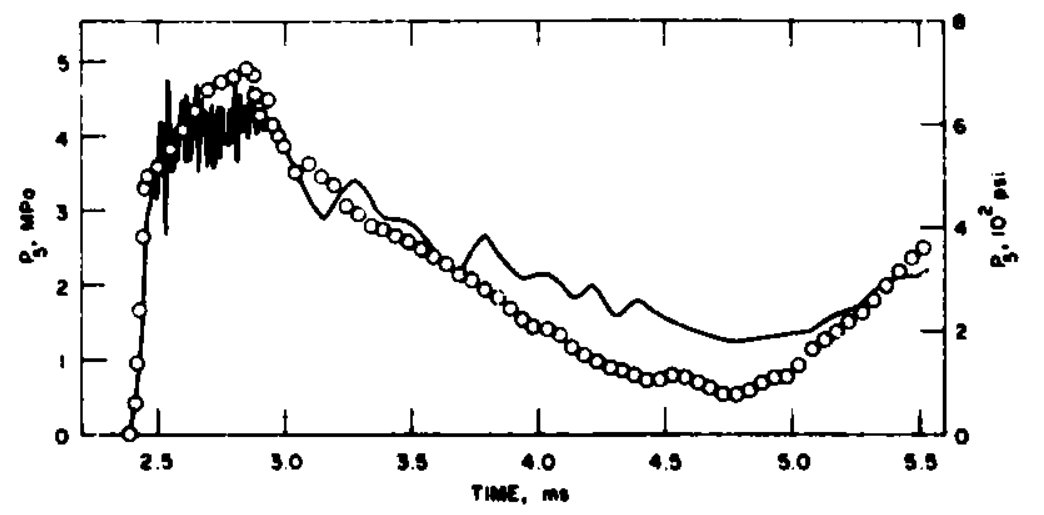

Fig. 29

Test FP-SP-102: Experimental and Computed Pressure Histories at $\mathbf{P}_{5}$

Fig. 30

Test FP-SP-102: Experimental and Computed Pressure Histories at $\mathbf{P}_{6}$
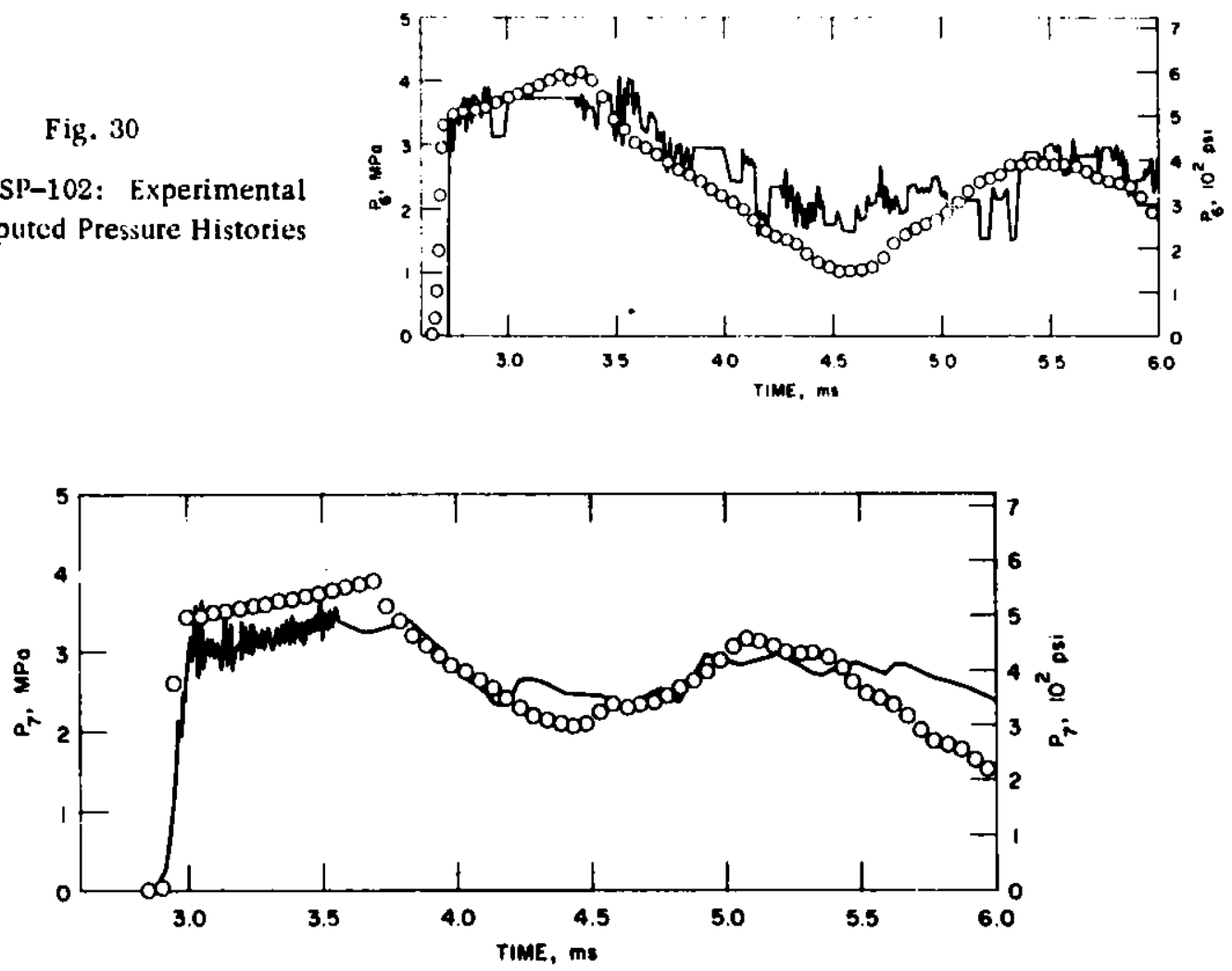

Fig. 31. Test FP-SP-102: Experimental and Computed Pressure Histories at $\mathbf{P}_{7}$

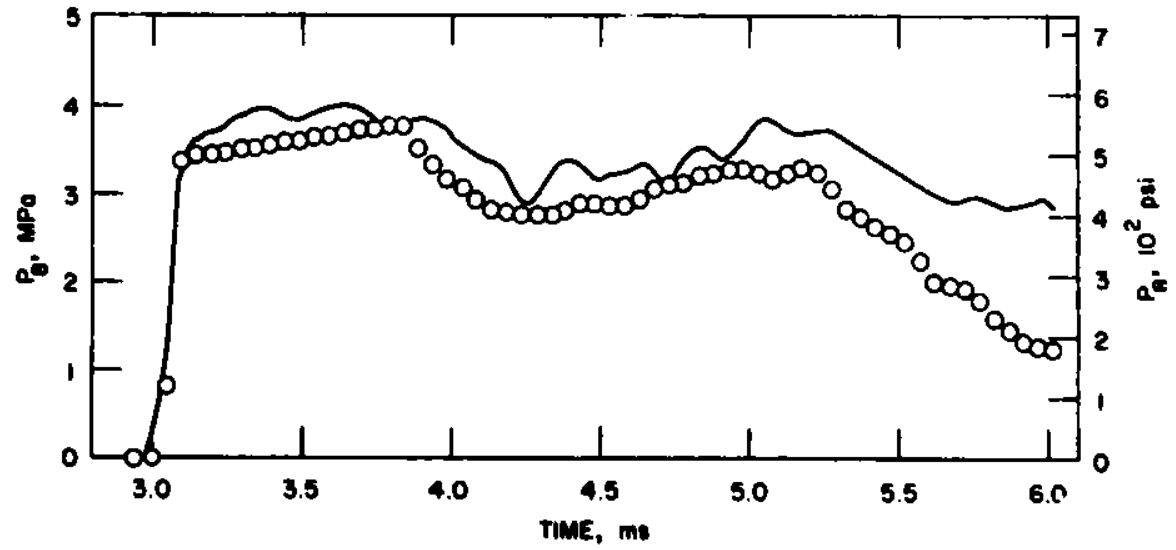

Fig. 32. Test FP-SP-102: Experimental and Computed Pressure Histories at $\mathbf{P}_{\mathcal{8}}$ 


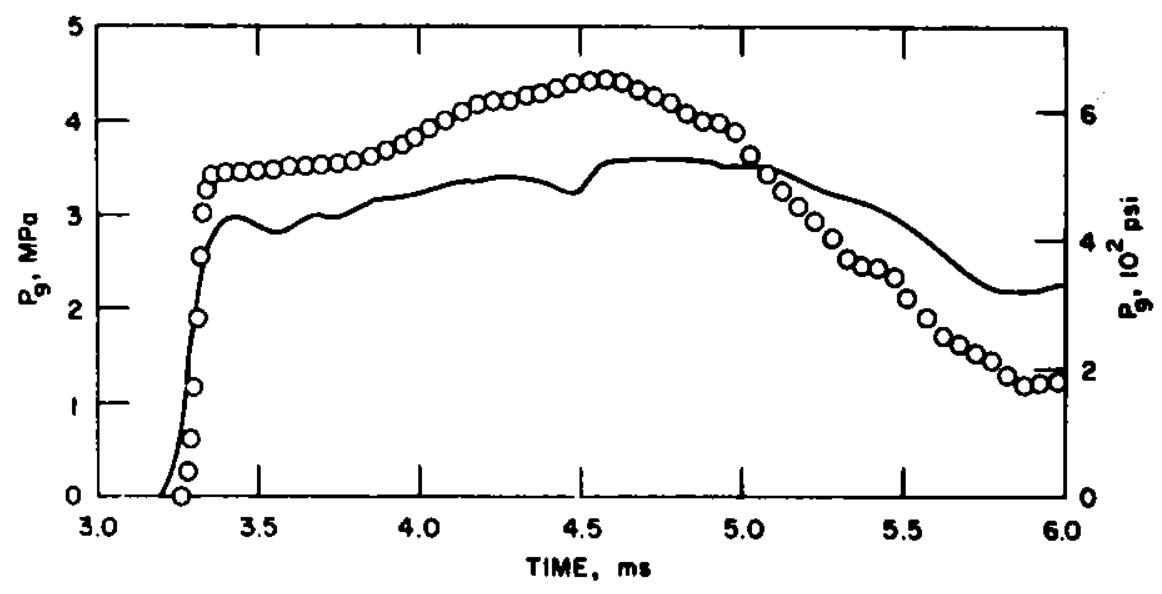

Fig. 33. Test FP-SP-102: Experimental and Computed Pressure Histories at $\mathrm{P}_{9}$

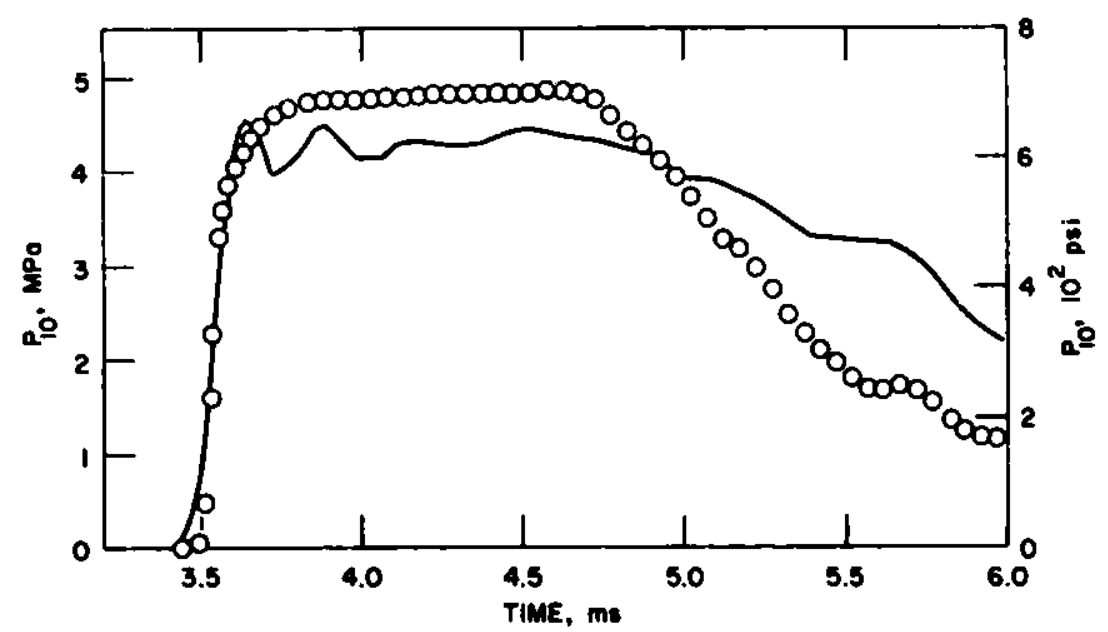

Fig. 34. Test FP-sP-102: Experimental and Computed Pressure Histories at $\mathbf{P}_{10}$

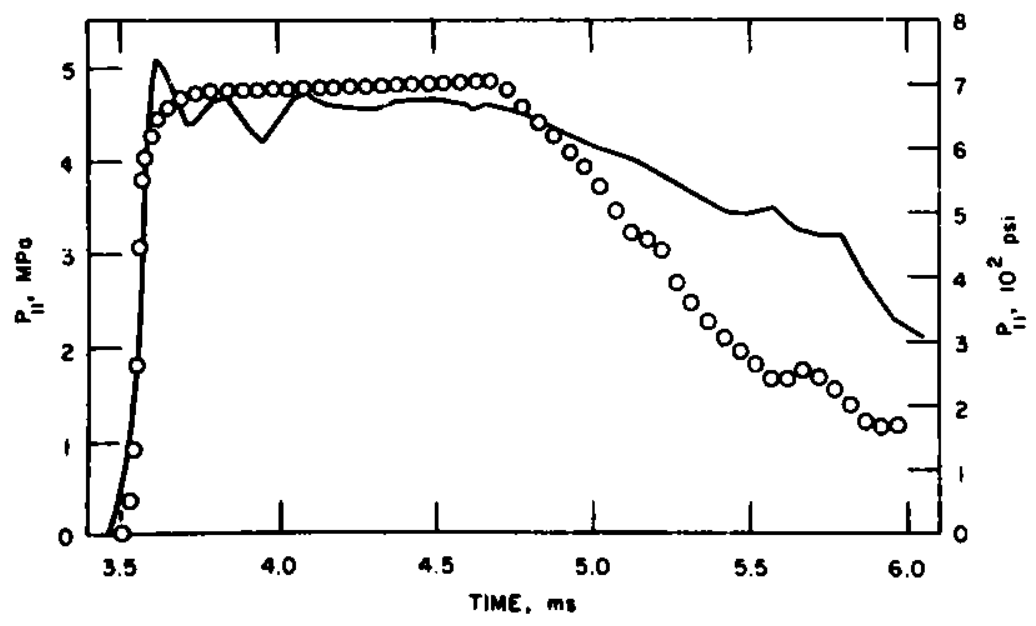

Fig. 35. Test FP-SP-102: Experimental and Computed Pressure Histories at $\mathbf{P}_{11}$ 
As in the previous test, the first peak in the experimental results at gauge $\mathrm{P}_{4}$ (see Fig. 28), vccurring at $2.4 \mathrm{~ms}$, does not show up in the computed results. However, there is no evidence for this peak in the strain history at this location, shown in Fig. 36. The second pressure peak in the experimental results, occurring at $2.5 \mathrm{~ms}$, is accurately reproduced by the PTA-1 computations and produces a dynamic plastic strain of about $1.2 \%$, as compared to the total elastic strain of $0.04 \%$. The subsequent large pressure fluctuations cause only small elastic oscillations in the strain, since the later pressure peaks are lower than the peak at $2.5 \mathrm{~ms}$ and therefore do not produce any further plastic deformation.

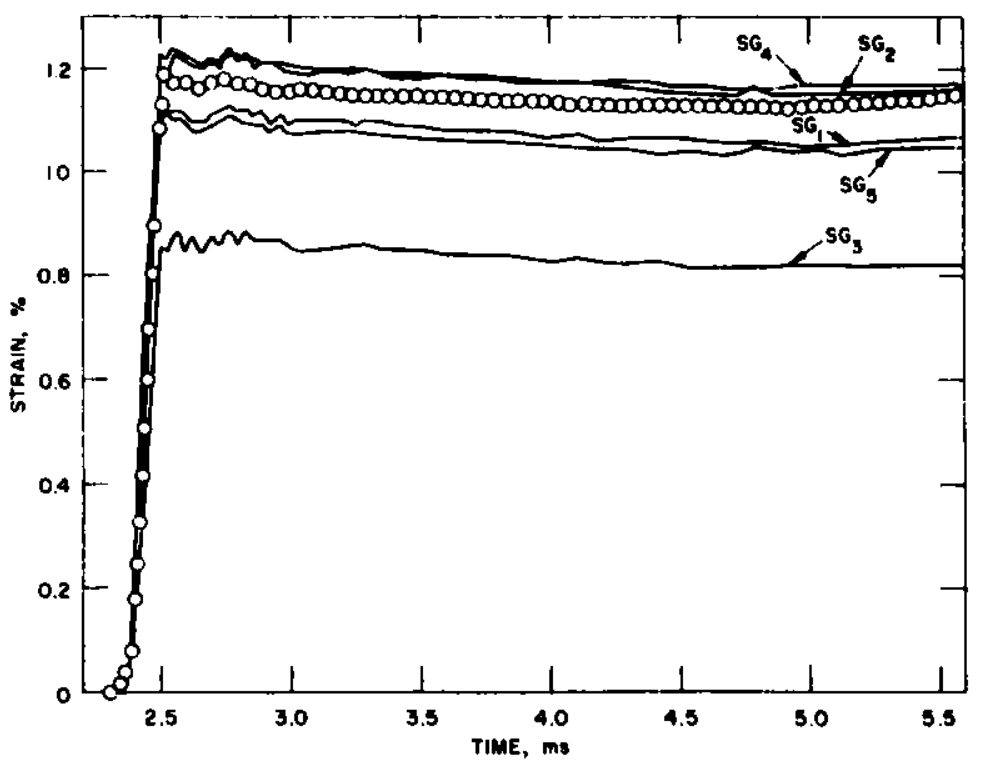

Fig. 36

Test FP-SP-102: Experimental and Computed Strain Historics at First Set of Gauges, $\mathrm{SG}_{1}-\mathrm{SG}_{5}$

The steep rise to the yield pressure at gauge $P_{5}$ (see Fig. 29) during the 2.4-2.5-ms time interval produces a short elastic "step" in the response at the second set of strain gauges (see Fig. 37). The more gradual increase in the pressure to about $5 \mathrm{MPa}(700 \mathrm{psi})$, which follows in the next few milliseconds, corresponds to a tenfold increase in the dynamic strair. The elastic strain is recovered during the decay of the pulse, leaving a large permanent strain in the pipe.

Fig. 37

Test FP-SP-102: Expcrimental and Computed Strain Histories at Second Set of Gauges, $S_{6}-S_{10}$

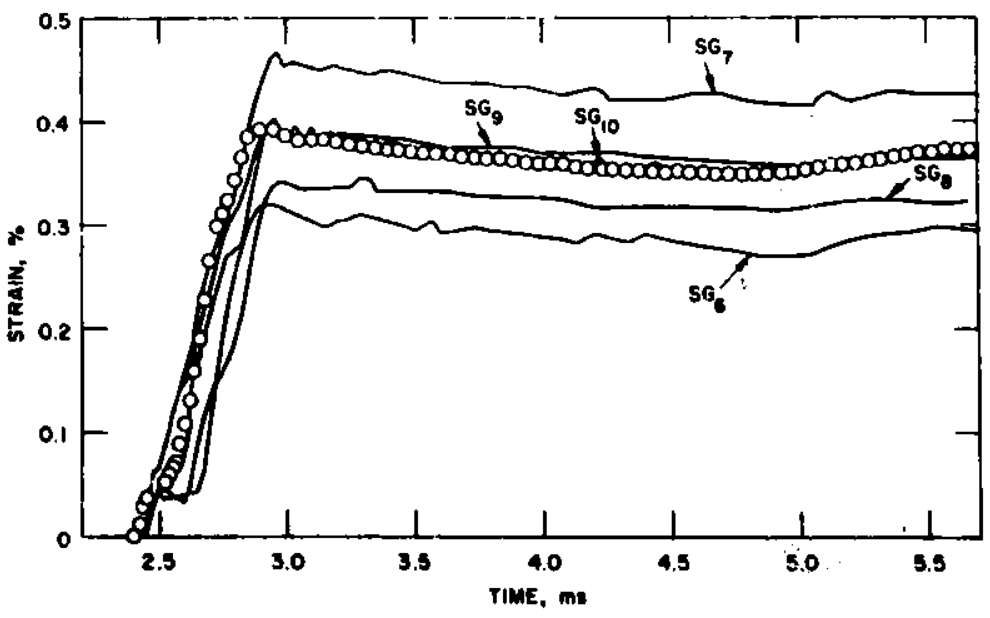


At the third set of strain gauges (see Figs. 33 and 38), the initial pressure plateau is at approximately the yield pressure and produces a long elastic "step" for the early strain response. The arrival of the reflected pulse at $4 \mathrm{~ms}$, although it corresponds to only a sma.11 increase in pressure, results in a large strain peak, because the pipe response is in the plastic range.

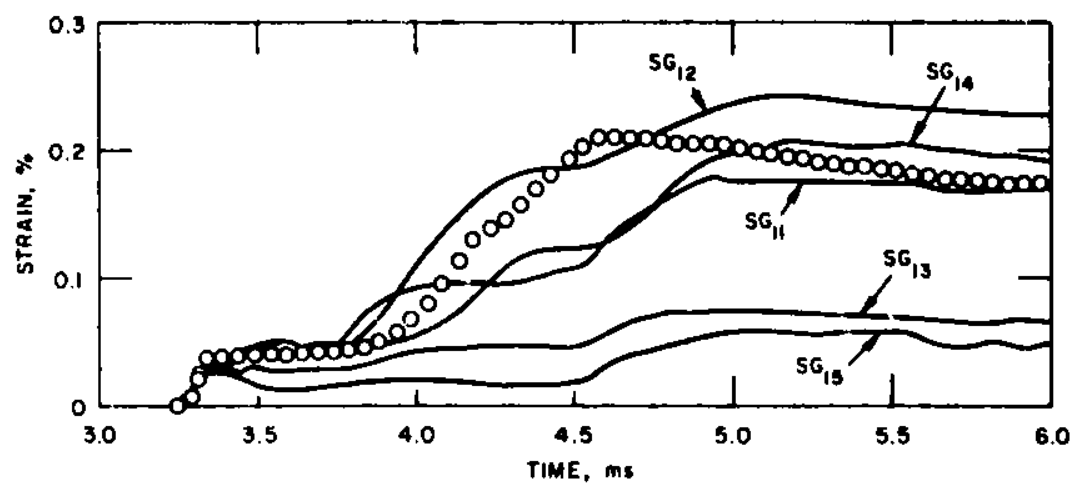

Fig. 38. Test FP-SP-102: Experimental and Computed Strain Histories at Third Set of Gauges, $\mathrm{SG}_{11}-\mathrm{SG}_{15}$

The last set of strain gauges (see Fig. 39) is sc close to the blind flange that the initial and reflected pulses practically coincide (see Fig. 34). A smooth growth to the peak strain then results; a higher maximum strain is measured here than at the third set of strain gauges, because the plastic-deformation effect reduces the reflected pressure pulse as it moves back up the pipe.

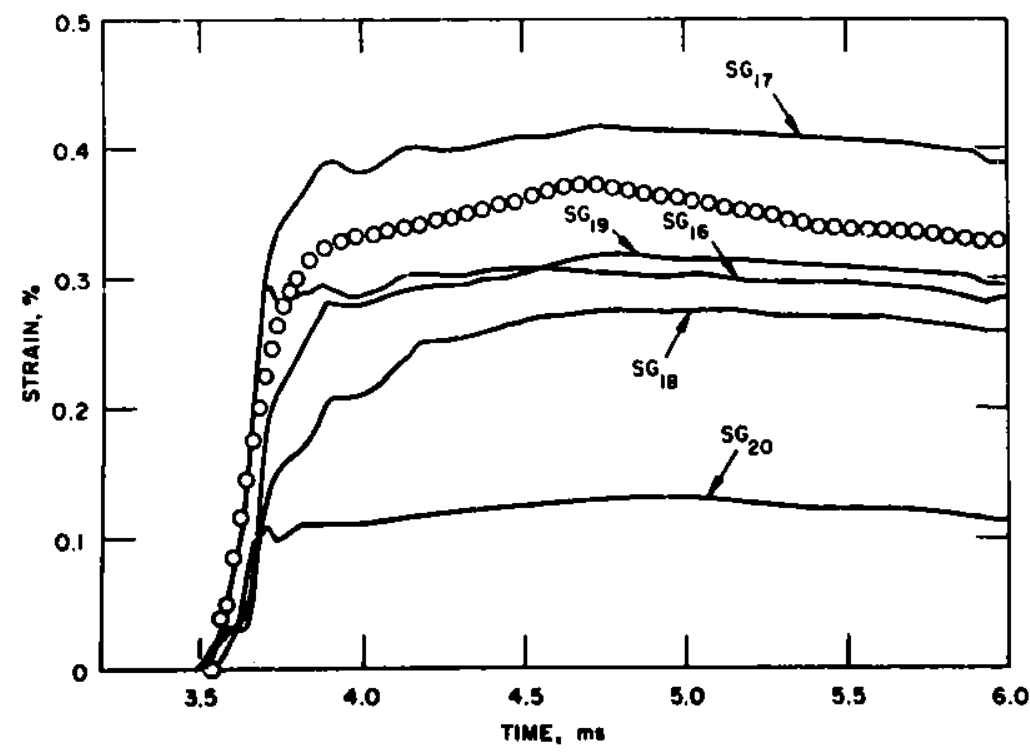

Fig. 39

Test FP-SP-102: Experimental and Computed Strain Histories at Fourth Set of ciauges, $S \mathrm{G}_{16}-\mathrm{SG}_{20}$

The profiles of maximum dynamic strain and permanent plastic strain along the nickel pipe are shown in Figs. 40 and 41 , respectively. The curves are the PTA-1 computation, the bars indicate the experimental variation in strain measured at each set of gauges, and the circles are averages of the five experimental readings. The agreement between experiment and computation 
is excellent, especially considering that large dynamic plastic strains are involved and steep strain gradients occur along the pipe. Posttest measurements of diameter change along the pipe correspond to a permanent deformation profile that agrees with Fig. 11 .

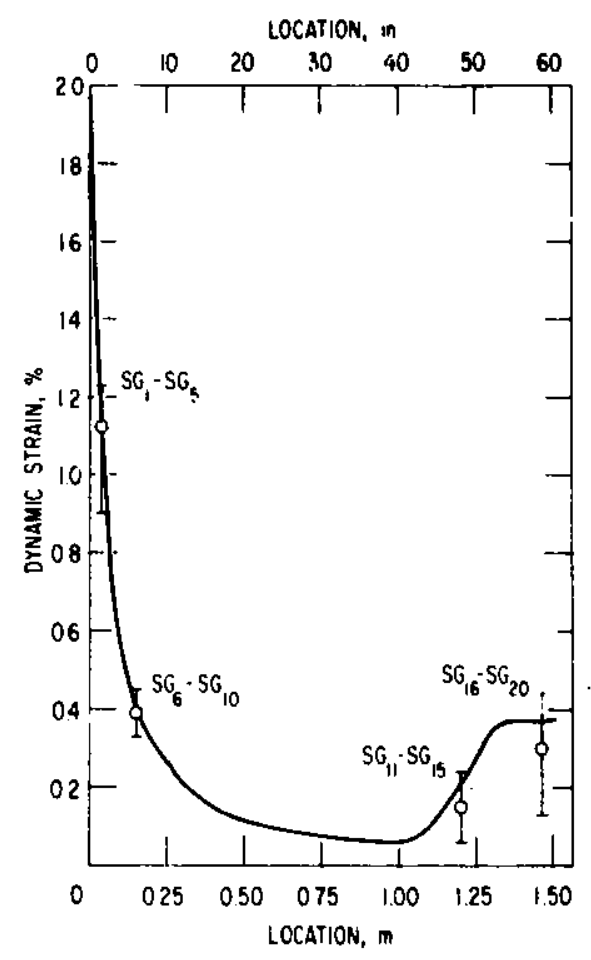

Fig. 40

Test FP-SP-102: Profiles of Experimental and Computed Maximum Dynamic Strain along Nickel Pipe

Fig. 41

Test FP-SP-102: Profiles of Experimental and Computed Permanent Plastic Strain along Nickel Pipe

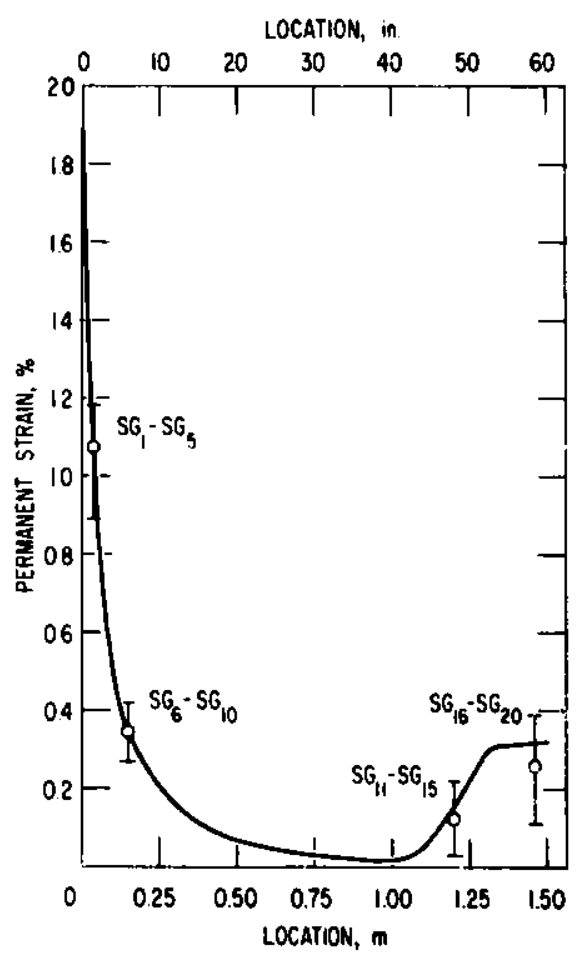


SRI attributes part of the variation in strain measurements within each set of circumferentially distributed gauges to variations in initial wall thickness around the circumference. Pretest measurements showed that the thickness varied between 1.57 and $1.75 \mathrm{~mm}(0.062$ and 0.069 in.), with an average of $1.65 \mathrm{~mm}(0.065 \mathrm{in}$.$) . In addition to the results shown in this section for a$ 1.65-mm thickness, PTA-1 computations were run for pipes with uniform walls having thicknesses of 1.57 and $1.75 \mathrm{~mm}$. These results indicate the sensitivity of strain to initial wall thickness.

At the first set of strain gauges (see Fig. 36), the maximum dynamic strain for the $1.57-\mathrm{mm}$ pipe was $1.27 \%$, and for the $1.75-\mathrm{mm}$-wall pipe it was $1.05 \%$. These values bound four of the five peak-strain readings measured by SRI. However, the variation in strain that can reasonably be attributed to wallthickness variation decreases as the pulse progresses down the pipe, so that the strain results at the last set of gauges for the thinner and thicker walls are barely distinguishable from the computed result shown in Fig. 39.

SRI attributes some of the strain variation to grain-size variations around the circumference also. The large sensitivity of strain to small variations in stress in the applicable regions of the stress-strain curve and the possibility of some bending of the pipe by the transient probably also contribute to the differences between strain-gauge measurements at the instrumented axial loc ations. 
C. Elbow-pipe Test FP-E-101

The locations of the pressure and strain gauges for Test FP-E-101 are shown in Fig. 3. Multiple pressure gauges were provided at locations near and at the elbow to determine the multidimensionality of the pressure transient in these regions; the experimental pressure histories showed that, for all practical purposes, the transient was one-dimensional. To isolate the effect of elbow curvature on pulse propagation, the elbow was modeled in the PTA-1 computation as a section of straight pipe having the same diameter, wall thickness, and average length as the elbow (see Sec. III.G). The pulse measured at $P_{1}$ (see Fig. 42) was used as the source pulse for the computation. In the comparisons of computed and experimental pressure and strain histories that follow, the curves are the experimental results and the circles indicate results computed with PTA-1.

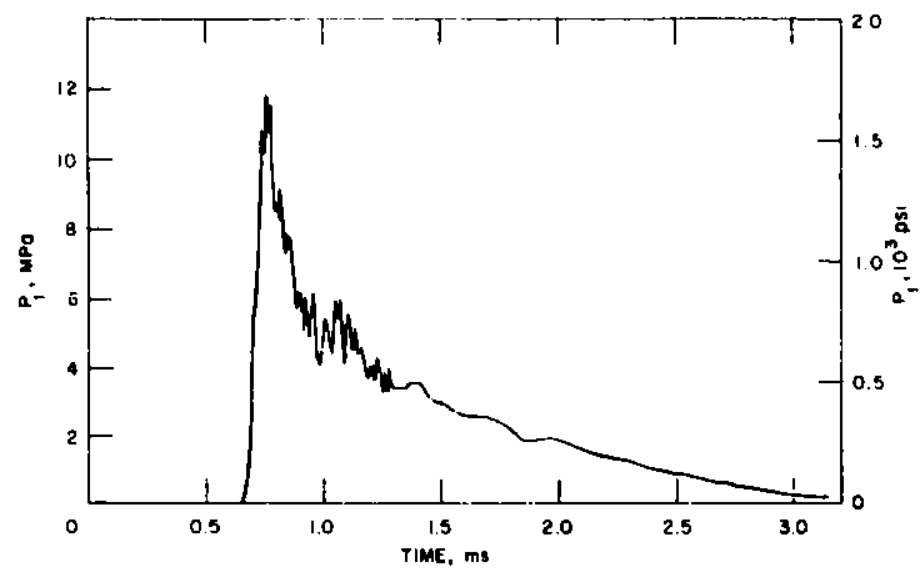

Fig. 42

Test FP-E-101: Experimental Pressure Pulse $P_{1}$ Used as Source Pulse for PTA-1 Computation

The early part of the transient matches that of the two straight-pipe experiments. Interaction of the initial part of the source pulse with the plastically deforming nickel pipe produces a rarefaction wave that travels from right to left in the steel pipe; the interaction of the rarefaction wave with the tail of the source pulse causes cavitation at gauges $P_{2}$ and $P_{3}$, as shown in Figs. 43 and 44 , respectively. The peak of the initial pulse is chopped off to about the yield

Fig. 43

Test FP-E-101: Experimental and Computed Pressure Histories at $\mathbf{P}_{2}$

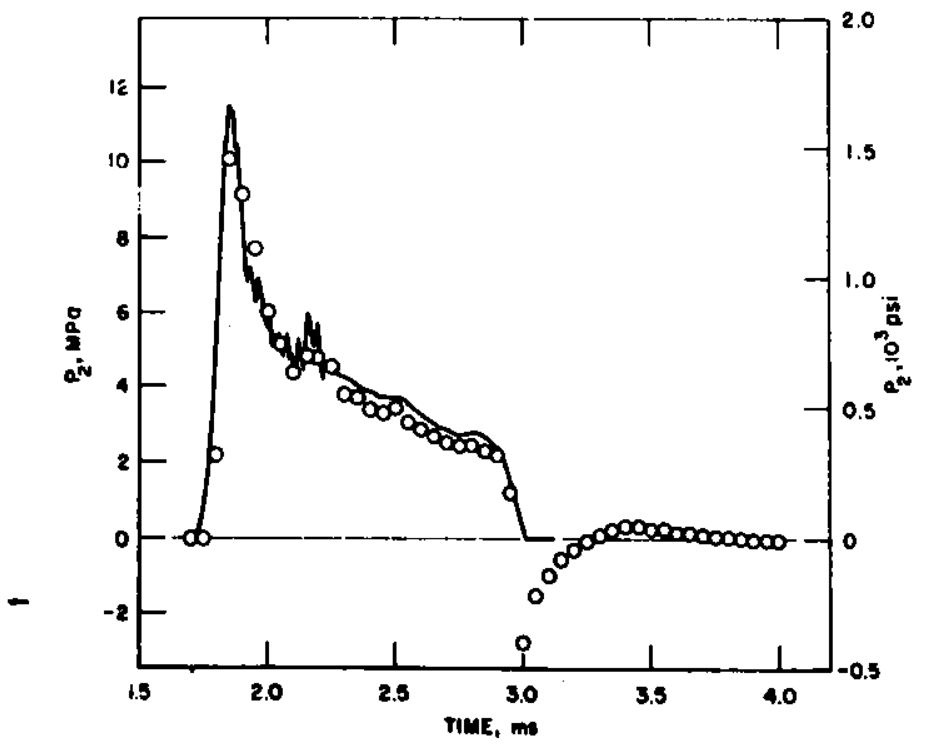




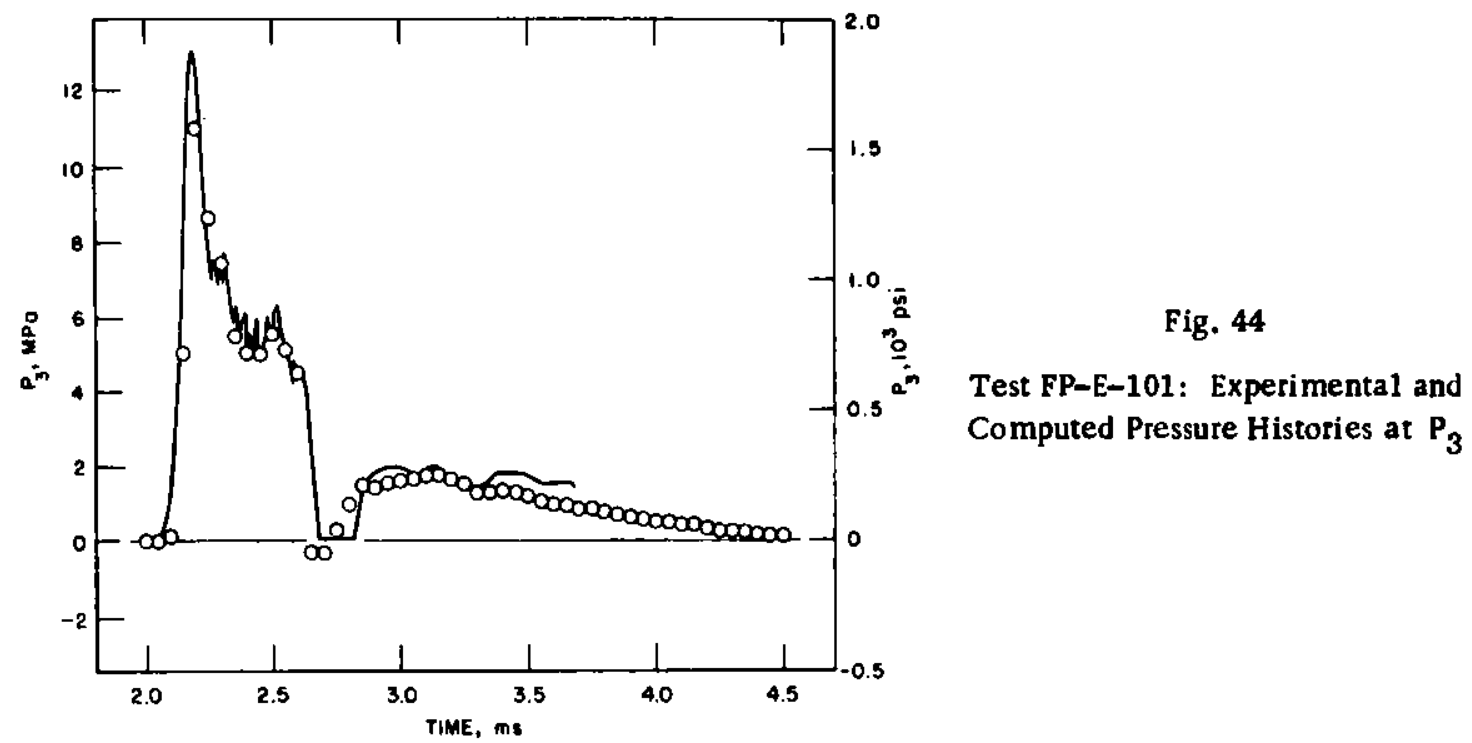

pressure of the piping, $3.4 \mathrm{MPa}(500 \mathrm{psi})$, as the pulse moves down the first nickel pipe. Figures 45-49 compare computed and experimental results at gauges $P_{4}-P_{8}$, respectively. Since the far end of the system is a free surface, there is no reflected wave. Consequently, the second plateau appearing in the straight-pipe tests does not occur in this test, and the pulse gradually decays to zero gauge pressure.

Fig. 45

Test FP-E-10I: Experimental and Computed Pressure Histories at $\mathbf{P}_{4}$
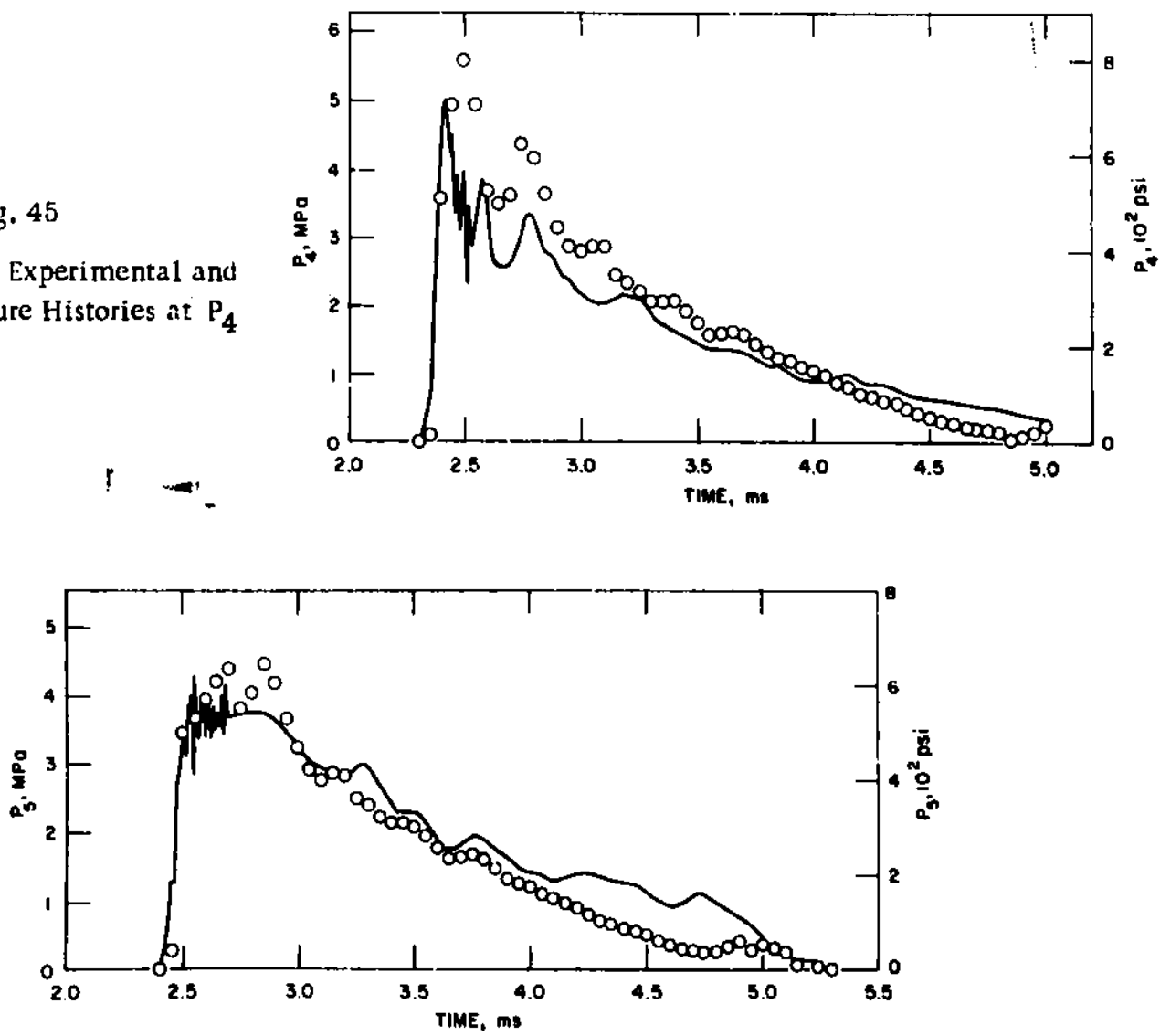

Fig. 46. Test FP-E-101: Experimental and Computed Pressure Histories at $P_{5}$ 

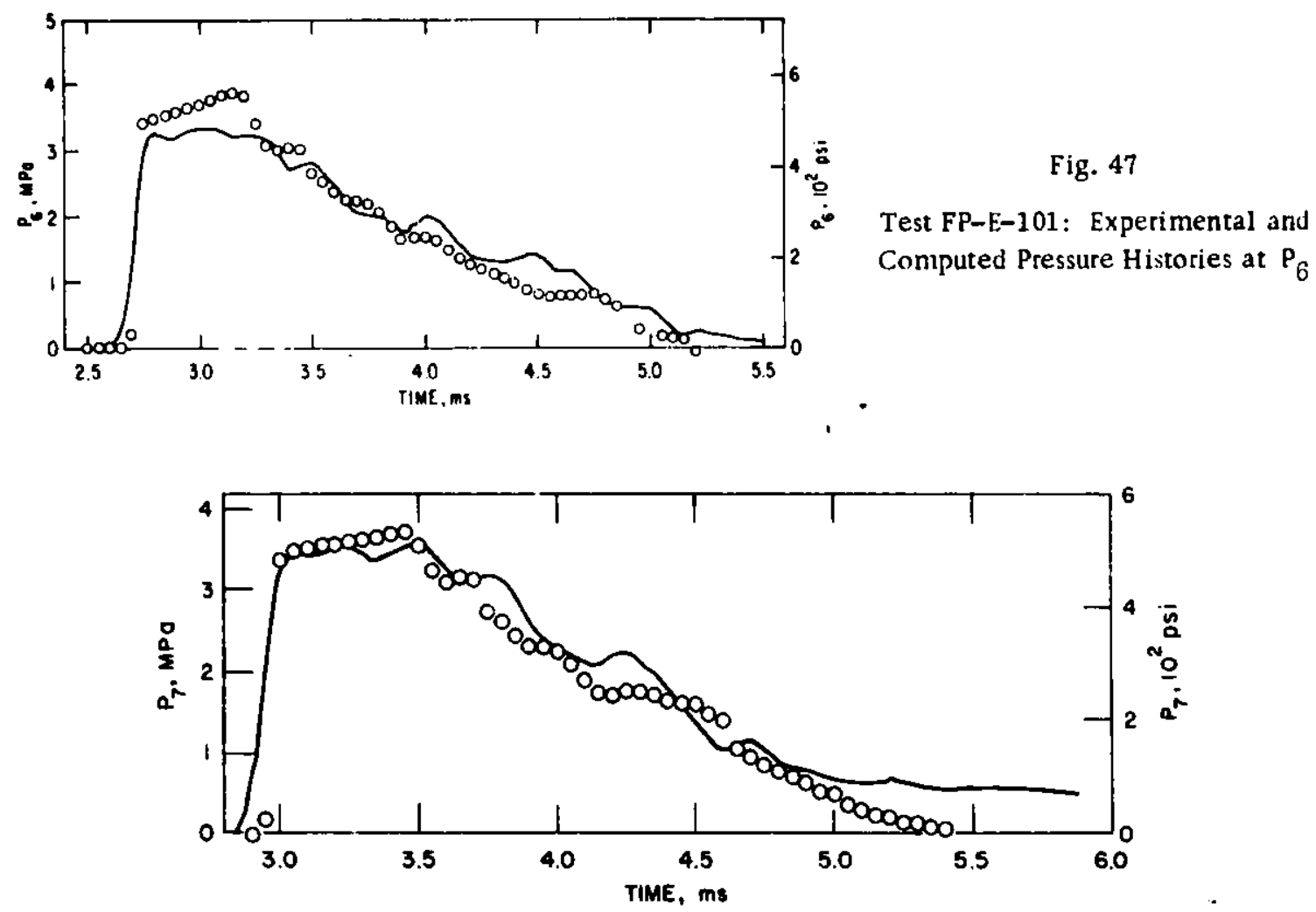

Fig. 48. Test FP-E-101: Experimental and Computed Pressure Histories at $P_{7}$

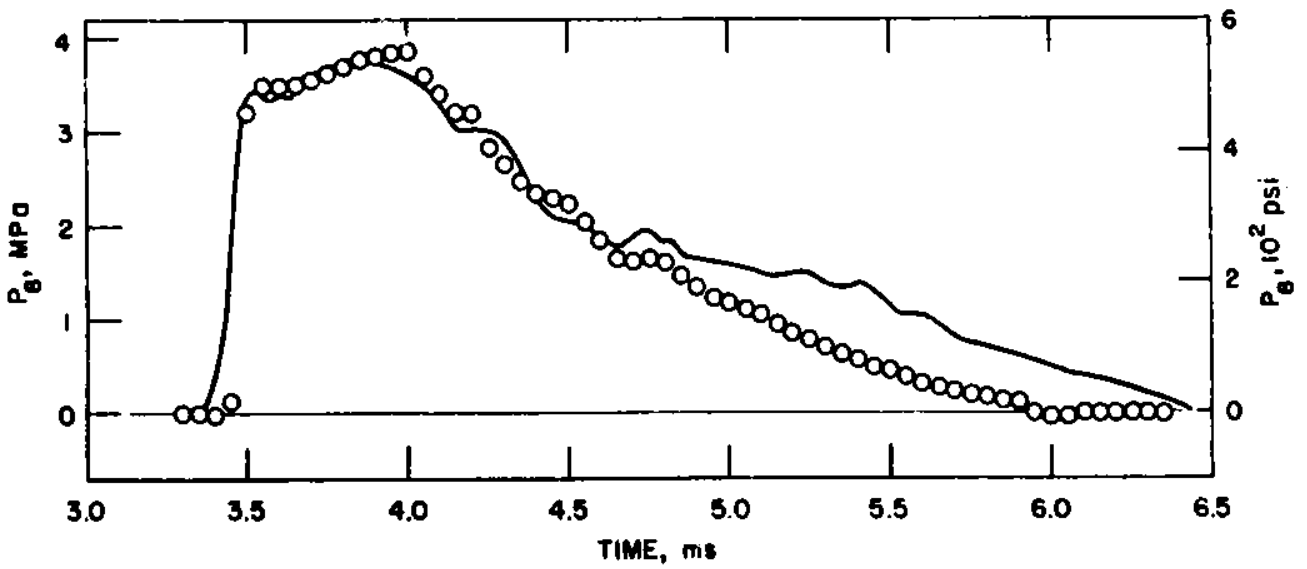

Fig. 49. Test FP-E-101: Experimental and Computed Pressure Histories at $P_{8}$

In analyzing the experimental results at the pipe locations with multiple pressure gauges $\left(P_{8}-P_{10}\right.$ before the elbow, $P_{11}-P_{13}$ at the elbow midsection, $P_{14}-P_{16}$ just after the elbow, and $P_{17}$ and $P_{18}$ farther beyond the elbow), SRI concluded for each set that the deviation between the measured pulses was within the experimental error and that the transient was essentially one-dimensional. Therefore, the experimental pulse at only one gauge of each set is shown here for comparison with the PTA-1 computation; the comparisons shown are for $P_{8}$ in Fig. 49, $P_{13}$ in Fig. 50, $P_{16}$ in Fig. 51, and $P_{18}$ in Fig. 52. 


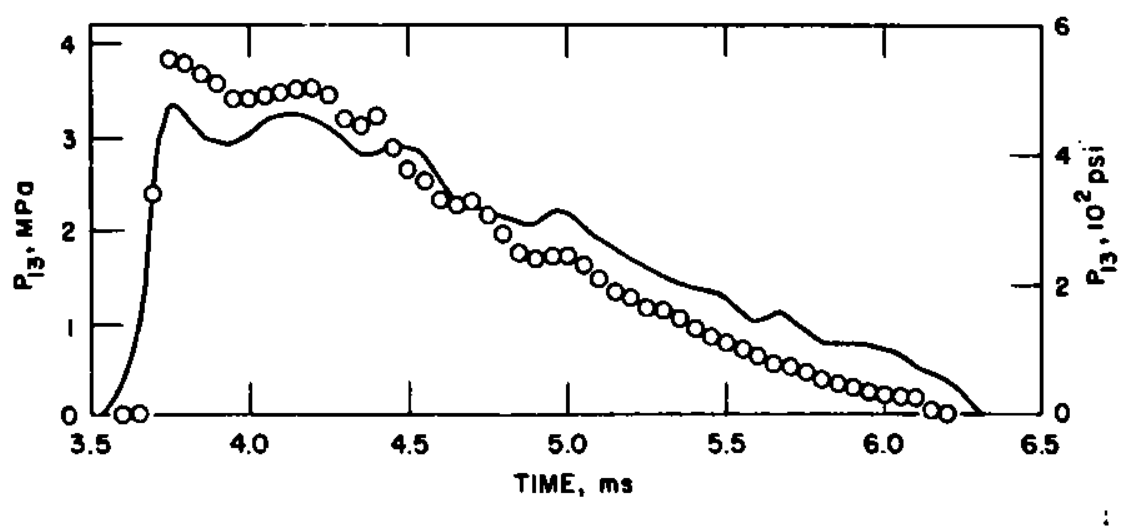

Fig. 50. Test FP-E-101: Experimental and Computed Pressure Histories at $P_{13}$

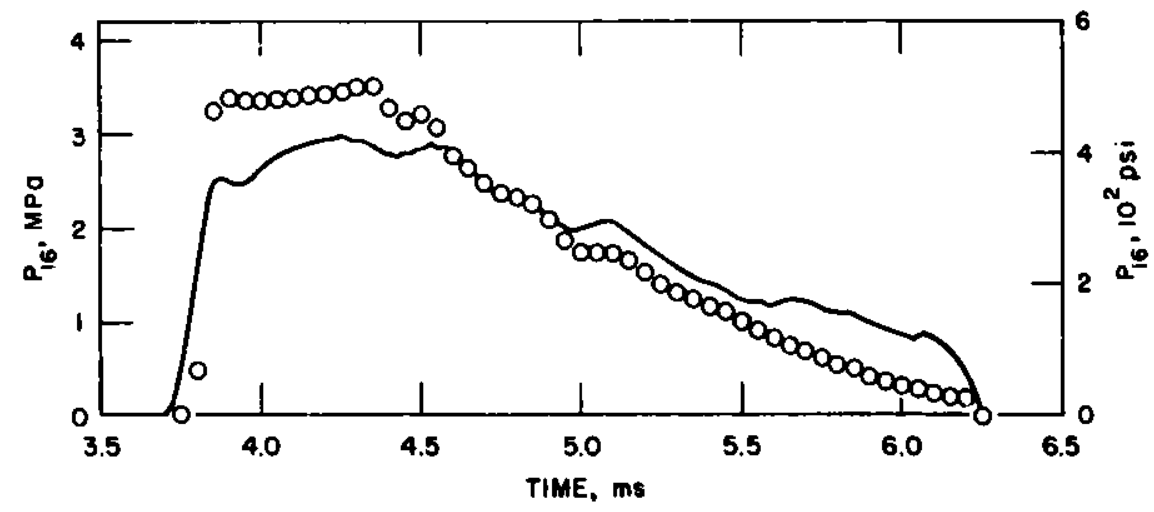

Fig. 51. Test FP-E-101: Experimental and Computed Pressure Histories at $P_{16}$

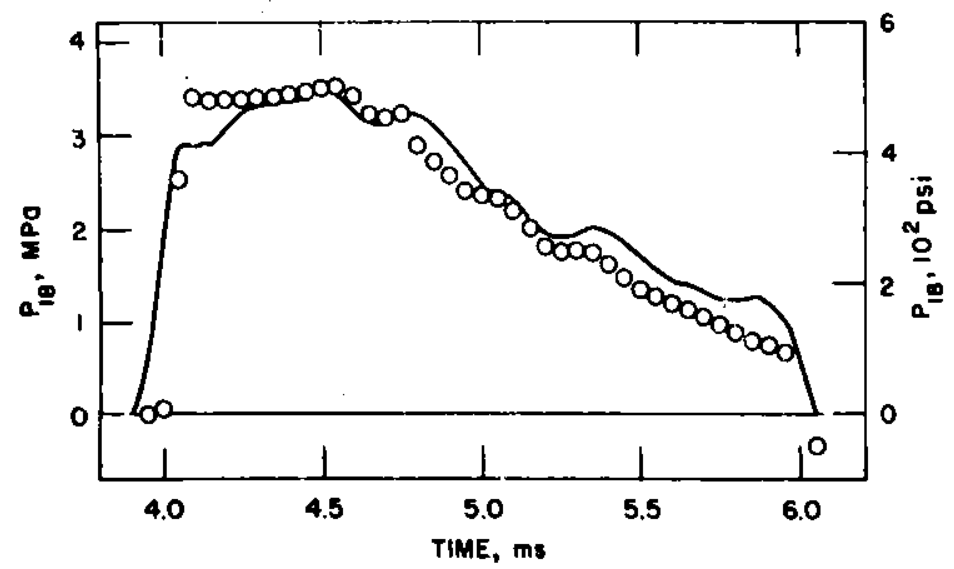

Fig. 52

Test FP-E-101: Experimental and Computed Pressure Histories at $\mathbf{P}_{18}$

Figures 50 and 51 show that PTA-1 overpredicts the experimental pulse right at the elbow, which may indicate a curvature effect not included in the modeling of the elbow in PTA-1 as a section of straight pipe or may be a result of the slight ovality $(\sim 2 \%)$ of the eliow cross section. However, the agreement between computed and experimental results is excellent at gauges $P_{8}$ and $P_{16}$, which are at $0.15 \mathrm{~m}$ ( 6 in.) before, and $0.30 \mathrm{~m}$ (12 in.) after, the elbow (see Figs. 49 and 52). Consequently, either there is no significant effect of elbow 
curvature on pulse propagation, or the effect is localized right at the elbow; in either case, the equivalent straight-pipe model seems adequate for engineering purposes. (The effect of elbow motion on the transient is not incorporated in either the experiment or the computation.) Note, however, that pipe plasticity may result in chopping of reflected and transmitted peaks at the elbow and therefore may be masking a curvature effect.

Experiment and computations also were compared using $\mathbf{P}_{7}$ from the experiment as the source puise to avoid the cavitated region of the piping system. Some improvement was obtained in predicting the shape of the tail of the pulse and some of the local "wiggles," but the results did not differ significantly from those computed using $P_{1}$ as the source.

Computed and experimental strin histories for the four sets of strain gauges are compared in Figs. 53-56. Kesults at the first two sets of gauges

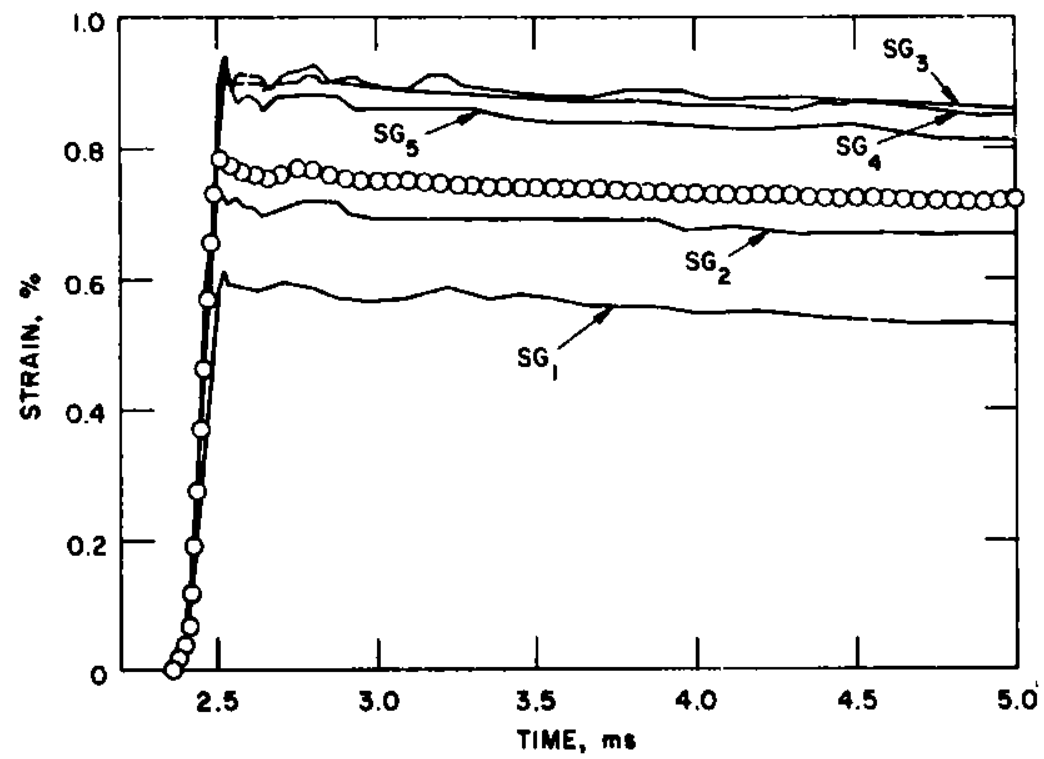

Fig. 53. Test FP-E-101: Experimental and Computed Strain Histories at First Set of Gauges, $\mathrm{SG}_{1}-\mathrm{SG}_{5}$

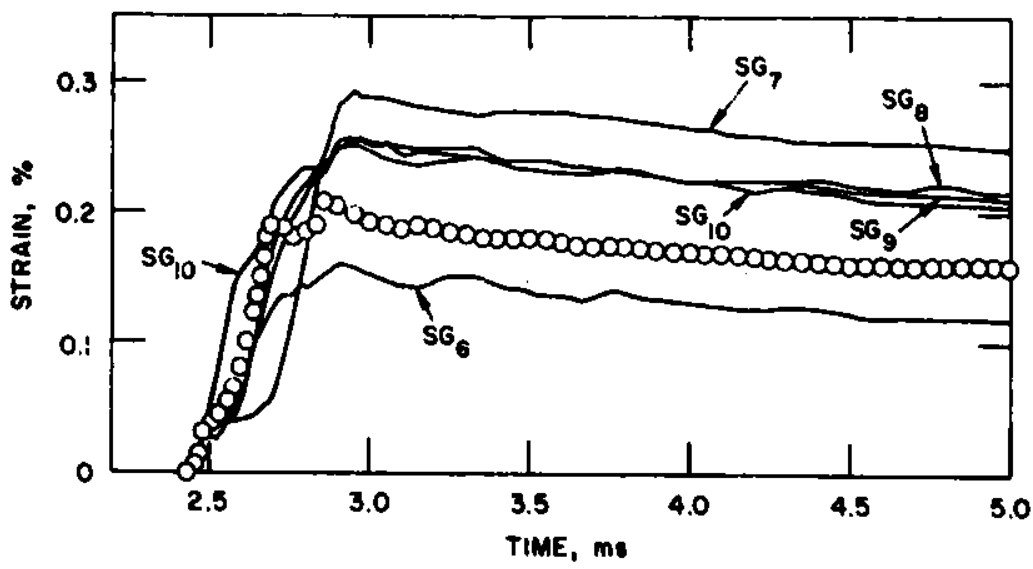

Fig. 54. Test FP-E-101: Experimental and Computed Strain Histories at Second Set of Gauges, $\mathrm{SG}_{6}-\mathrm{SG}_{10}$ 


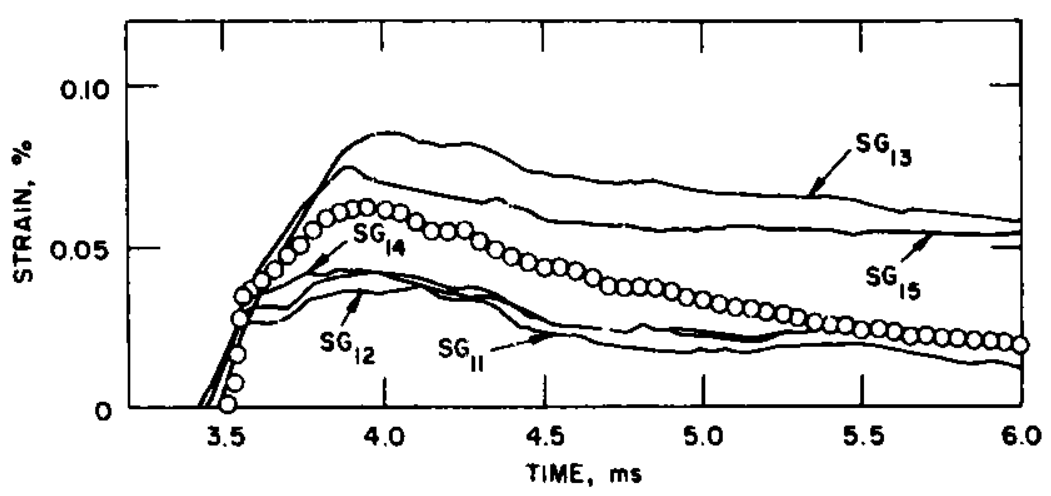

Fig. 55. Test FP-E-101: Experimental and Computed Strain Histories at Third Set of Gauges, $\mathrm{SG}_{11}-\mathrm{SG}_{15}$

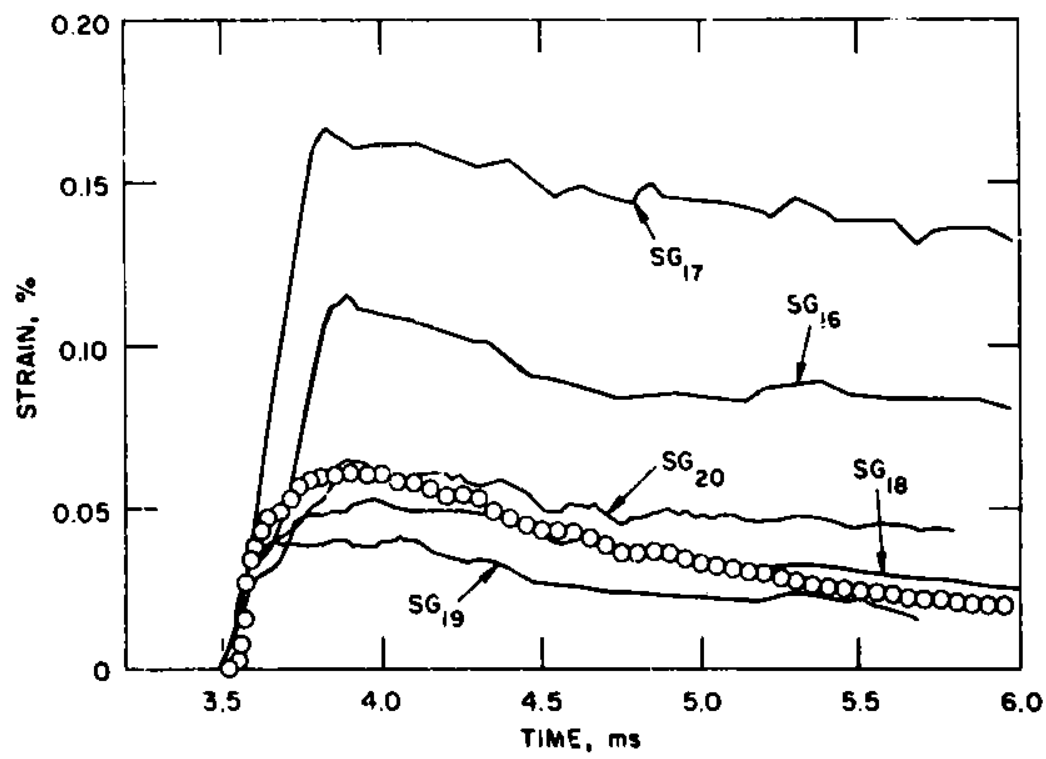

Fig. 56. Test FP-E-101: Experimental and Computed Strain Histories at Fourth Set of Gauges, $S G_{16}-S G_{20}$

are similar to the corresponding comparisons for the straight-pipe experiments (see Figs. 19, 20, 36, and 37). At the first set of strain gauges (see Fig. 53), the initial steep pressure peak, shown in Fig. 45, produces a corresponding rapid increase in strain to well into the plastic range, the maximum elastic strain being $0.04 \%$. Subsequent large pressure fluctuations cause only small elastic oscillations in the strain, since the later pressure peaks are lower than the initial peak.

At the second set of strain gauges (see ig. 54), the pressure peak (see Fig. 46) has been chopped off by plastic deformation of the piping, and the peak strain is considerably smaller than that measured at the first set of gauges. The small initial step measured by some of the gauges and registered slightly in the PTA-1 computation is at the elastic limit. 
The results at the third and fourth set of gauges (shown in Figs. 55 and 56) differ from the corresponding results for the straight-pipe experiments, shown in Figs. 21, 22, 38, and 39. The reflected pulse in the straight-pipe tests is slightly larger than the initial wave and produces significant plastic deformation. There is no reflected pulse in the elbow test, because there is no blind flange at the end of the system. Since the initial pulse is chopped off to about the yield pressure of the piping by the plastic-deformation effect, the strains measured at the third and fourth sets of gauges are small and correspond to a region of the stress-strain curve where strain is particularly sensitive to stress. Consequently, Figs. 55 and 56 are drawn to a smaller strain scale than the corresponding figures for the straight-pipe tests, and there is considerable variation in the measured plastic strains at each set.

The large variation in strain as the wave proceeds down the first nickel pipe is further shown in Figs. 57 and 58, the maximum-dynamic-strain profile and permanent-plastic-strain profile, respectively. The curves are the computed strain distributions along the pipe, the bars give the circumferential variation in strain at each axial position where strain gauges are located, and the solid circles are the averages of the five gauges at each location. The bulge at the right end of the pipes shown in the corresponding straight-pipe test results (see Figs. 23, 24, 40, and 41) is almost completely absent in the elbowtest results.

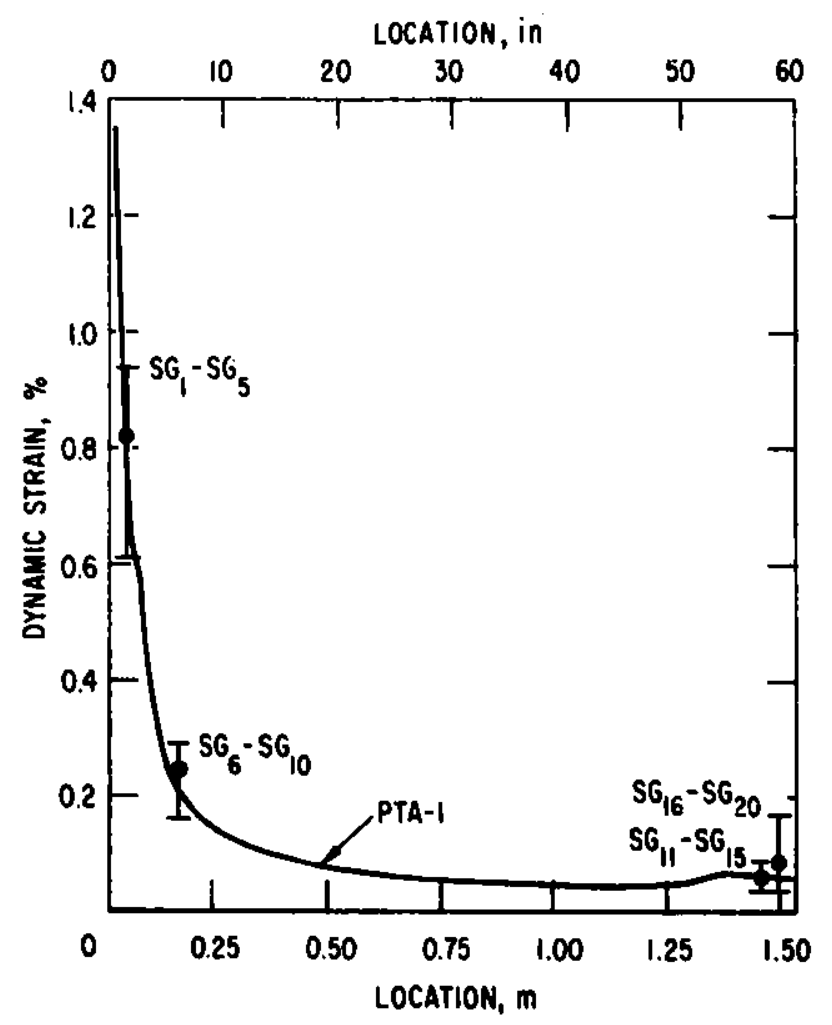

Fig. 57. Test FP-E-101: Profile of Experimental and Computed Maximum Dynamic Strain along First Nickel Pipe

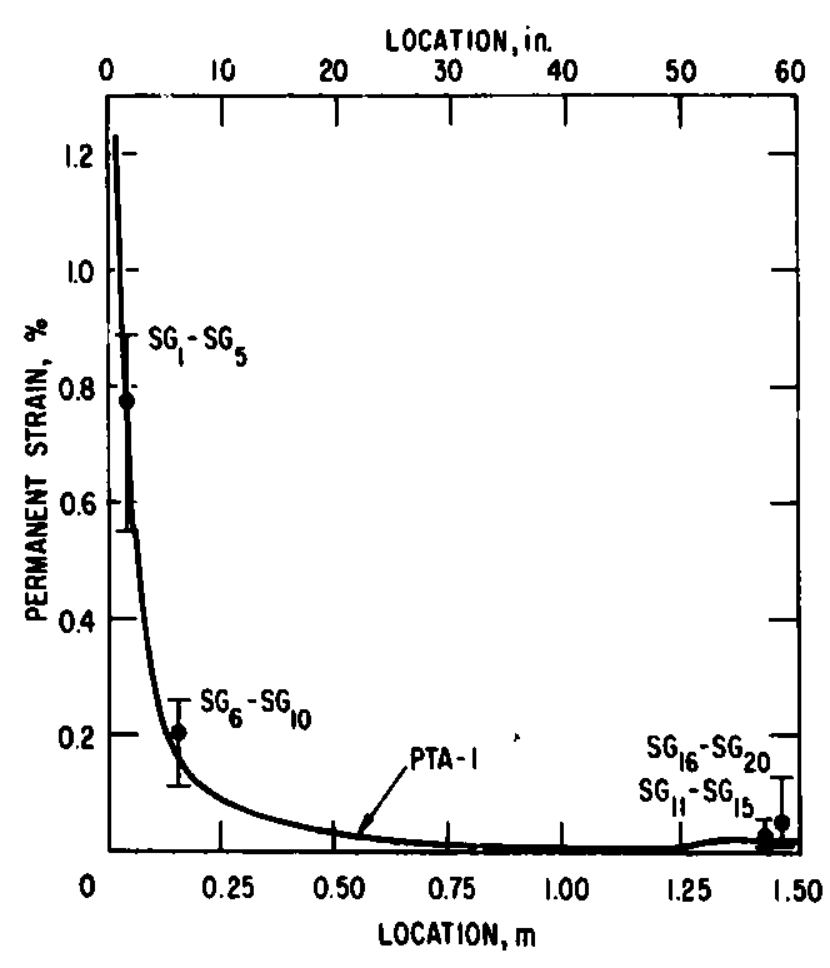

Fig. 58. Test FP-E-101: Profiles of Experimental and Computed Permanent Plastic Strain along First Nickel Pipe 
One cause of the rather wide circumferential variation between straingauge readings in each set, as illustrated in Figs. 53-58, is the sensitivity of strain to stress in the ranges involved. As an indication of this sensitivity, Table I contrasts the range of maximum dynamic strains measured at each group of gauges with the corresponding range of stresses in equilibrium with these strains (see Fig. 6), assuming a one-dimensional ring-type response. A large strain range is measured at each group of gauges: At the first set, the largest peak strain is $50 \%$ more than the smallest peak strain; at the second and third sets, the largest peak strain is about twice the smallest peak strain; and at the fourth set, the largest peak strain is four times the smallest peak strain. The corresponding stresses vary only about $10 \%$ for the first three sets of gauges and about $20 \%$ for the last set. The computed peak strains and stresses are close to the average of the experimental values for each set of gauges. This agreement is particularly noteworthy, considering the great sensitivity of the strain measurements to details of the transient and the experimental arrangement.

TABLE I. Comparison of Peak Strains and Stresses for Test FP-E-101

\begin{tabular}{lccccc}
\hline \multirow{2}{*}{$\begin{array}{c}\text { Strain } \\
\text { Gauges }\end{array}$} & $\begin{array}{c}\text { Experimental } \\
\text { Range }\end{array}$ & $\begin{array}{c}\text { PTA-1 } \\
\text { Computation }\end{array}$ & & $\begin{array}{c}\text { Experimental } \\
\text { Range }\end{array}$ & $\begin{array}{c}\text { PTA-1 } \\
\text { Computation }\end{array}$ \\
\hline $\mathrm{SG}_{1}-\mathrm{SG}_{5}$ & $0.61-0.94$ & 0.79 & & $117-128$ & 123 \\
$\mathrm{SG}_{6}-\mathrm{SG}_{10}$ & $0.16-0.29$ & 0.21 & & $94-103$ & 98 \\
$\mathrm{SG}_{11}-\mathrm{SG}_{15}$ & $0.043-0.085$ & 0.063 & & $77-86$ & 83 \\
$\mathrm{SG}_{16}-\mathrm{SG}_{20}$ & $0.040-0.166$ & 0.061 & & $76-95$ & 83 \\
\hline
\end{tabular}

The pressure pulse traversing the second nickel pipe was at or below the yield pressure and produced negligible plastic deformation, as indicated by PTA-1 computations and posttest measurements of changes in diameter. 


\section{Elbow-pipe Test FP-E-103}

Figure 5 shows the test configuration and locations of pressure and strain gauges for Test FP-E-103. As in the other elbow test, measured circumferential pressure variations at locations near the elbow, where more than one pressure gauge was provided, were not significant, and SRI concluded that the pulse propagation around the elbow was essentially one-dimensional. Therefore, comparisons with computations will be shown for only one of the pressure gauges at multigauge locations. To isolate the effect of elbow curvature on transient propagation, the elbow will again be modeled in the PTA-1 computation as an equivalent section of straight pipe (see Sec. III.G).

Two sets of PTA-1 computations were performed for Test FP-E-103. In the first set, the pressure pulse at gauge $P_{1}$, shown in Fig. 59, was used

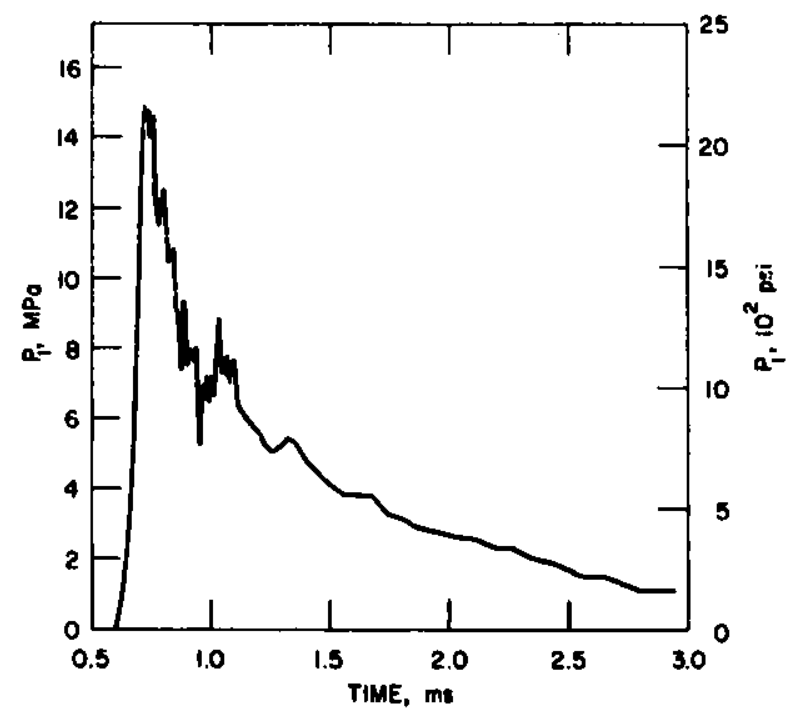

Fig. 59

Test FP-E-103: Experimental Pre:sure Pulse $P_{1}$ Used as Source Pulse for First PTA-1 Computation

Fig. 60

Test FP-E-103: Experimental and Computed Pressure Histories at $\mathrm{P}_{2}$ as the source pulse. Figures 60-69 compare experimental results (curves) and PTA-1 computations (circles) at various pressure-gauge locations. Experimental data at gauge $P_{1}$ are given for a pulse duration of about $2.3 \mathrm{~ms}$; therefore, computed pressure pulses at other locations are meaningful only for this duration. Since experimental measurements were made for much longer time intervals at gauges $P_{4}-P_{18}$, a second set of computations was made, using the pressure pulse measured at gauge $P_{5}$ (see Fig. 63) as the source pulse. This gauge was selected because it is far enough from the elbow that interaction effects are not significant and the pulse is not as "noisy" as that measured at gauge $P_{4}$. Results for this set of computations are shown as solid circles on Figs. 64-69.

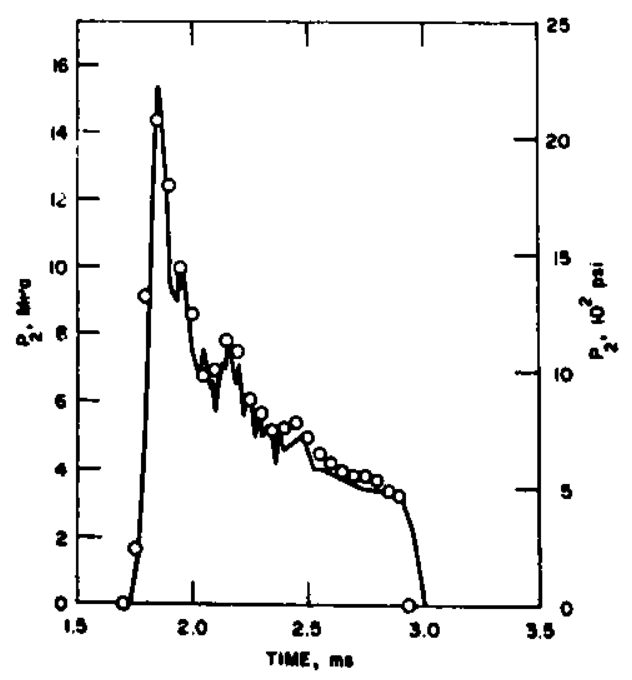




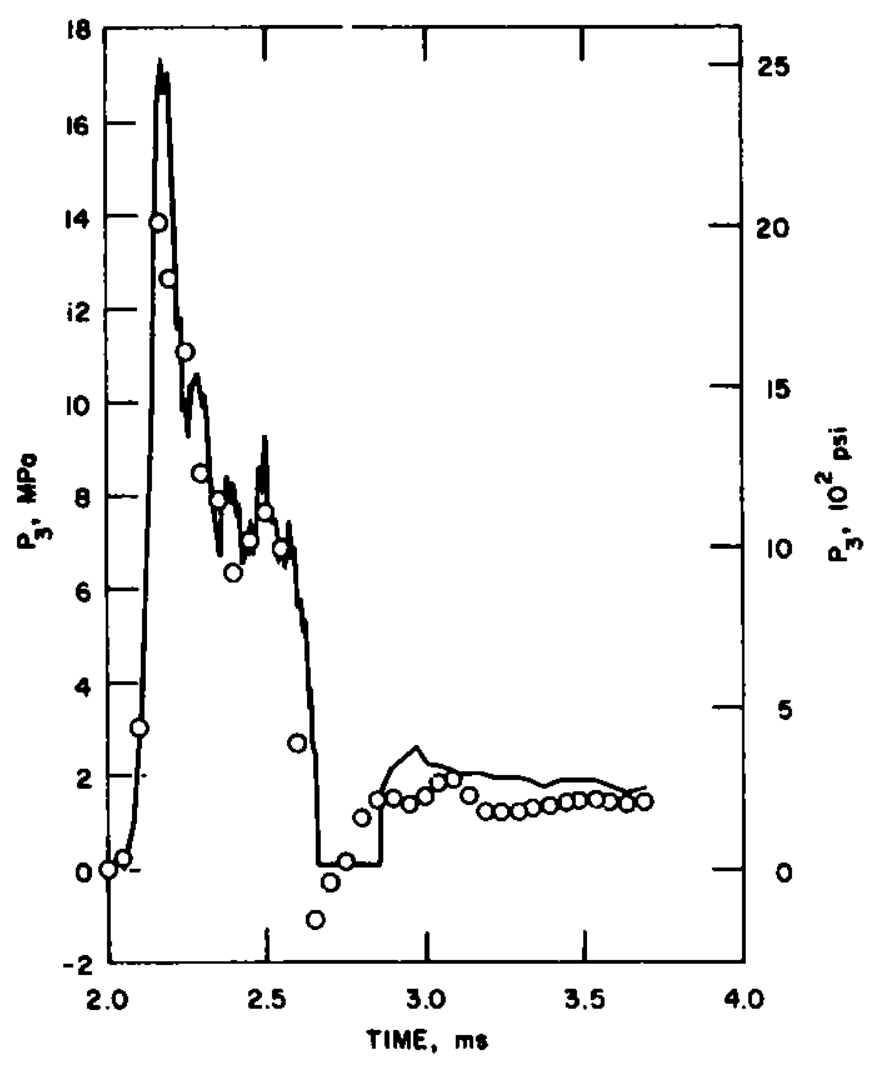

Fig. 61. Test FP-E-103: Experimental and Computed Pressure Histories at $P_{3}$

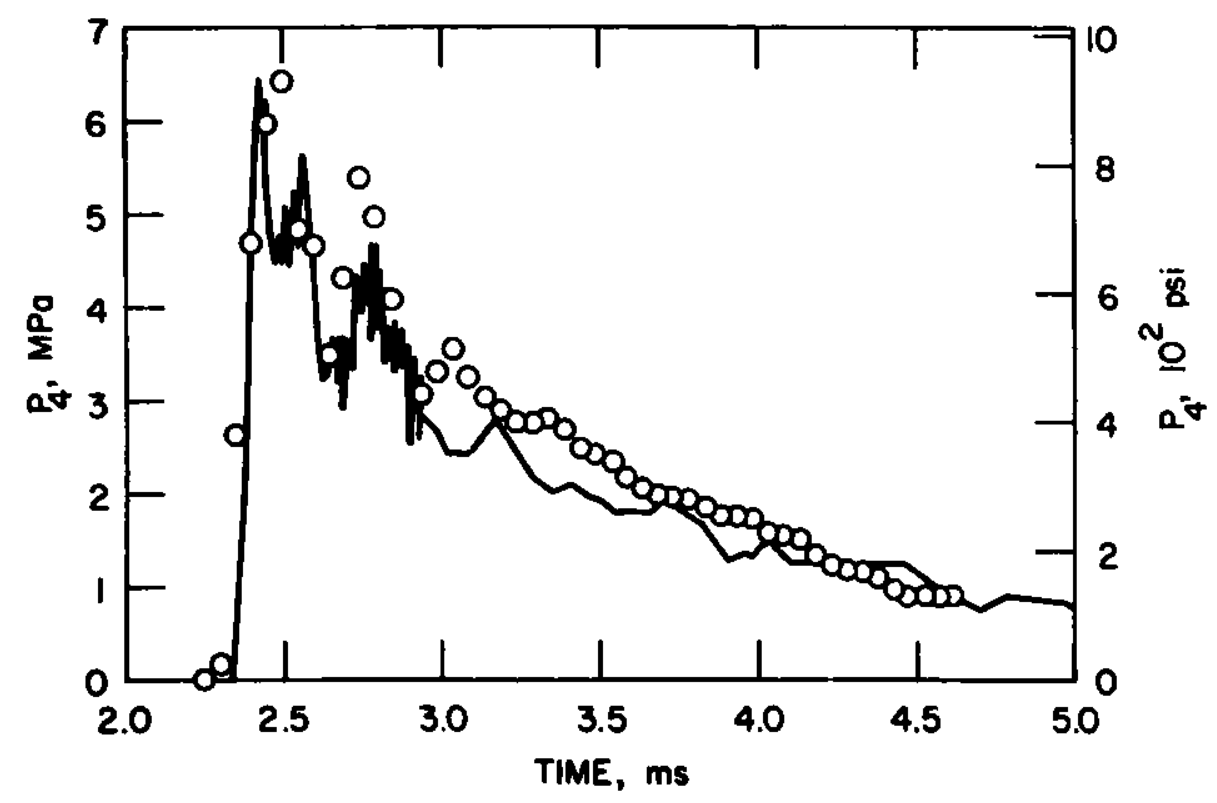

Fig. 62. Test FP-E-103: Experimental and Computed Pressure Histories at $\mathrm{P}_{4}$ 


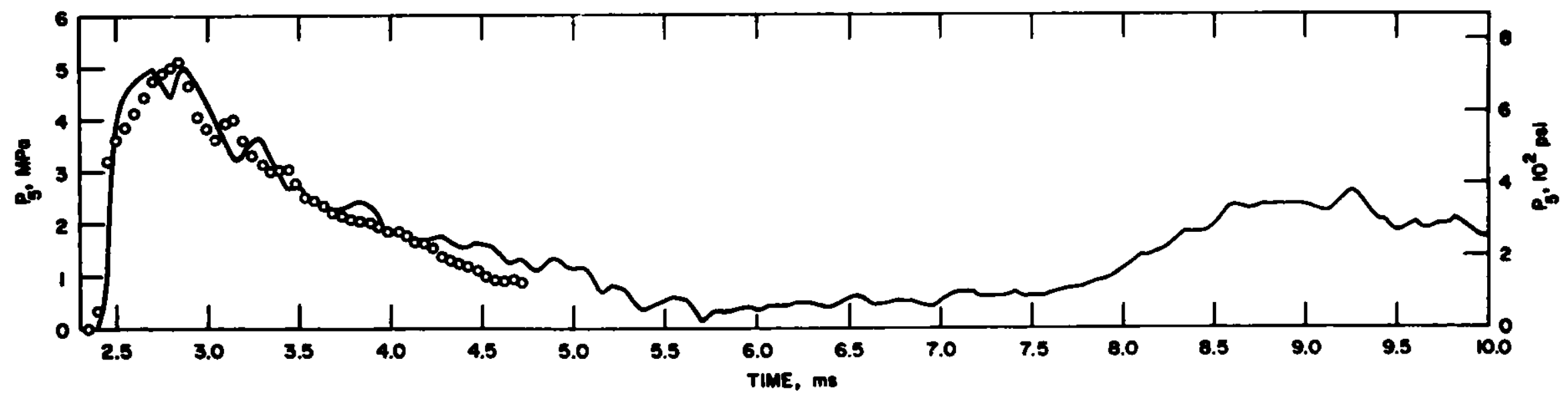

Fig. 63. Test FP-E-103: Experimental and Computed Pressure Histories at $P_{5}$. Experimental pulse used as source pulse for second PTA-1 computation.

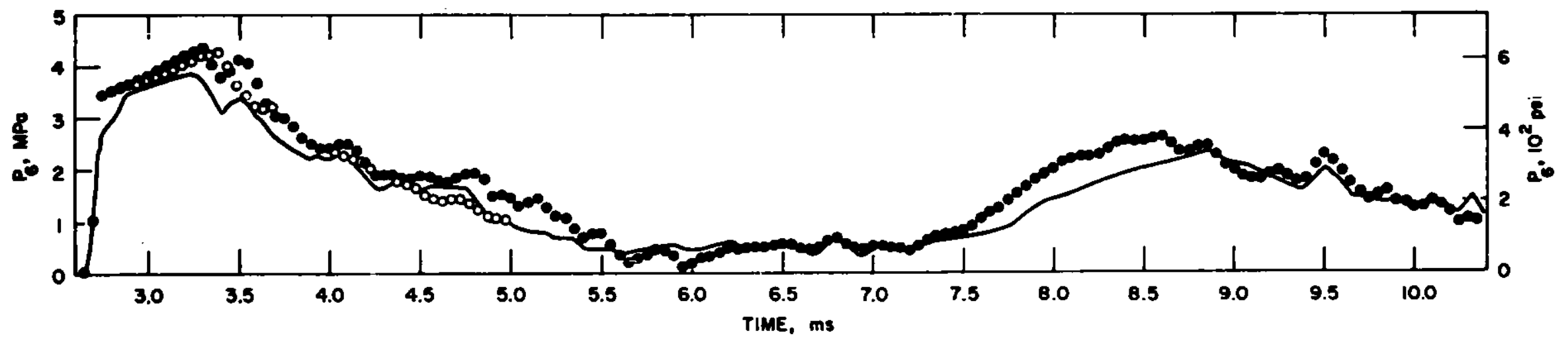

Fig. 64. Test FP-E-103: Experimental and Computed Pressure Histories at $P_{6}$ 


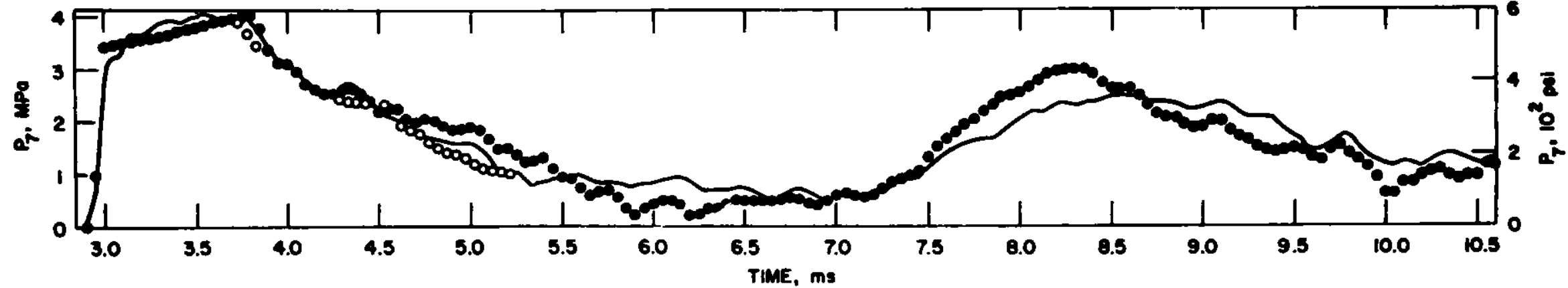

Fig. 65. Test FP-E-103: Experimental and Computed Pressure Histories at $\mathbf{P}_{7}$

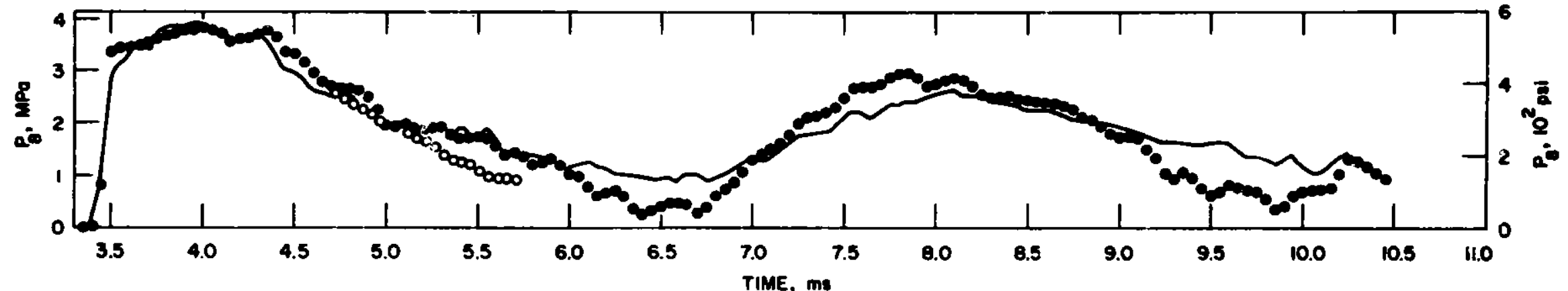

Fig. 66. Test FP-E-103: Experimental and Computed Pressure Histories at $P_{8}$ 


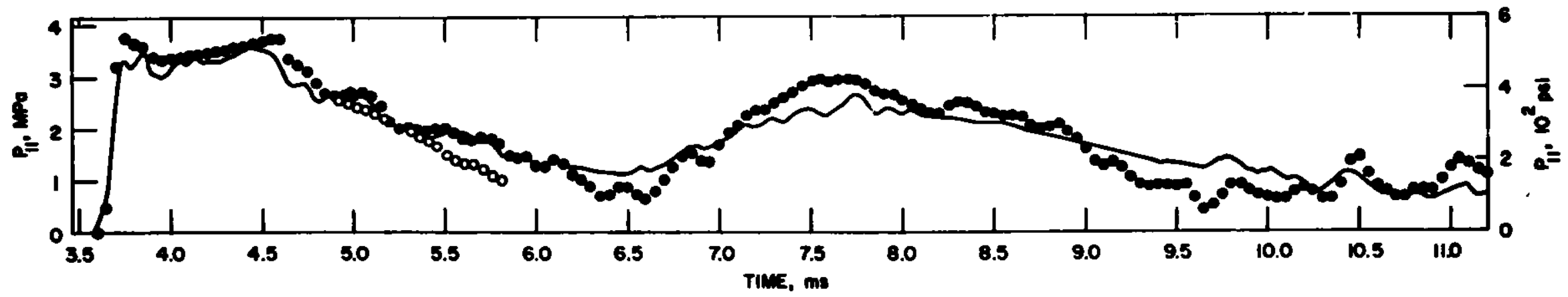

Fig. 67. Test FP-E-103: Experimental and Computed Pressure Histories at $\mathrm{P}_{11}$

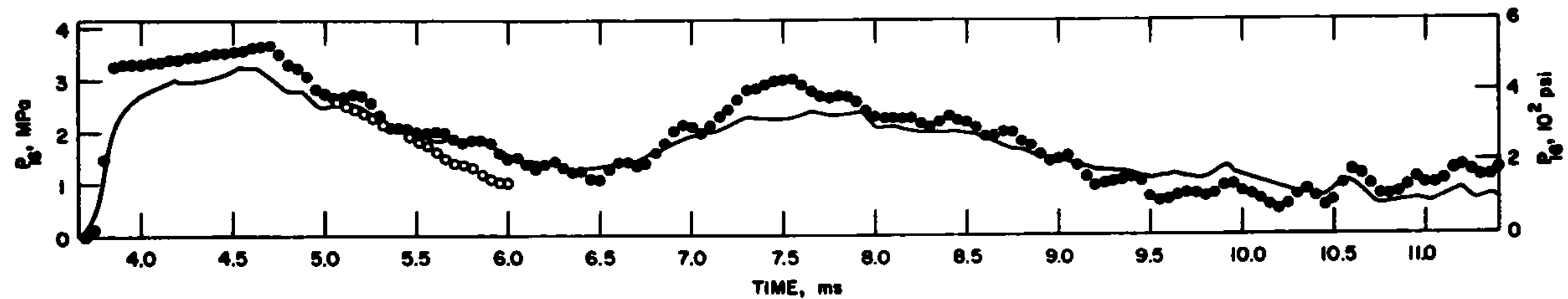

Fig. 68. Test FP-E-103: Experimental and Computed Pressure Histories at $\mathbf{P}_{16}$

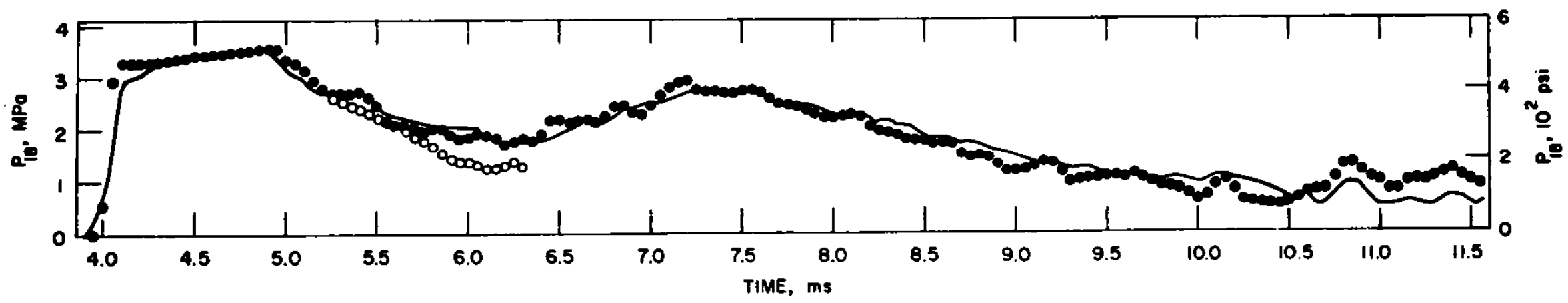

Fig. 69. Test FP-E-103: Experimental and Computed Pressure Histories at $\mathrm{P}_{18}$ 
The comparisons show excellent agreement between PTA-1 computations and experimental pressure measurements for Test FP-E-103. As in the experiments discussed previously, cavitation occurs at gauges $P_{2}$ and $P_{3}$ (see Figs. 60 and 61 ) in the steel pipe, because a rarefaction wave is reflected back from the plastically deforming nickel pipe; cavitation is indicated by the negative pressures in the PTA-1 results and the bottoming out of the pressuregauge measurements. The second peak in each of Figs. 63-69 is the reflection of the original pulse off the blind flange at the end of the system. The computations overpredict the peaks at gauge $P_{16}$ (see Fig. 68), just beyond the elbow; this may be caused by neglecting either the elbow-curvature effect on pulse propagation or the effect of ovality of the elbow cross section. However, the excellent agreement over the entire duration of the test at gauge $P_{18}$, which is $0.3 \mathrm{~m}$ (12 in.) beyond the elbow, indicates that any elbow effect not accounted for in the equivalent straight-pipe model is localized at the elbow.

Computed and experimental strain histories for the four sets of strain gauges are compared in Figs. 70-73. The curves are the experimental results and the circles show dynamic strains computed with PTA-1, using the pulse at $P_{1}$ as the source. The spread among the five gauge readings in each set is considerably larger for this experiment than for the other three experiments. This is difficult to explain, because the source pulses are similar for all the tests (compare Figs. 8, 25, 42, and 59), and the excellent agreement between computed and experimental pressure histories for Test FP-E-103 would imply that there was nothing unusual about this test. The wide spread in strain measurements may indicate that an asymmetric strain pattern caused by pipe bending was superimposed on the strains resulting from the pressure transient.

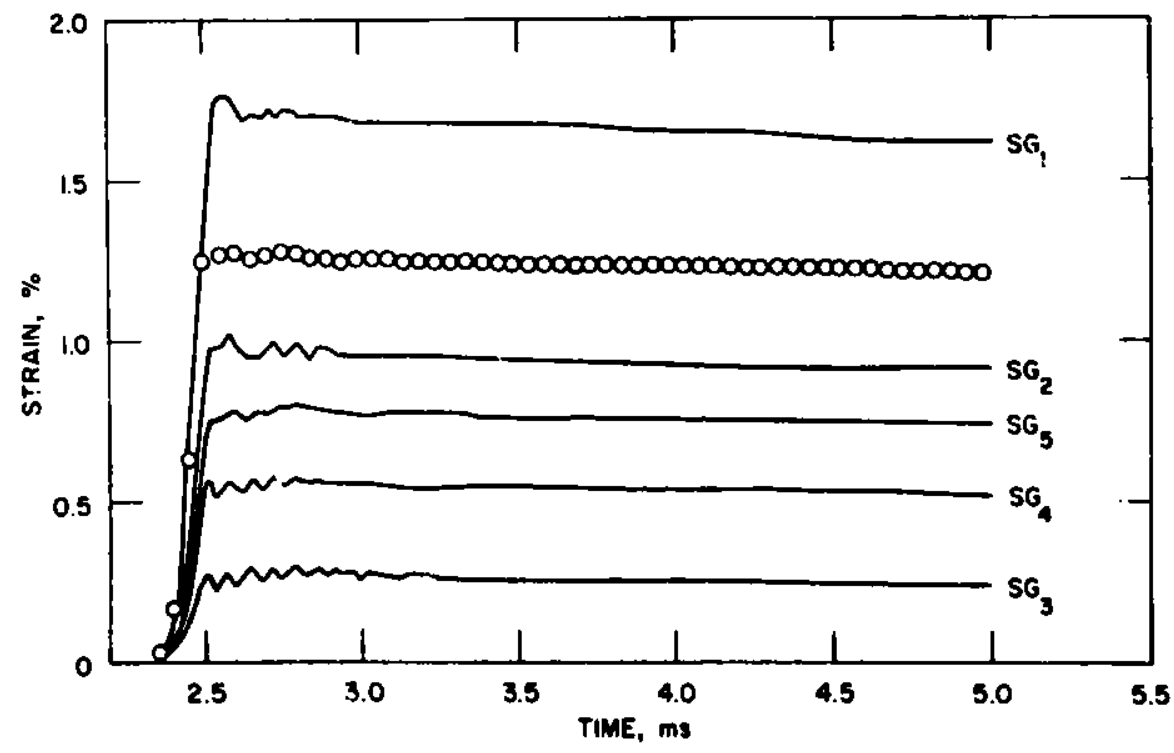

Fig. 70. Test FP-E-103: Experimental and Computed Strain Histories at First Set of Gauges, $\mathrm{SG}_{1}-\mathrm{SG}_{5}$ 


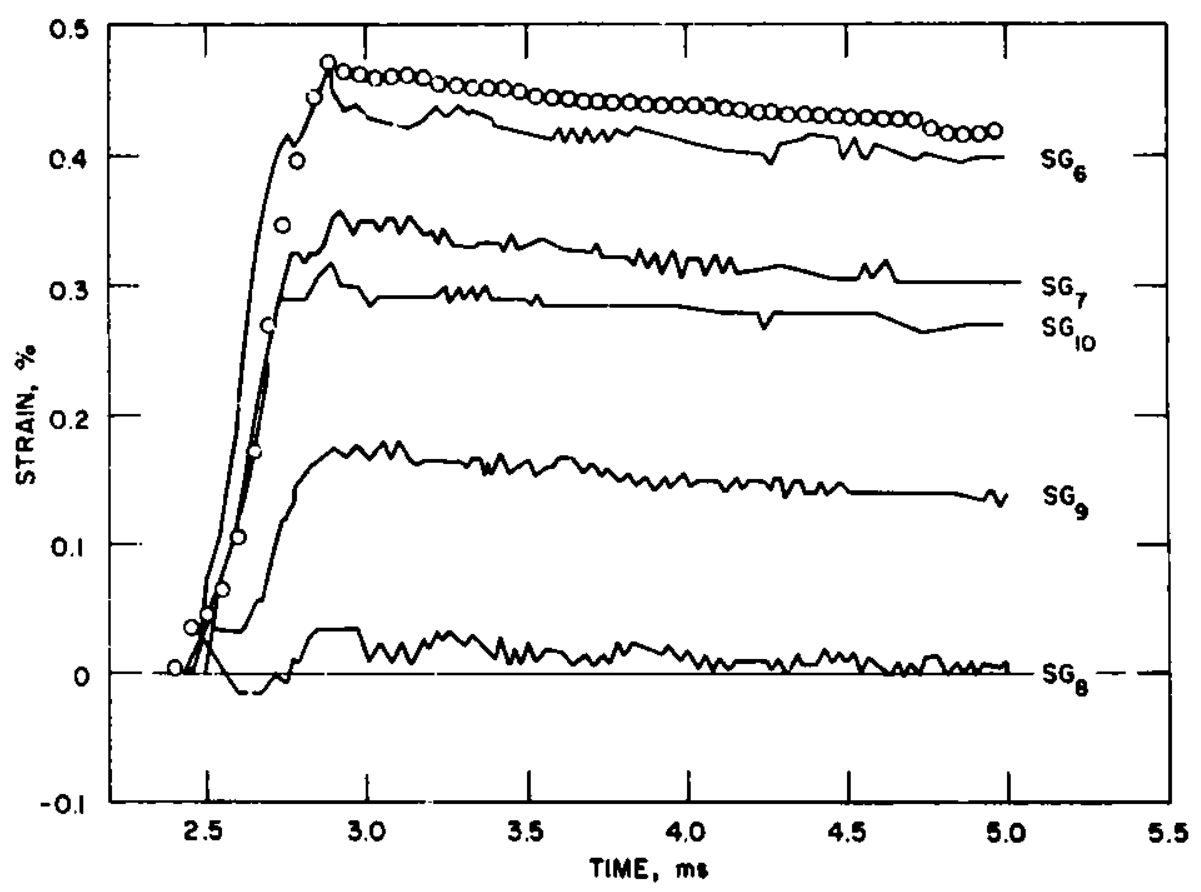

Fig. 71. Test FP-E-103: Experimental and Computed Strain Histories at Second Set of Gauges, $\mathrm{SG}_{6}-\mathrm{SG}_{10}$

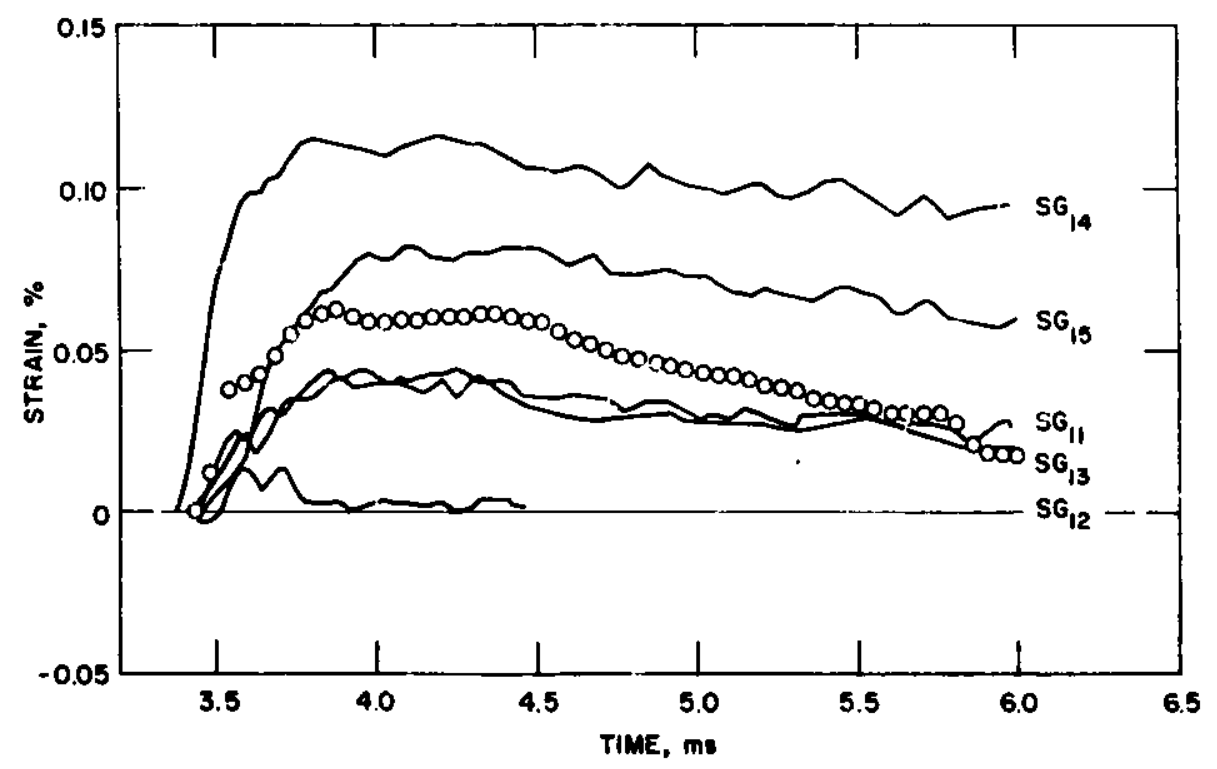

Fig. 72. Test FP-E-103: Experimental and Computed Strain Histories at Third Set of Gauges, $\mathrm{SG}_{11}-\mathrm{SG}_{15}$ 


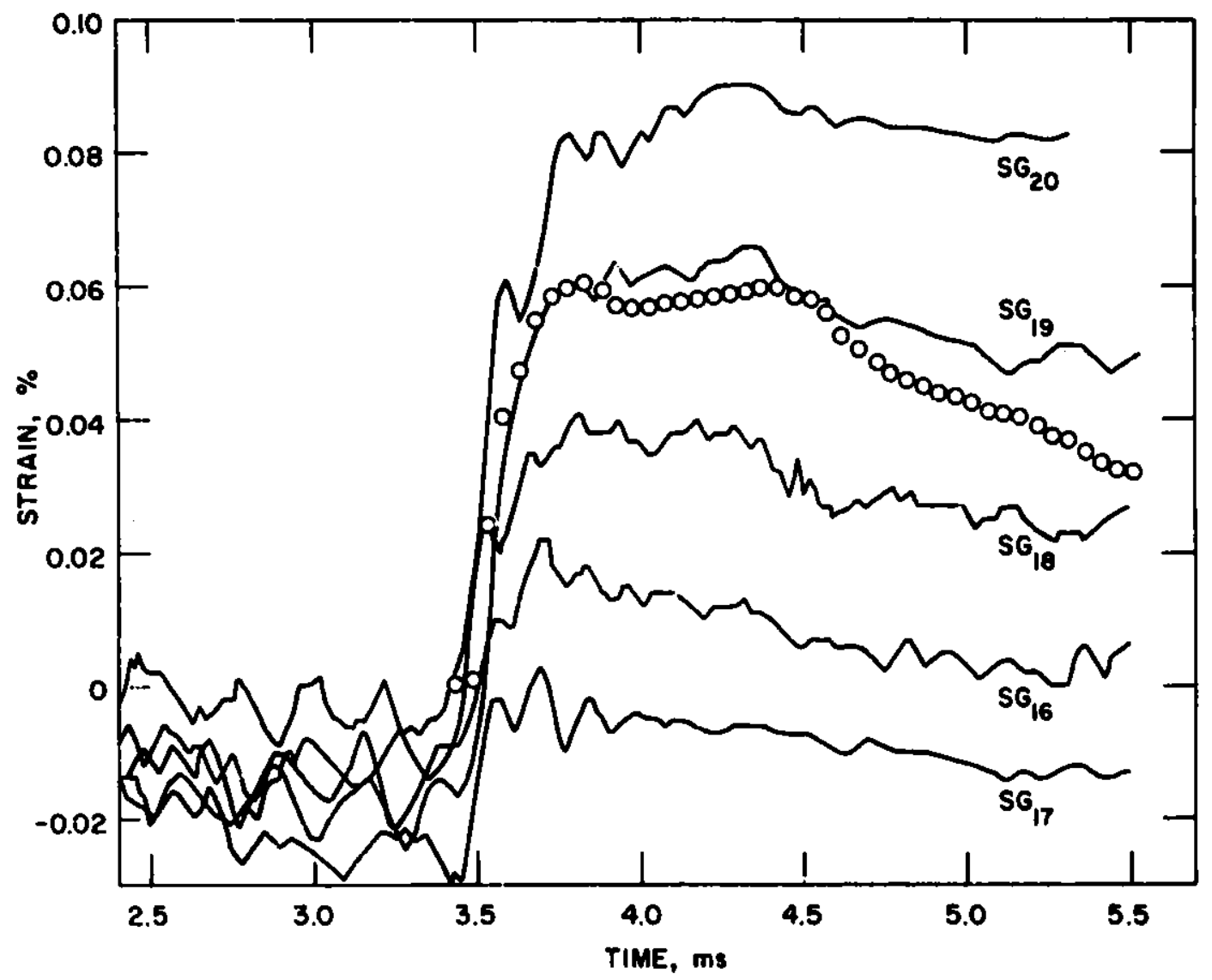

Fig. 73. Test FP-E-103: Experimental and Computed Strain Histories at Fourth Set of Gauges, $\mathrm{SG}_{16}-\mathrm{SG}_{20}$

Figure 73 shows negative strains occurring before the arrival at $3.5 \mathrm{~ms}$ of the pressure pulse traveling through the fluid. These negative strains probably correspond to an elastic compressive wave traveling in the pipe wall. This is the only set of gauges for which SRI reported precursor waves; either they did not occur in the other tests or they were not measured. Whatever the cause of the spread in the measured strain data for this test, the computed strain histories still provide a reasonable prediction of the dynamic plastic strains in the pipe.

Figure 74 compares computed and experimental values of maximum dynamic strain. The curve is the strain distribution along the first nickel pipe as computed by PTA-1; the bars give the circumferential variation in strain at each axial position where strain gauges are located; the solid circles are the average of the five gauges at each location. As discussed above, agreements between computed and experimental strains at the gauge locations near the left end of the pipe are not as good for this test as they were for the other three tests (compare Figs. 23, 40,57, and 74), even though the initial pressure peaks that produce these maximum strains are similar (see Figs, $11,12,28$, $29,45,46,62$, and 63). 


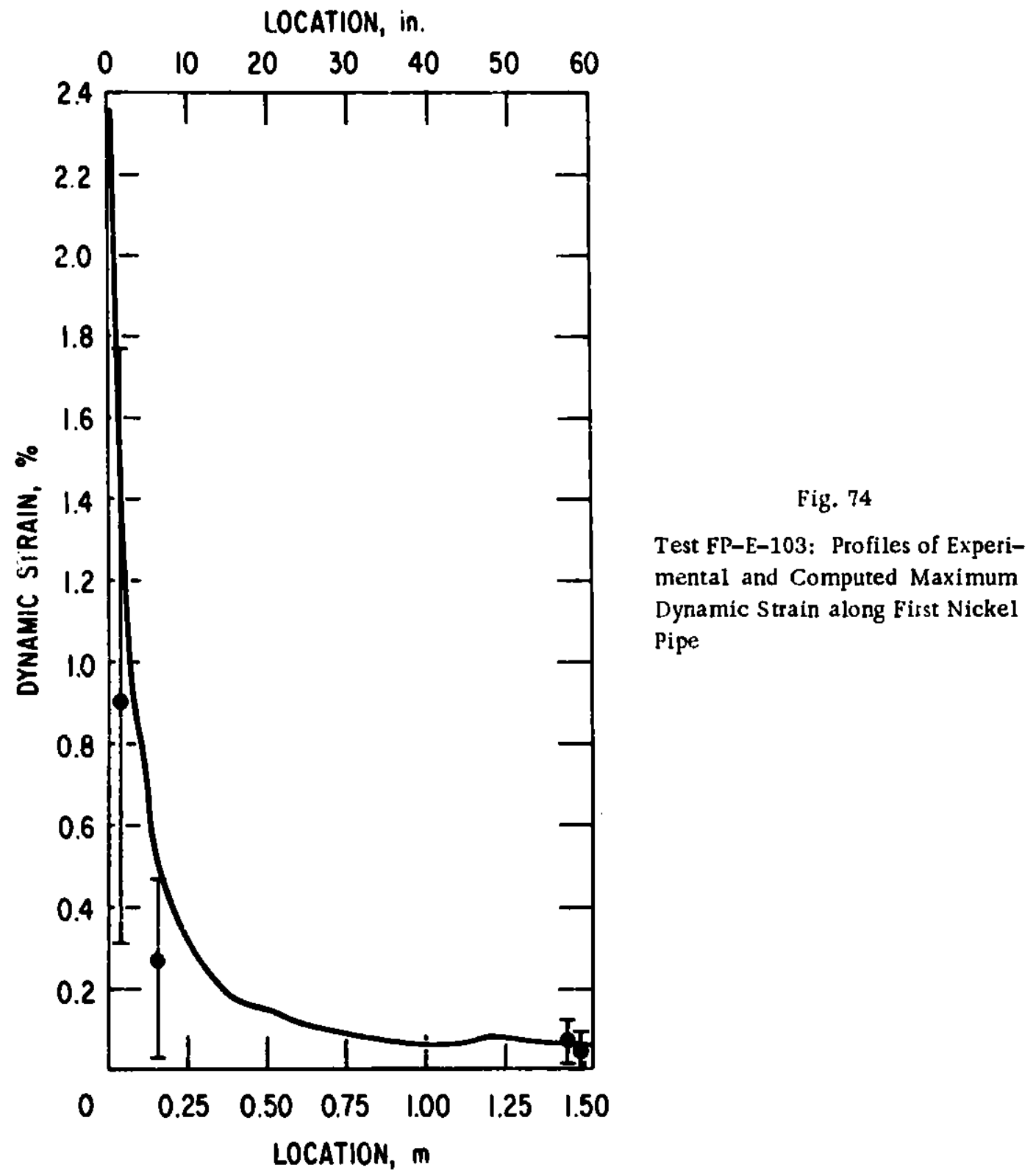




\section{CONCLUSIONS}

Several conclusions and observations on pressure-transient analysis can be based on the studies performed to validate the PTA-1 computer code using experimental data obtained by SRI. In addition, conclusions drawn by SRI based on experimental evidence alone are repeated here when they bear on the interpretation of the computation/experiment comparisons or when they are pertinent to the analytical modeling of pressure transients.

A. Effect of Pipe Plasticity on Pressure-transient Analysis

1. Plastic deformation of piping typical of reactor heat-transport systems has a significant qualitative and quantitative effect on pressure-pulse propagation. In particular, pulse peaks are chopped off to the yield pressure of the piping as the pulse propagates down the system; this phenomenor, which appears consistently in the experiments, is accurately modeled in PTA-1.

2. Classical fluid-hammer analysis based on rigid or elastic pipewall behavior gives completely erroneous results for pulse propagation in plastically deforming pipes. This is evident in the results shown in Sec. IV.A for Test FP-SP-101, where a classical computation is compared with the experiment and the PTA-1 results.

3. The one-dimensional computational model incorporated in PTA-1 for predicting plastic-deformation effects on pressure transients is accurate with respect to computing both pulse propagation in the fluid and dynamic strains in the piping. As the comparisons in Sec. IV show, PTA-l is able to predict the large variations in pulse shape and dynamic strain that occur because of pipe plasticity, with very little increase in computer time over a classical fluid-hammer treatment, which does not include plasticity effects.

B. Effect of Elbows on Pulse Propagation

1. SRI measurements show that, in their tests, pulse propagation is one-dimensional around the elbows. Consequently, a one-dimensional computational model is reasonable and appropriate for the pulse characteristics and elbow geometry typified by the experiments.

2. In an attempt to isolate an elbow-curvature effect, the elbow was replaced in the PIA-l computation by a section of straight pipe having the same material properties, diameter, wall thickness, and average length as the elbow. The excellent agreement obtained in the comparisons for Tests FP-E-101 and -103 show that the effect of elbow curvature on pulse propagation is negligible or is masked by the plastic-deformation effect. The small discrepancies between comp ted and experimental pressures right at the elbow may indicate a localized effect of elbow curvature or may be a result of the ovality of the elbow cross section.

3. The effect of elbow motion on pulse propagation is not included in either the experiments or the computations. SRI carefully clamped down their pipe layouts at the flanges to eliminate pipe-motion effects. PTA-l does not 
have a computational model for the forces on elbows caused by the fluid transient and the feedback effect of the resultant elbow motion on the pulse propagation; the state of the art is such that it is not obvious what an appropriate model would be.

4. Additional experimental data are needed to develop a computational model for the effect of elbows on pulse propagation. The large number of elbow: in a typical LMFBR secondary system implies that, even if the effect per elbow is small, the total effect of the elbows on the prediction of pressure transients may be significant.

\section{Cavitation}

1. Plastic deformation of piping can cause cavitation in other parts of the system. This occurred in all the experiments. The classical elastic computation in Sec. IV.A for Test FP-SP-101 shows that this cavitation would not have occurred if the pipes had only deformed elastically.

2. Inclusion of a cavitation model ${ }^{19}$ in the new pressure-transient code PTA- $2^{18}$ improves the match of the "tails" of the computed and experimental pressure histories reported here.

3. The low operating pressures typical of LMFBR coolant systems make it likely that rarefaction waves produced by the source event or resulting from wave interactions at impedance mismatches will cause cavitation in the system.

D. Strain-measurement Accuracy

1. SRI attributed the experimental variations in dynamic strain around the circumference of the nickel piping to wall-thickness variations and variations in grain-size distributions.

2. Computations were made for different wall thicknesses that span the range of measured thickness variations for Test FP-SP-102 (see Sec. IV.B). The computed strain variations are of the same order of magnitude as the measured variations for the first set of gauges, which have the largest plastic deformation. At the other gauges, the computed strain variations are smaller than the measured ranges. This indicates that probably part, but not all, of the circumferential val iation in measured strain can be attributed to wallthickness variation. However, since the computations were for uniformthickness piping, with separate runs made for different values of thickness, they did not exactly model the actual case of circumferentially varying thickness.

3. Some of the circumferential variation in strain may be due to bending deformation of the piping. Bending could result from nonaxisymmetric forces imparted by the pulse gun to the piping, or from prestressing from reaction forces at the support.

4. Inaccuracies in the calibration of instrumentation may be the source of some of the measured variation in strain. 
5. As indicated by $T$ able $I$ and the accompanying discussion, the circumferential variations in strain are not as significant as they appear initially. The corresponding variations in stress are relatively much smaller, because the pertinent points on the stress-strain curve are locations where strain is sensitive to stress. Experimental measurements of dynamic plastic strain are notoriously inaccurate; therefore the measured variations may simply correspond to the usual deviations in this type of experiment. Fortunately SRI provided multiple gauges at each axial location.

6. The fact that PTA-1 computes a good average of the experimental strain histories, even where strain is sensitive to stress and other factors, shows that the computational model is accurate.

E. Miscellaneous Effects

1. PTA-1 does not compute the first sharp peak at $2.4 \mathrm{~ms}$ measured at pressure gauge $P_{4}$ in each test. However, since there is no evidence for this peak in the experimental strain measurements at this location, it probably is an instrumentation overshoo: caused by the short rise time of the pulse.

2. The "noise" in the pressure-gauge readings at the left end of the system damps out with time and distance down the pipe. It probably corresponds to stress waves in the pipe wall, transmitted to the piping from the pulse gun and picked up by the pressure-gauge instrumentation, rather than real pressure fluctuations.

3. The initial oscillation in pressure at the blind flange in the straight-pipe tests may be caused by axial motion of the whole flange or lateral vibration of the blind end.

4. Inclusion in PTA-l of the effect of flanges on radial deformation of the piping does not seem to be necessary, since computed strains compare well with experimental strains at locations close to flanges.

5. The inclusion of flanges and other small features of pipe fittings as short lengths of pipe does not significantly affect the computational results. Consequently, they $c$ an be ignored in setting up the computer representation of the piping system.

6. The effect on the fluid transient of overall pipe motion produced by the fluid forces is not computed in PTA-1. This effect does not show up in the experiments either, since the pipes were securely fastened down. Additional analysis and experimentation are needed to establish computational models for this type of fluid-structure interaction, especially since heattransport system piping is $r$ ather loosely supported to permit thermal expansion. 


\section{REFERENCES}

1. C. K. Youngdahl and C. A. Kot, PTA-1: A Computer Program for Analysis of Pressure Transients in Hydraulic Networks, Including the Effect of Pipe Plasticity, ANL-76-64 (Nov 1976).

2. V. L. Streeter and E. B. Wylie, Hydraulic Transients, McGraw-H111 Book Co., New York (1967).

3. C. R. Bell and M. P. Helsler, TRANSWRAP--A Compressible Hydrodynamic Code for Large-Leak Sodium/Water Reaction Analysis, Atomics International Report TI-001-130-025 (Feb 1973).

4. S. Fabic, Computer Program WHAM for Calculation of Pressure, Velocity, and Force Transients in Liquid Filled Piping Networks, Kaiser Engineers Report 67-49-R (1967).

5. Y. W. Shin, The Method of Characteristics for Analysis of Pressure Transients Resulting from Sodium-Water Reaction in Hydraulic Networks, ANL-8049 (Dec 1973).

6. A. H. Wiedermann, Analysis of Transient Loads in a Sodium Heated Steam Generator Due to Tube Breakage--BREAK I, IITRI Project J6270, Contract AT(11-1)-3045 (June 1972).

7. Hydraulic Transients (HYTRAN) Computer Program--User's Manual, U. S. Army Corps of Engineers, Huntsville Division, HNDTR-73-9-ED-R (Apr 1973).

8. G. L. Fox, Jr., and D. D. Stepnewski, Pressure Wave Transmission in a Fluid Contained in a Plastically Deforming Pipe, J. Pressure Vesse1 Technol. 96(4), 258-262 (Nov 1974).

9. C. K. Youngdah1 and C. A. Kot, Computation of the Effest of Pipe Plasticity on Pressure-pulse Propagation in a Fluid System, ANL-75-5 (Apr 1975).

10. C. M. Romander and D. J. Cagliostro, Experiments on the Fiesponse of Flexible Piping Systems to Internal Pressure Pulses, Stanford Research Institute Project PYD-1960, Fourth Interim Report (Apr 1976).

11. C. M. Romander, D. J. Cagliostro, A. L. Florence, and J. K. Gran, "The Response of Water-Filled Pipes to Pressure Pulses," Trans. 4th Int. Conj. on Structural Mechanics in Reactor Technology, Vol. E, Paper E4/7 (Aug 1977).

12. C. K. Youngdahl and C. A. Kot, "PTA-1 Computer Program for Treating Pressure Transients in Hydraulic Networks Including the Effect of Pipe Plasticity," Trans. 4th Int. Conf. on Structural Mechanics in Reactor Technology, Vol. B, Paper B1/7 (Aug 1977).

13. C. K. Youngdahl and C. A. Kot, "Computing the Effect of Plastic Deformation of Piping on Pressure Transient Propagation," Proc. Symp. on Computational Methods for Fluid-Structure Interaction Problems, ASME Pub1. AMDVo1. 26, 35-47 (1977).

14. Liquid Metal Fast Breeder Reactor Materials Handbook, HEDL-TME 71-32.

15. J. A. Swaffield, The Influence of Bends on Fluid Transients Propagated in Incompressible Pipe Flow, Proc. Inst. Mech. Eng. 183(1), No. 29, 603-614 (1968). 
16. J. A. Fox, Hydrauitic Aiulysis of Unstecty Flow in Pipe Networks, John Wiley and Sons, New Yor', p. 146 (1977).

17. M. Hishida and M. Hor1, Experiment on Pressure Wave Propagation (I) The Result of Experiment on Branches and Bends, Power Reactor and Nuclear Fue1 Development Corporation Report N951 74-09, Translation JAPFNR-187 (Nov 1974).

18. C. K. Youngdah1, C. A. Kot, and R. A. Valentin, Pressure Transient Analysis in Piping Systems Including the Effects of Plastic Deformation and Cavitation, ANL-CT-78-24 (Mar 1978).

19. C. A. Kot and C. K. Youngdah1, Transient Cavitation Effects in Fluid Piping Systems, Nuc1. Eng. Des. 45, 93-100 (1978). 